University of Louisville

ThinkIR: The University of Louisville's Institutional Repository

$12-2011$

\title{
Narrative comprehension abilities of children from low-income families : role of temperament, attention skills, and cognitive engagement.
}

Tara N. Weatherholt

University of Louisville

Follow this and additional works at: https://ir.library.louisville.edu/etd

\section{Recommended Citation}

Weatherholt, Tara N., "Narrative comprehension abilities of children from low-income families : role of temperament, attention skills, and cognitive engagement." (2011). Electronic Theses and Dissertations. Paper 1539.

https://doi.org/10.18297/etd/1539

This Doctoral Dissertation is brought to you for free and open access by ThinkIR: The University of Louisville's Institutional Repository. It has been accepted for inclusion in Electronic Theses and Dissertations by an authorized administrator of ThinkIR: The University of Louisville's Institutional Repository. This title appears here courtesy of the author, who has retained all other copyrights. For more information, please contact thinkir@louisville.edu. 


\title{
NARRATIVE COMPRHENSION ABILITIES OF CHILDREN \\ FROM LOW-INCOME FAMILIES: \\ ROLE OF TEMPERAMENT, ATTENTION SKILLS, AND COGNITIVE \\ ENGAGEMENT
}

\author{
By \\ Tara N. Weatherholt \\ B.A. University of Louisville, 2000 \\ M.A. University of Louisville, 2005

\begin{abstract}
A Dissertation
Submitted to the Faculty of the

College of Arts and Sciences of the University of Louisville in Partial Fulfillment of the Requirements for the Degree of
\end{abstract} \\ Doctor of Philosophy \\ Department of Psychological and Brain Sciences \\ University of Louisville \\ Louisville, KY
}

December 2011 
Copyright 2011 by Tara N. Weatherholt

All Rights Reserved 


\section{NARRATIVE COMPREHENSION ABILITIES OF CHILDREN FROM LOW-INCOME FAMILIES: \\ ROLE OF TEMPERAMENT, ATTENTION SKILLS, AND COGNITIVE ENGAGEMENT}

\section{By}

Tara N. Weatherholt

B.A. University of Louisville, 2000

M.A. University of Louisville 2005

A Dissertation Approved on

December 13, 2011

by the Following Dissertation Committee:

Barbara Burns, Dissertation Director

Cara H. Cashon

Usha Margaret 


\section{DEDICATION}

This dissertation is dedicated to my grandmother, Elizabeth Potts Weatherholt, whose presence in my life made all of the difference. 


\section{ACKNOWLEDGEMENTS}

First and foremost, I would like to thank my graduate advisor, Dr. Barbara Burns, for her immeasurable guidance over the years. Her inspiring commitment to helping impoverished families and children has greatly influenced my path in life. I will be forever grateful for her enduring faith in me to succeed.

I am also grateful for the support of numerous friends and family members, especially Austin Mayberry, whose words of encouragement, listening ears, and bits of

helpful advice kept me focused, motivated, and at my computer when I felt that I couldn't write another word. I also cannot give enough thanks to Katie Rosenbalm, who was an invaluable resource for statistical guidance. Finally, I would like to acknowledge the plight of children who grow up in homes that are void of encouragement, love, and support, yet persist in achieving their goals and following their dreams. 


\author{
ABSTRACT \\ NARRATIVE COMPREHENSION ABILITIES OF PRESCHOOL CHILDREN \\ FROM LOW-INCOME FAMILIES: \\ ROLE OF TEMPERAMENT, ATTENTION SKILLS AND COGNITIVE \\ ENGAGEMENT \\ Tara N. Weatherholt \\ December 13, 2011
}

The current study investigated narrative comprehension ability in children from low-income families by examining the contributions of temperament, attention skills, and cognitive engagement. Research has identified narrative comprehension skills as significant for successful literacy outcomes, but few studies have examined the effect of individual level characteristics on comprehension ability. As reading and prereading skills in children from disadvantaged homes has been shown to be lower than that of children from more privileged backgrounds, it is critical to examine the factors that contribute to comprehension skills in this population. The current study focuses on the relationships among temperament, attention network skills, cognitive engagement, and comprehension abilities of children from low-income families. A television viewing methodology was employed to assess children's factual and causal comprehension as well as visual attention to the television in two conditions, one with distracter and one with no distracters. The goal of experiment one was to establish the role of temperament and attention network skills in children's factual and causal comprehension performance both 
in the presence and absence of competing distracters. Rothbart's temperament dimensions of effortful control and extraversion were used in separate analyses, along with attention network skills identified by Posner, to predict narrative comprehension performance. Findings partially supported the hypotheses, signifying the importance of effortful control for both factual and causal comprehension in the presence of distracters. Extraversion and attention skills were not significantly related to either type of comprehension in either condition. Experiment two hypothesized that cognitive engagement would significantly predict comprehension in the distracter condition after controlling for effortful control, and that cognitive engagement would be more important for causal comprehension than factual. Unexpectedly, the results showed that cognitive engagement was significantly related to factual comprehension but not causal comprehension. However, additional analyses showed that total time looking at the television was significantly related to causal comprehension in the distracter condition. The findings are discussed in terms of both theoretical and applied implications and future directions in research are explored. 


\section{TABLE OF CONTENTS}

PAGE

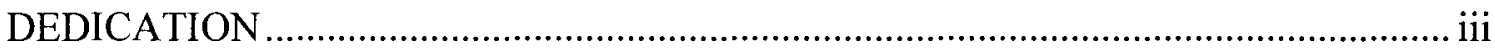

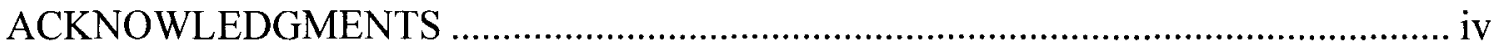

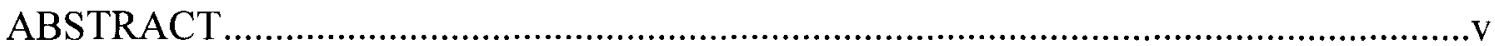

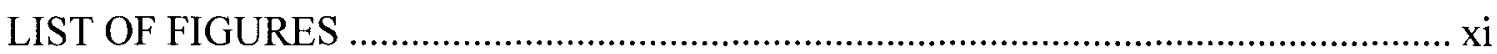

LIST OF TABLES ...........................................................................................

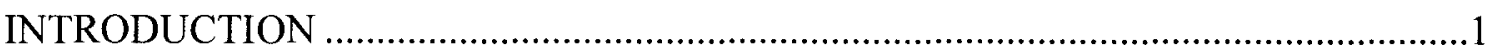

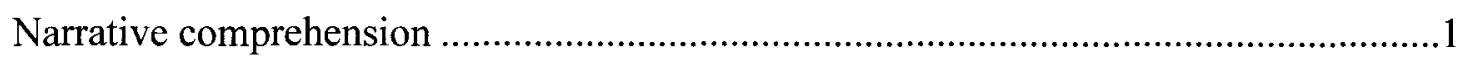

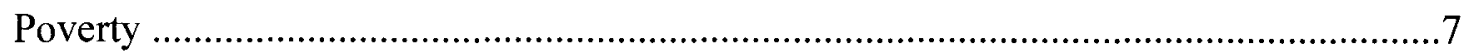

Narrative comprehension and poverty .....................................................11

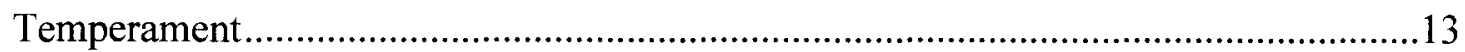

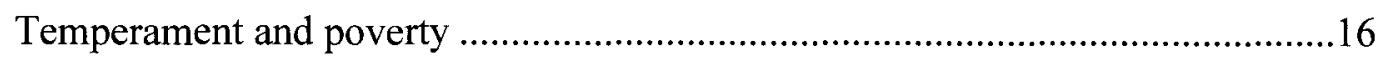

Temperament and narrative comprehension ................................................ 17

Temperament, narrative comprehension, and poverty ......................................19

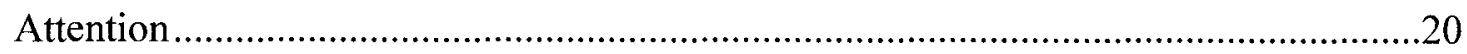

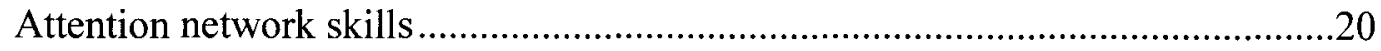

Attention network skills and poverty ................................................23

Attention network skills and narrative comprehension ........................24

Attention network skills, narrative comprehension, and poverty .............25

Temperament and attention network skills ......................................25 
Attention network skills, temperament, narrative comprehension, and poverty

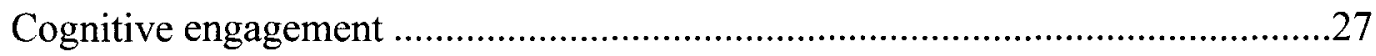

Cognitive engagement and narrative comprehension ............................28

Cognitive engagement and poverty ................................................33

Cognitive engagement, temperament, narrative comprehension, and

poverty

Current study

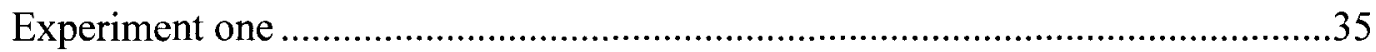

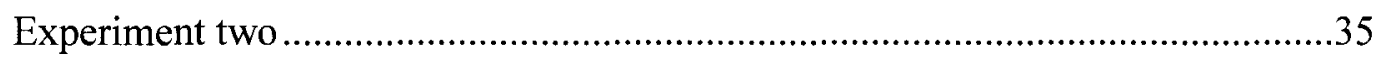

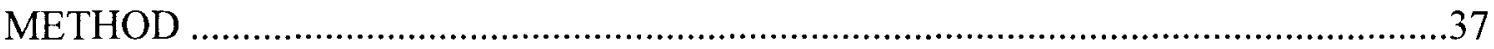

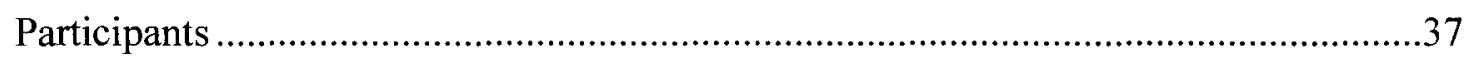

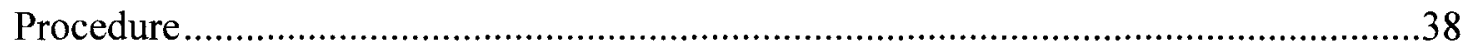

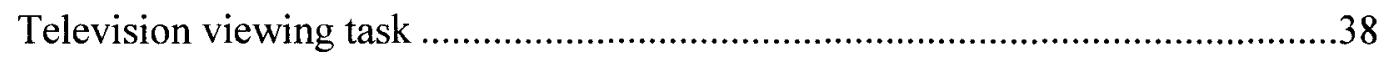

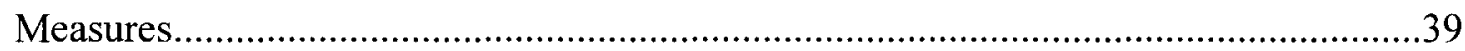

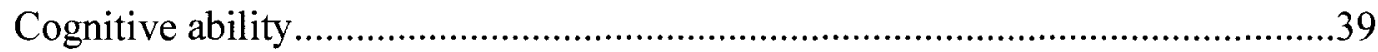

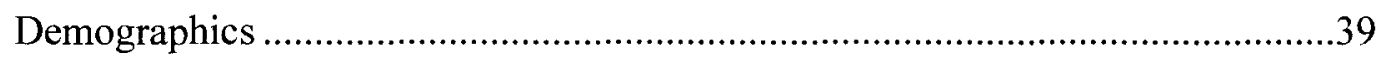

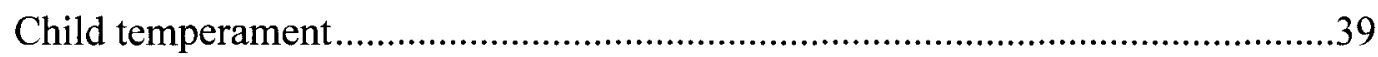

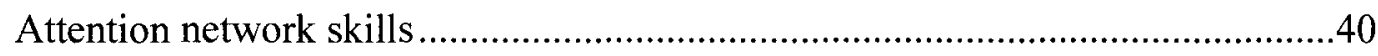

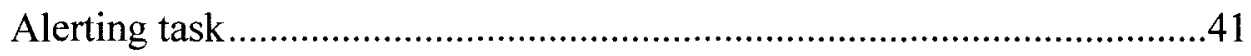

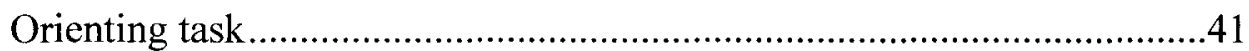

Executive task ........................................................................4 


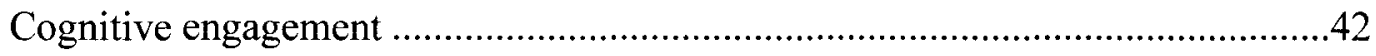

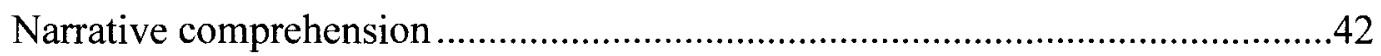

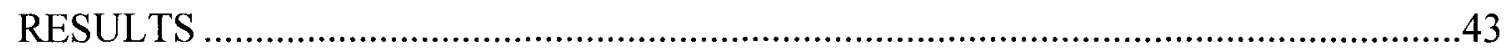

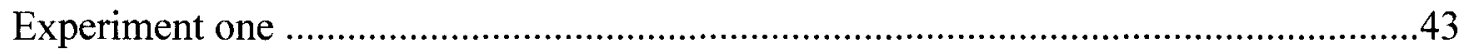

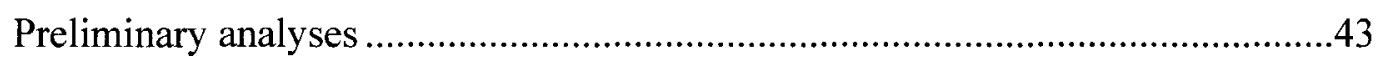

Comprehension performance ........................................................44

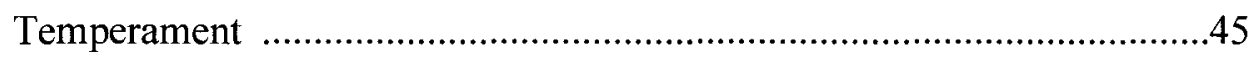

Attention network skills ...........................................................45

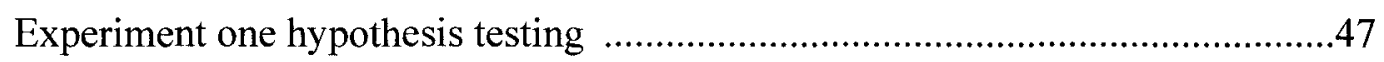

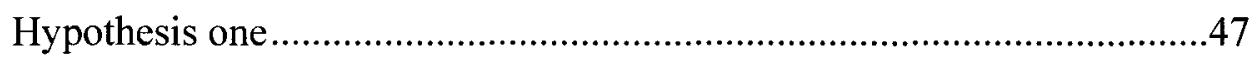

Statistical assumptions ................................................. 48

Hypothesis testing results ................................................48

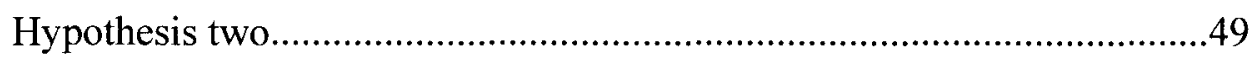

Statistical assumptions ..................................................50

Hypothesis testing results .................................................50

Hypothesis three .......................................................................... 51

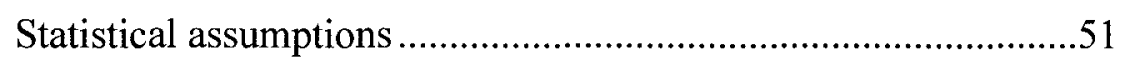

Hypothesis testing results .................................................51

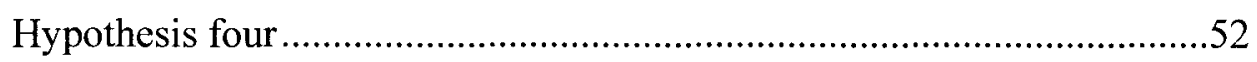

Statistical assumptions ....................................................53

Hypothesis testing results ..................................................53

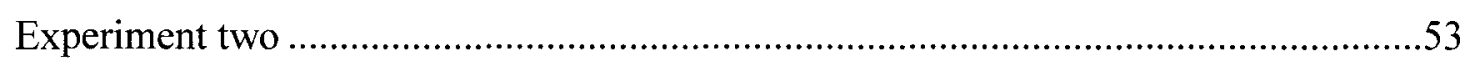

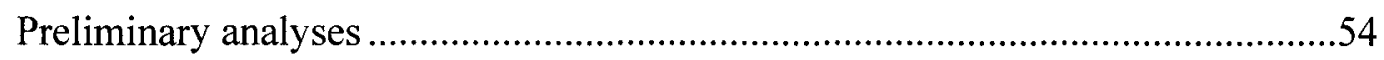




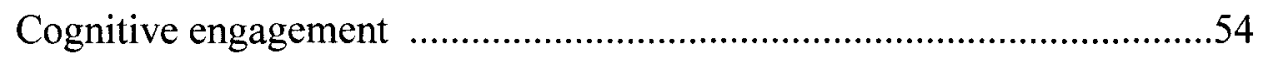

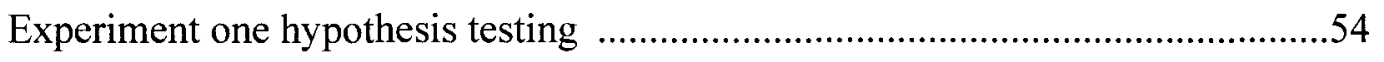

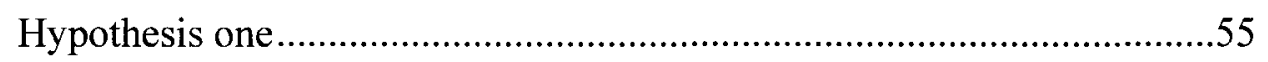

Statistical assumptions ....................................................55

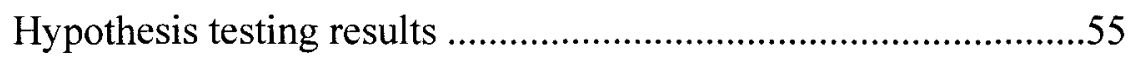

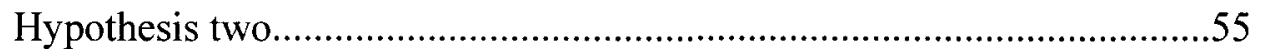

Statistical assumptions ...................................................56

Hypothesis testing results ...............................................56

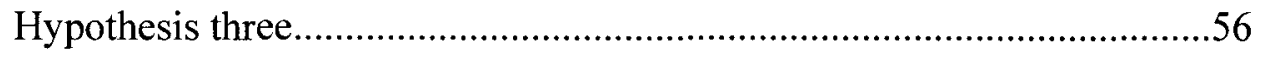

Hypothesis testing results ....................................................56

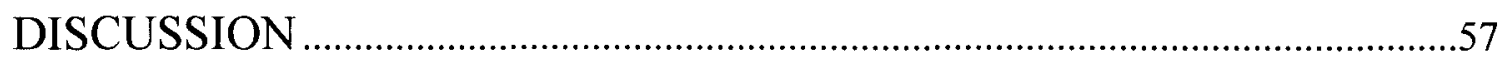

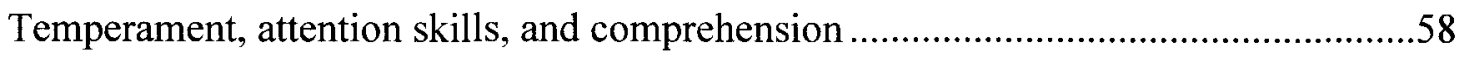

Cognitive engagement, temperament, and comprehension.....................................63

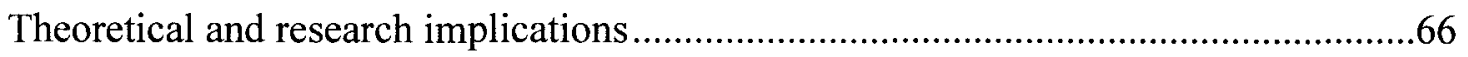

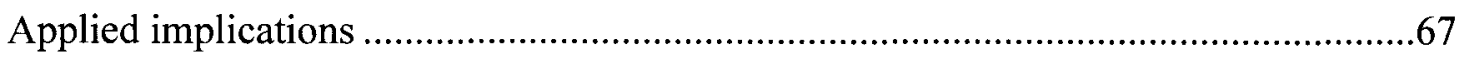

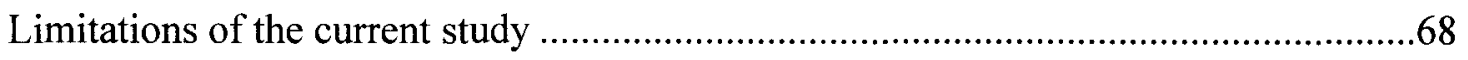

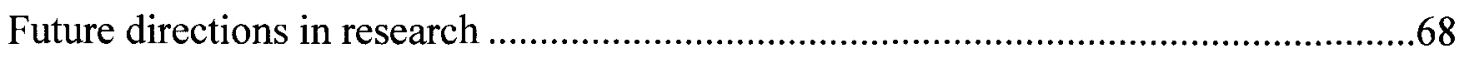

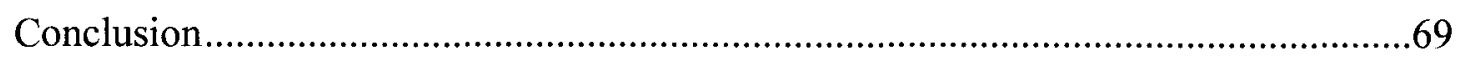

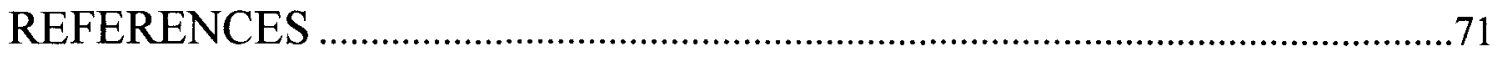

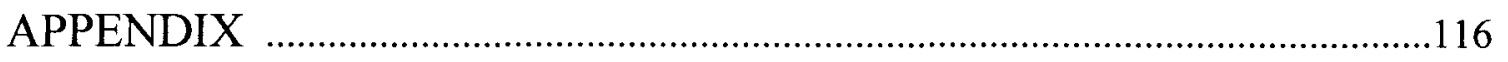

CURRICULUM VITAE ........................................................................ 118 


\section{LIST OF FIGURES}

FIGURE

PAGE

1. Frequencies of families per income category .....................................................91

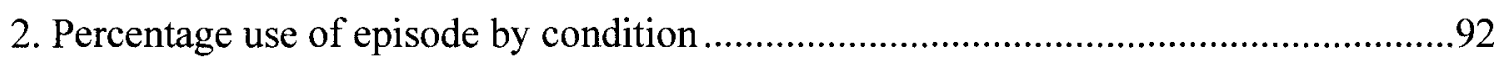

3. Number of factual and causal questions per episode ...........................................93

4. Number and type of questions deleted from original comprehension scores ...............94

5. Means of comprehension performance of original comprehension scores and

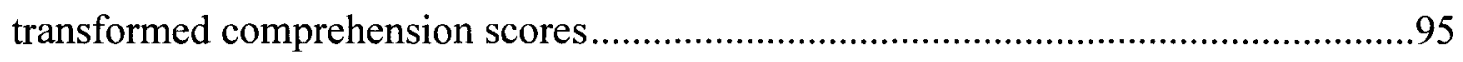

6. Mean proportion of overall comprehension performance for each Rugrats® episode by

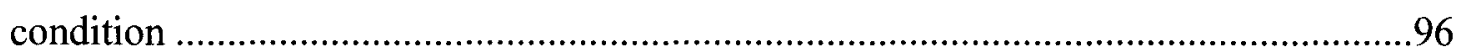

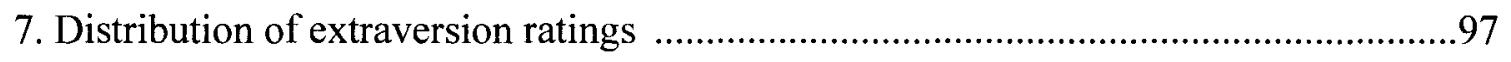

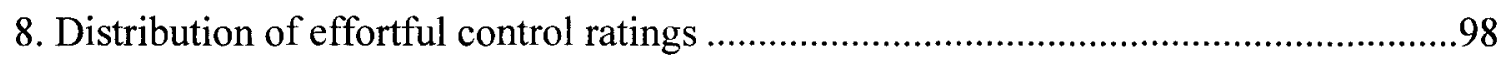

9. Boxplots of factual and causal comprehension in the distracter condition...................99 


\section{LIST OF TABLES}

$\begin{array}{ll}\text { TABLE PAGE } & \text { PAT }\end{array}$

1. Covariate Analyses with Gender, Age, and Cognitive Ability ................................100

2. Means, Standard Deviations, Range, and Medians of Comprehension Performance by

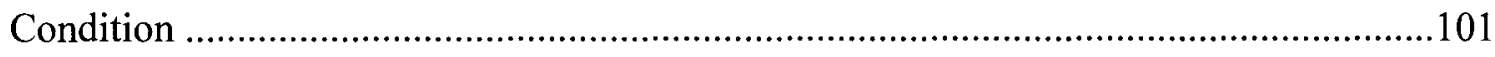

3. Means and Standard Deviations of Comprehension Performance by Age Group and

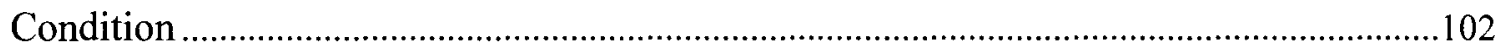

4. Means and Standard Deviations of MRT and Accuracy on Attention Network Measure

5. Correlational Analyses with Attention Network MRTs and Age, Gender, and Cognitive Ability 104

6. Summary of Hierarchical Regression Analysis for the Prediction of Causal Comprehension in the Distracter Condition by Effortful Control and Attention Skills...105

7. Summary of Hierarchical Regression Analysis for the Prediction of Causal Comprehension in the Distracter Condition by Extraversion and Attention Skills 106

8. Summary of Hierarchical Regression Analysis for the Prediction of Factual Comprehension in the Distracter Condition by Effortful Control and Attention Skills...107

9. Summary of Hierarchical Regression Analysis for the Prediction of Factual Comprehension in the Distracter Condition by Extraversion and Attention Skills 108 
10. Summary of Hierarchical Regression Analysis for the Prediction of Causal Comprehension in the No-Distracter Condition by Effortful Control and Attention Skills

11. Summary of Hierarchical Regression Analysis for the Prediction of Causal Comprehension in the No-Distracter Condition by Extraversion and Attention Skills....110

12. Summary of Hierarchical Regression Analysis for the Prediction of Factual Comprehension in the No-Distracter Condition by Effortful Control and Attention Skills

13. Summary of Hierarchical Regression Analysis for the Prediction of Factual Comprehension in the No-Distracter Condition by Extraversion and Attention Skills....112

14. Means and Standard Deviations of Visual Attention Behavior by Age Group and by Condition

15. Summary of Hierarchical Regression Analysis Predicting Factual Comprehension in the Distracter Condition by Effortful Control and Cognitive Engagement.

16. Summary of Hierarchical Regression Analysis Predicting Causal Comprehension in the Distracter Condition by Effortful Control and Cognitive Engagement 


\section{INTRODUCTION}

From an early age children are surrounded by narratives, or stories, in a variety of forms. Typically, very young children are told stories orally by their parents and participate in joint book-reading activities. Other narratives such as experiences with televised narratives and movies and hearing or participating in conversations are part of the fabric of most children's daily lives. Many argue that exposure to narratives serves as an important aspect of children's learning of language, promotes literacy and is a significant contributor to emerging literacy skills (Oakhill, Cain, \& Bryant, 2003; Paris \& Paris, 2003; Snow, 1991; van den Broek et al., 2005). Earlier claims that basic language skills must be acquired before the development of comprehension skills have been replaced and a great deal of research has taken the approach that comprehension skills develop simultaneously rather than following basic language skills (Kendeou, Lynch, van den Broek, Espin, White, \& Kremer, 2005; Whitehurst \& Lonigan, 1998). As a result of the awareness of the importance of comprehension skills for successful reading, the need for more investigations of higher-order reading skills, such as comprehension, has grown.

\section{Narrative Comprehension}

The study of narrative comprehension begins with the parsing of the components of a narrative and the processes involved that support comprehension. A narrative is defined as a description of actions and events that occur over time according to causal principles. The comprehension of a narrative involves the effort to construct relations 
among these actions and events to form a coherent whole. In order to accomplish this successfully, it is proposed that children form a mental representation of the current narrative and assimilate it into their previous understanding of the world (Rapp, van den Broek, McMaster, Kendeou, \& Espin, 2007). Preschoolers do this using narrative scripts which are knowledge structures that describe events and sequences of routine activities, such as a birthday party or a visit to the doctor (Paris \& Paris, 2003). Children then develop narrative schemas, which include knowledge about the main events of stories, such as characters, settings and problems, and temporal concepts in the story (Paris \& Paris, 2003). Preschoolers also acquire understanding of the internal responses of characters, such as mental processes and states. Young children then acquire narrative thinking skills, such as representational abilities and perspectives (Paris \& Paris, 2003). Essentially, children must integrate meanings across actions, delete extraneous information, retain main ideas, form expectations regarding future events, monitor ongoing comprehension, and backtrack to previous events when comprehension fails (Paris \& Paris, 2003).

Several important developmental changes in narrative comprehension of children can be noted. As children mature, they become more understanding of the role of internal states and goals implicated in story plots (van den Broek, 1997). Research has also shown that children use scripts or event knowledge from their experiences with the world to guide their understanding of narratives or stories and make predictions about upcoming events (Calvert \& Huston, 1987). With age, this ability becomes more flexible, allowing for the understanding of even non-canonical versions of stories (Low \& Durkin, 2000). 
The study of comprehension processes in younger children is quite limited because of the difficulty in assessing comprehension in prereaders and early readers. Researchers have employed a variety of media, such as television and picture books, to investigate comprehension of young children. Given the central role of television in most children's lives, the use of televised narratives in the investigation of comprehension is reasonable. Television can be a highly motivating and attractive tool for young children. It is also a naturalistic and familiar task as reports indicate that the average child between 2 and 5 years old spends 32 hours per week watching television (McDonough, 2009). Furthermore, research has also shown that there is a positive transfer of skills and knowledge across different types of media (van den Broek, Lorch, \& Thurlow, 1996). Commonalities in content exist between television programs and printed materials, including story genres (e.g. mystery), topics (e.g. sharing, strangers), information (e.g. science facts), and narrative conventions (e.g. flashbacks). Televised narratives and reading also require many of the same cognitive processes, such as the ability to allocate attentional resources strategically, to sequence events, to make inferences, and to understand motives and link them to events. Researchers found that comprehension and memory skills were constant across media by which children encounter information (van den Broek et al., 1996). In addition, Kendeou et al. (2005) presented narratives to children ages 4 and 6 by either video or audiotape. The results showed that measures of narrative comprehension across television and aural presentation were highly interrelated. Two years later, the same children were retested and results indicated that narrative comprehension of aural and television narratives at age 6 predicted reading comprehension at age 8 , thus providing more evidence for the analogous relationship of 
comprehension of televised narratives and text. Thus, the utilization of television is a suitable methodology in the study of narrative comprehension in children.

Many theories of narrative comprehension have noted the importance of causal relations between events in a story, citing that causality is a key determinant of how comprehensible a story is (Trabasso \& Magliano, 1996). Studies have shown that as they mature, children increasingly become more aware of causal connections between story events (Trabasso \& Stein, 1997). Children as young as 4 years of age have better recall for events with many causal connections than those with few causal connections (van den Broek, Lorch, \& Thurlow, 1996). As they develop, children become better at identifying these causal connections and using them to aid in recall of the story (van den Broek, 1989). The ability to understand causal connections in a story has been shown to be important for reading achievement, literacy skills, and comprehension in children (Kendeou, Bohn-Gettler, White, \& van den Broek, 2008; Kendeou, van den Broek, White, \& Lynch, 2007; Lynch, van den Broek, Kremer, Kendeou, White, \& Lorch, 2008).

Cognitive models of narrative comprehension mostly focus on two comprehension components, attribution of mental states and theory of mind, and construction of story representation and integration. Neuroimaging research across models has supported frontal lobe areas, temporal lobe areas, and the anterior cingulate as playing a role in narrative comprehension, supporting working memory and theory of mind processes (Mar, 2004). Areas in the frontal lobe, such as the prefrontal cortex, are associated with perspective taking, or theory of mind, and the processing of sequential information. Specific frontal areas also modulate attention in ways useful for story 
integration through recruitment of other cortical areas. Temporal lobe activation has also been implicated in the construction of story representation (Fletcher et al., 1995). The anterior cingulate is related to the story comprehension processes of error detection, monitoring, working memory, and executive attention. These three main brain areas and their related processes together contribute to effective comprehension of a story. The study of narrative comprehension in children is important not only because of its relation to literacy outcomes, but also given the insight it provides into the complex cognitive processes involved. It is also of further importance to study characteristics of children that have the propensity to enhance or hinder abilities such as comprehension or the skills contributing to comprehension.

One such individual difference characteristic that has gained considerable interest in many areas of cognition is temperament, which is defined by Rothbart and colleagues as "individual differences in reactivity and self-regulation assumed to have a constitutional basis" (Rothbart, Derryberry, \& Hershey, 2000, p. 85). Combinations of the temperament dimensions of extraversion, negative affect, and effortful control can facilitate or impede children's abilities, development, and interaction with the world. Past research has shown that temperament is associated with early literacy skills and reading ability (Coplan, Barber, \& Lagacé, 1999; Deater-Deckard, Mullineaux, Petrill, \& Thompson, 2009), as well as the recall of information (Wachs, Morrow, \& Slabach, 1990). However, child temperament has not been studied in relation to comprehension of a narrative in prereaders.

Another construct important for children's narrative comprehension ability is attention. Research has shown that deficits in attention are associated with poor 
comprehension (Lorch et al., 2000) and poor reading ability (August \& Garfinkel, 1990). Research examining the development of comprehension shows that as attentional capacities mature, certain comprehension abilities, such as understanding causal relations, improve as well (van den Broek, 1997). However, attention can be conceptualized and measured in various ways. One way of thinking about and measuring attention is through computerized tasks designed to test different facets of attention or attention skills. Specific attention skills, including the ability to stay vigilant, shift attention, select relevant information, and use attention as an organizer of higher level processing, are proposed to be implicated in comprehension (Rapp \& van den Broek, 2005; Rapp, van den Broek, McMaster, Kendeou, \& Espin, 2007). However, these skills have yet to be studied as contributory factors to narrative comprehension in children.

Related to attention is the construct of cognitive engagement which can be thought of as an active and thoughtful attempt to understand and engage in a task. Cognitive engagement, measured through duration of visual attention, has been studied extensively in research using televised narratives by Lorch and colleagues (Lorch et al., 2004; Lorch, Milich, Astrin, \& Berthiaume, 2006). Children with attention deficits have been shown to have differing looking patterns toward the television than children without attention deficits, and these differences relate to comparisons of their comprehension performance (Lorch et al., 2006). This avenue of research has established cognitive engagement, a measure of sustained attention, as an important factor in comprehension of televised narratives and clearly shows that differences in children's cognitive engagement relate to children's narrative comprehension through television. 
Understanding temperament and attention variables and how they impact narrative comprehension is of particular importance in children from low-income homes as this environment has shown to negatively affect children's development. Poverty has been widely documented as a risk factor for a range of problems in child development, including reading ability and comprehension (Breznitz, 1987; Raz \& Bryant, 1990). Although narrative comprehension has been identified as an important preliteracy skill, research surrounding what makes a child successful at comprehension has left out individual-level factors, especially in young children. Variations of child temperament dimensions could promote or hinder comprehension processes, as it has been shown to do in reading ability. Attention skills have been identified as necessary components of comprehension, but this relationship has not been systematically studied in children. Cognitive engagement has been shown to be directly related to narrative comprehension, but has only been studied in middle-income populations. The inclusion of temperament, attention skills and cognitive engagement in the study of narrative comprehension in children of poverty will add substantial insight into the understanding of how individual characteristics contribute to differences in comprehension ability, especially under the umbrella of living in an impoverished environment.

\section{Poverty}

One of the most deleterious factors affecting a child's development is the experience of growing up in poverty. The harmful influence of poverty on children is supported by a substantial body of research and reaches a variety of child outcomes, including cognitive ability and school achievement (Bradley \& Corwyn, 2002), socioemotional, behavioral and social well-being (Bolger, Patterson, Thompson, \& 
Kupersmidt, 1995), and physical health (Starfield, 1992). Because of both the tremendous effect poverty has on children and the considerable amount of existing research, the current section will provide an overview of the detrimental role that poverty plays in various areas of children's lives.

Bradley and colleagues (Bradley, Corwyn, McAdoo, \& Coll, 2001) delivered an extensive description of the home environment of children growing up poor in America. Data was analyzed from the Home Observation for Measurement of the EnvironmentShort Form (HOME-SF) collected for the National Longitudinal Survey of Youth (NLSY) from 1986 - 1994. The results paint a bleak picture for the poor children of this country. Poor children are less likely to have three or more children's books than the nonpoor. Poor children are less likely to experience enriching places and events, such as the museum or theater. Poor children experience less talk from their mothers and fewer demonstrations of affection. Poor children are more likely to be spanked and spanked often, over eight times per week. Poor children are less likely for their mother to read to them or teach them numbers, colors, or the alphabet. Poor children are less likely to be encouraged to have hobbies or special lessons. Poor children are less likely to have discussions about television programs they watched. Poor children are less likely to have a safe play environment. Poor children are more likely to live in dark, monotonous, unclean, and cluttered homes. Poor children are less likely to see their fathers daily. In this study, poverty effects were demonstrated in all six environmental domains studied, including parental responsiveness and teaching, quality of the physical and learning environment, discipline and contact with fathers. 
Given the deprived environment associated with living in poverty, it is not surprising that research has established a relationship between socioeconomic status (SES) or poverty and children's cognitive ability and school achievement (Bradley \& Corwyn, 2002; Dearing, McCartney \& Taylor, 2001; To et al., 2004). One such study by Smith, Brooks-Gunn and Klebanov (1997) examined the effect of poverty on cognitive ability among a group of young children, ages 2 through 8 . Findings showed that family income affected children as early as age 2 , based on an infant IQ test. Additionally, children in families with incomes less than .5 of the poverty line had IQ scores 6 to 13 points lower than children in families with incomes 1.5 to 2 times the poverty line. Petterson and Albers (2001), in a study of children from the National Maternal and Infant Health Survey, found the following specific differences between poor and nonpoor children: 1) $80.9 \%$ of nonpoor versus $69.8 \%$ of poor children could name 4 colors, and 2) $60.4 \%$ of nonpoor versus $45.9 \%$ of poor children could count to 10 . Overall, they found a difference of .28 standard deviations between the mean cognitive score of poor and nonpoor children. Another study of first- through fifth-graders found that incomes-tomeans ratios, a measure of poverty calculated by dividing family income by the federal poverty threshold, uniquely predicted child academic competence (Ackerman, Brown, \& Izard, 2004).

Children from disadvantaged backgrounds suffer further deleterious effects including negative socio-emotional, behavioral, and social outcomes. Economic disadvantage has been associated with low self-esteem (Isralowitz \& Singer, 1986), higher levels of both internalizing and externalizing behavior problems (Werner, 1989) and lack of peer acceptance (Patterson, Vaden, Griesler, \& Kupersmidt, 1991). A four- 
year longitudinal study of 534 students beginning in the second through fourth grades assessed behavior problems, peer relations and self-concept through surveys and teacher interviews (Bolger et al., 1995). Using growth curve analysis, researchers were able to show that children who experienced persistent family economic hardship were more likely than those who did not to have difficulties in all three areas throughout all of the years of the study. McLoed and Shanahan (1993) studied data from the NLSY to explore relationships among poverty and 4- to 8-year-old children's mental health. Results showed that persistent poverty significantly predicted children's internalizing symptoms, including anxiety, depression, and dependency. Another study explored psychopathology in a group of rural children for eight years, for which income increased for $14 \%$ of the sample (Costello, Compton, Keeler, \& Angold, 2003). First, they found a significant negative correlation between family income and child psychiatric diagnoses and number of symptoms. Second, after the increase in income for part of the sample, the researchers showed that moving out of poverty was associated with a decrease in frequency of psychiatric symptoms over the ensuing four years. Third, they found that the effect of poverty was strongest for behavioral symptoms of conduct and oppositional disorder.

Furthermore, children's physical health and well-being is affected by economic disadvantage and it has been shown to start before birth due to poor prenatal care including substance abuse and poor nutrition. Children from low-SES families are more likely to experience growth retardation and inadequate neurobehavioral development in utero (DiPietro, Costigan, Shupe, Pressman, \& Johnson, 1998; Kramer, 1987). They are also more likely to be born prematurely, at low birth weight, with a birth defect or disability, fetal alcohol syndrome, or AIDS (Crooks, 1995; Hawley \& Disney, 1992; 
Vrijheid et al., 2000; Wasserman, Shaw, Selvin, Gould, \& Syme, 1998). After birth, lowSES infants are more likely to suffer injuries and to die (Overpeck, Brenner, Trumble, Trifiletti, \& Berendes, 1998). SES is also associated with an increased risk of higher blood lead levels (Starfield, 1992), iron deficiency (Starfield, 1989), and sensory impairment (Wilson, 1993). Additionally, the average length of stay for poor children in acute care hospitals is longer than the average for nonpoor children (Bradley \& Kelleher, 1992).

The aforementioned studies provide a picture of the lives and negative outcomes of millions of children living in impoverished environments. In an effort to determine what processes are adding to the low literacy rates of this population, narrative comprehension has been studied as well. The following section describes the existing research regarding the narrative comprehension abilities of children growing up in poverty.

Narrative comprehension and poverty. Narrative comprehension ability has been shown through studies of literacy to be lower in children from low-SES backgrounds. For instance, Breznitz (1987) administered a reading comprehension test to both low- and high-SES first-graders and found that the first-graders from low-SES obtained significantly lower comprehension scores than children from high-SES. Basavanna and Rani (1984) also found that low-SES children scored lower on tests of paragraph comprehension. In an attempt to understand the differences in reading ability between low-SES and high-SES children, Dickinson and Snow (1987) studied the oral language and prereading abilities of kindergarteners from low-SES and high-SES households. The results showed that there were disparities in a multitude of measures, 
including story understanding of factual details. Another study by Raz and Bryant (1990) examined first-graders' reading comprehension skills in low-SES and middle-SES groups. Substantial social group differences in beginning first-graders' reading comprehension skills were found, even after controlling for general intelligence and phonological awareness skills. In a similar study, Bowey (1995) also found significant differences in the reading comprehension skills, among other prereading abilities, of children from low- and high-SES groups after controlling for general nonverbal intelligence.

Mattingly (1984) posited that lower SES children might lack the skills from which language awareness develops. Hecht, Burgess, Torgesen, Wagner, and Rashotte (2000) followed 197 children from kindergarten through the fourth grade, assessing readingrelated abilities and measuring reading comprehension skills. First, they found that SES explained a significant percentage of variance in growth of reading comprehension skills over time. They also found that social class differences in growth of reading comprehension skills were attenuated but not entirely explained by reading-related abilities, such as phonological awareness, decoding, and print knowledge. As aforementioned, Raz \& Bryant (1990) also found that differences in comprehension existed even after controlling for phonological awareness skills.

In addition, some of the informal literacy experiences may be qualitatively or quantitatively different for children from low-income backgrounds, contributing to lower comprehension ability. Many studies have noted a lack of reading materials in the home and that the bedtime story is rare among lower-SES communities (Bradley \& Bryant, 1983; Hecht et al., 2000). In addition, many studies have argued that experiences with 
language prior to reading instruction are critically important to literacy skills, such as comprehension (Bradley \& Bryant, 1983; Dickinson \& Snow, 1987; Hecht et al., 2000; Raz \& Bryant, 1990). As described previously, children living in impoverished backgrounds are generally not exposed to the kinds of rich experiences that promote literacy.

Studies have established that children from impoverished backgrounds show poorer comprehension and have related that difference to other prereading abilities. It is also likely that the lack of literacy-related experiences also play a role in the lagging comprehension ability in children from disadvantaged backgrounds. However, it is also clear from these studies that there are factors that remain to be studied in relation to the comprehension abilities of these children. In order to understand what distinguishes successful comprehension from poor comprehension in children, it is essential to examine individual-level factors. The following sections now discuss temperament, attention skills, and cognitive engagement and provide evidence that they could be related to narrative comprehension ability in children.

\section{Temperament}

Temperament has been recognized as a powerful influence on development, but has only recently been considered with respect to narrative comprehension. The work regarding temperament and narratives mainly examines language, reading, and memory. However, before describing the work on temperament and narratives, an overview of the key theoretical models of temperament will be described in order to provide a background of temperament research. 
As is obvious to anyone who has seen more than one child, children differ from one another in many observable ways, including their emotions, activity level, and attention, from the earliest days of life. The study of these differences has led to major progress in temperament research. Although the construct of temperament can be traced back to the Greeks and Romans (Garrison \& Earls, 1987), the connection of temperament to the study of children has been relatively recent. Shirley (1933) identified temperament as the early core of personality, which she indicated that children's individuality could be observed in their reactions of timidity, positive affect, and irritability. Gesell (1928) noted that temperament characteristics interacted with social experiences to influence child outcomes.

However, the biggest impact on childhood temperament research came from the work of Stella Chess and Alexander Thomas and associates with the New York Longitudinal Study (NYLS; Thomas \& Chess, 1977). Concerned by the ideology of psychoanalytic and environmentalist views of child development, Thomas and Chess (1977) described temperament as the early appearance of a child's behavioral style and suggested that temperament is biologically based, influencing interactions between children and their environment. The researchers identified nine dimensions of temperament variability, including activity, distractibility, and persistence, based on a content analysis of mothers' reports of their children's behavior during the first six months of life.

Most researchers agree that temperament has developmentally early, biological roots, interacts with the environment to influence behavior, and also follows a developmental course as children gain more control over their emotions and behavior 
(Rothbart \& Derryberry, 1981). However, there is less agreement among researchers concerning the specific variables that should be included in the conceptualization and measurement of temperament. Bates and Wachs (1994) organized a list of temperament concepts from the literature, which includes negative emotionality, difficultness, adaptability, reactivity, activity, attention regulation, and positive emotionality. Temperament theorists group and measure these concepts in different ways. For example, the following are the nine dimensions of temperament as developed by Thomas \& Chess (1977): 1) activity level, 2) rhythmicity, 3) approach/withdrawal, 4) adaptability, 5) intensity of reaction, 6) quality of mood, 7) persistence/attention span, 8) distractibility, and 9) threshold of responsiveness. However, Buss \& Plomin (1984) consider only three dimensions of temperament - emotionality, activity and sociability. Strelau (1983) views temperament as consisting of reactivity and activity and is mainly related to central nervous system activity.

Researchers have noted the reactive components of temperament in children, but recent developments have identified a regulatory component as well. Rothbart and colleagues define temperament as "constitutional differences in reactivity and regulation in the domains of emotion, activity, and attention influenced over time by heredity, maturation, and experience" (Rothbart \& Derryberry, 1981, p. 37). The term "reactivity" refers to "the characteristics of the individual's reaction to changes in the environment" (Rothbart \& Derryberry, 1981, p.37). Self-regulation is defined as the neural and behavioral processes functioning to modulate this underlying reactivity (Rothbart \& Derryberry, 1981). Self-regulatory capacities develop in the preschool years and continue throughout the early school years. 
Rothbart and colleagues reviewed temperament research, such as that by Chess and Thomas, and behavioral genetic literature in order to identify possible temperament variables. Variables were chosen which a) were biologically-based or b) showed variability in infants. Rothbart developed the Child Behavior Questionnaire (CBQ; Rothbart, Ahadi, Hershey, \& Fisher, 2001) by generating items to assess theoretically derived temperament dimensions. Ultimately, Rothbart's research revealed three temperament dimensions: extraversion, negative affectivity, and effortful control. Extraversion is made of items assessing impulsivity, high-intensity pleasure, activity level, shyness (reversely scored), and positive anticipation or approach. Negative affectivity consists of the scales of sadness, discomfort, anger/frustration, fear, and soothability. Finally, effortful control includes inhibitory control, attentional focusing, low-intensity pleasure, perceptual sensitivity, and smiling and laughter. These variables are similar to the temperament dimensions studied by Thomas and Chess (1977), but Rothbart and colleagues differ in their view of temperament as a "behavioral style". The individual differences studied by Rothbart include phenomenological experience and psychophysiological functioning as well as behavior (Goldsmith et al., 1987). Rothbart's theory of temperament also differs from Buss and Plumin (1984) in that emotionality is not limited to the negative emotions and from Goldsmith and Campos (1986) in that temperament includes aspects of orienting and motor activation, rather than just emotionality (Goldsmith et al., 1987).

Temperament and poverty. Some research also show evidence for a relationship between SES or family income and temperament (Curby, Rudasill, Edwards \& PerezEdgar, 2011; Jansen et al., 2009). For example, Curby et al. (2011) found that children 
with lower income-to-needs ratios were more likely to be rated as having a difficult temperament. Jansen et al. (2009) also found that lower SES was associated with more difficult infant temperament. In addition, the results showed that the effect of SES on distress to limitations, recovery from distress, and duration of orienting scores was largely explained by family stress and maternal depression. It is proposed that certain factors associated with a low-income household, such as parental stress, harsh parenting behaviors, poor prenatal health, parental mental health and chaotic home environment, may have a negative effect on the children's temperament. The possible link between SES and temperament gives further reason to examine temperament in children from disadvantaged homes.

Temperament and narrative comprehension. The body of research examining the relationship between temperament and comprehension is small although studies have shown that certain temperament dimensions can be protective factors that facilitate early literacy skills, receptive vocabulary, and narrative and reading ability. Several studies have noted that high effortful control skills, such as persistence and low distractibility, are related to better literacy skills in preschoolers (Coplan, Barber, \& Lagace-Seguin, 1999; Fuhs, Wyant, \& Day, 2011; Miller, 2000). For example, Martin and Holbrook (1985) found that high persistence and low distractibility significantly predicted reading grades in first-grade. Another study found that children with lower intelligence who were rated higher in persistence learned to read better than other children of equivalent intelligence who were not as persistent. Other studies have noted that high negative affect and related behavior, such as high emotionality and low soothability, hinders literacy skills (Miller, 2000; Noel, Peterson, \& Jesso, 2008). For example, a study of preschoolers 
found that children's emotionality was negatively related to narrative ability, as measured by length of narratives and level of description (Noel et al., 2008). Additionally, Miller (2000) found in a study of at-risk preschoolers that the temperament characteristics of low intensity, low distractibility, and high adaptability were significantly related to firstgrade reading achievement.

For infants, studies have shown that higher extraversion is related to both better receptive vocabulary and recognition of stimuli (Bauer, Burch, \& Kleinknecht, 2002; Gunnar \& Nelson, 1994; Morales, Mundy, Delgado, Yale, Neal, \& Schwartz, 2000). For example, Gunnar and Nelson (1994) presented faces to 91 twelve-month-old infants, while measuring their event-related potentials. Findings showed a significant positive relationship between ratings of positive affect and ERP's during presentation of familiar stimuli. A study of infants showed that temperament dimensions of orienting, smiling and laughter were related to children's receptive vocabulary (Morales, Mundy, Delgado, Yale, Neal, \& Schwartz, 2000).

However, studies have shown that as infants mature, extraversion may become less helpful in recall performance (Bauer, Burch, \& Kleinknecht, 2002). It is thought that extraversion may be important for memory in infancy due to its effect on maintaining interest, but as infants get older, the need to be able to focus and regulate their attention becomes more important in order to remember long-term information. As children age, higher extraversion may be detrimental for persistence on tasks that require attention whereas effortful control becomes more important for persistence, lower activity level and memory performance. For example, Bauer and colleagues (2002) found differing patterns for 13- and 20-month-old children in their study of temperament characteristics 
and long-term recall performance. They found that for the 13-month-olds, long-term recall of ordered actions was positively correlated with the Pleasure subscale. Higher levels of recall were observed for children whose parents described them as able to find pleasure in new experiences. Among the 20-month-olds, long-term recall was negatively correlated with the Activity Level subscale and positively correlated with the Interest and Persistence subscale. A study by Greenhoot, Ornstein, Gordon, and Baker-Ward (1999) found that the temperament characteristics of higher manageability and persistence were important for the event recall of three-year-olds and five-year-olds, respectively, giving more evidence to the importance of effortful control to memory in preschool- and schoolaged children. As the above studies show, the relation of temperament dimensions, especially extraversion and effortful control, to narrative comprehension has yet to be definitively characterized and deserve further examination.

Temperament, narrative comprehension, and poverty. Although the temperament of children growing up in impoverished environments has never been studied in relation to narrative comprehension, there is reason to examine these factors together. Research has reported a higher prevalence of more difficult temperament traits in children from lower-income environments. Temperament dimensions contributing to a "difficult" temperament have been studied as risk factors for negative outcomes such as internalizing symptoms of anxiety and depression (Barrocas \& Hankin, 2011; Mian, Wainwright, Briggs-Cowan, \& Carter, 2011), conflictual relationships with teachers and students (Rudasill, Reio, Stipanovic, \& Taylor, 2010), mastery- and performanceavoidant goal achievement motivation (Bjørnebekk \& Diseth, 2010) and poor academic achievement (Curby et al., 2011). Given this capability for certain aspects of 
temperament to lead to poor outcomes, and studies showing that these aspects of temperament are common in children from low-income backgrounds, it is reasonable to explore the relationship between temperament in this population of children and important abilities, such as narrative comprehension. Of particular interest are the dimensions of extraversion and effortful control, as these have been shown to relate to measures of recall in children.

\section{Attention}

Attention has been both implicated in narrative comprehension models and studied in direct relation to comprehension, although in different forms. The broad construct of attention has allowed for research to conceptualize it in many ways. As such, there have been many investigations into the study of attention in an attempt to define it and describe the processes associated with it. The current section will review two avenues of research on attention, the attention network model and cognitive engagement, and then will describe them as factors contributing to narrative comprehension.

Attention network skills. The study of attention has matured since the surge of research and theories during the mid-twentieth century. In the 1950s, Colin Cherry (1953) studied selective auditory attention and Broadbent (1958) posited his view that attention is a filter through which a wide variety of everyday phenomena is sent. Mackworth also conducted studies of sustained attention in the 1950s (Mackworth \& Mackworth, 1956) and Mountcastle (1978) used microelectrodes to study shifts in visual attention.

Advancements in methods to study cognitive processes were made in the $1950 \mathrm{~s}$ and $60 \mathrm{~s}$ with the measurement of microelectrodes and event-related potentials. More recently, modern methods in neuroscience combined with behavioral studies have yielded more 
evidence for a multi-faceted view of attention by localizing brain activity related to different attention skills. Positron emission tomography (PET) allowed for tracing brain activity and functional Magnetic Resonance Imaging (fMRI) has improved spatial and temporal resolution in neuroimaging, leading to thinking of attention as a system with its own circuitry that develops early in life under the control of genes and experience.

Through this work, Posner identified a system of networks of attention in which specific attention processes can be mapped onto certain areas of the brain (Posner \& Petersen, 1990). The three brain networks that have been identified are the alerting, orienting, and executive.

The alerting network has also been called sustained attention or vigilance (Posner \& Petersen, 1990). It involves the ability to increase and maintain response readiness for an impending stimulus and as such has been regarded as a foundational form of attention on which other functions rest (Raz \& Buhle, 2006). Neuroimaging studies have shown that it is related to the right frontal lobe, the right parietal lobe, and the locus coeruleus (Posner \& Petersen, 1990).

The orienting network is responsible for selecting information from multiple sensory stimuli, disengaging and re-engaging attention, as well as adjusting the scale or breadth of attention. The orienting system works by influencing increases in neural activity in a given sensory system. For example, orienting to a face would result in relative increased activity to the fusiform face area (Carmel \& Bentin, 2002; Corbetta, Miezin, Dobmeyer, Shulman, \& Petersen, 1991). Most of the research in orienting has been in the visual domain, but recent work has suggested that orienting could also encompass other sensory systems and mental processes, such as working memory 
(Desimone \& Duncan, 1995; Griffin \& Nobre, 2003). The orienting network is distributed across the superior colliculus, the pulvinar nucleus of the thalamus, superior parietal lobe, the temporoparietal junction, superior temporal lobe, and frontal eye fields.

The executive network is related to the control of goal-directed behavior, target detection, error detection, conflict resolution, and inhibition (Posner \& Petersen, 1990). It has also been called supervisory, selective, and focused attention (Raz \& Buhle, 2006). Executive attention is commonly measured through tasks such as the Stroop, flanker, and Simon tasks. This network includes the anterior cingulate gyrus, SMA, and portions of the basal ganglia, all located in the midline frontal area (Posner \& Petersen, 1990).

The attention networks have been studied to determine at what point capacities emerge, develop and mature. The alerting network is believed to become under the child's internal control between 3.5 and 4.5 years of age, based on the findings that during that time the amount of errors of omission and response time on reaction time (RT) tasks decreases significantly (Ruff \& Rothbart, 1996). Morrison (1982) reported that adults and eight-year-olds alerted more quickly and sustained alertness better than five-year-olds. It is believed that the alerting network continues to mature into adulthood (Rueda, et al 2004). The orienting attention network is evident in young infants as shown by their characteristic visual exploration. Very young infants have trouble disengaging their attention from highly salient stimuli but by four months of age, infants gain more control over the shifting of attention (Johnson, Posner, \& Rothbart, 1991). During the preschool period, research shows that attentional control becomes less exogenous and more endogenous, meaning that orienting seems to be formed as early as 4 years of age. 
The executive attention network emerges near the end of the first year and shows strong development from 4 to 7 years of age (Ruff \& Rothbart, 1996).

To date, most attention network studies involving children focus on their development (Hrabok, Kerns, \& Müller, 2007; Rueda et al., 2004). However, it is also important to examine differences in attention skills and their relation to other processes or outcomes in children given that not only are they fundamental to cognitive activity, the efficiency and variability of functioning differs among individuals across domains. Such studies could contribute to the understanding and characterizations of children's learning styles, as well as school success. For example, in a study of preschoolers from lowincome backgrounds, Chang and Burns (2005) found that children categorized as performance-oriented, or challenge-avoidant, were less accurate on orienting and alerting tasks than children categorized as mastery-oriented. These findings have important implications for facilitating better outcomes for children.

Attention network skills and poverty. Few studies have been conducted examining attention in children from poverty through the attention network model. One such study examined differences in children's attention network skills as a function of SES (Mezzacappa, 2004). Results showed SES differences in the RTs and accuracy of 5to 7-year-olds on the ANT test of alerting, orienting and executive skills in that children from lower SES had slower RTs and made more errors in the alerting and executive, but not orienting, tasks. Regarding their alerting skills, children from higher SES were better able to use alerting cues to effectively increase their RT and lower their errors than their disadvantaged counterparts. As for executive attention skills, children from higher SES were better able to inhibit a response to a competing demand than children from lower 
SES in terms of both RT and accuracy. It is interesting to note that a study of children with ADHD showed similar patterns (Mullane, Corkum, Klein, McLaughlin, \& Lawrence, 2011). Children with ADHD were significantly slower in alerting and executive attention performance, as well as less accurate in alerting. There were no differences in orienting attention skills. However, a study by Brown, Day, and Burns (2010) found only subtle differences in the attention network skills between children from low-income and middle-income families. These conflicting findings further the need to study and characterize attention network skills in children from poverty.

Attention network skills and narrative comprehension. There is evidence to suggest that the attention networks could contribute to narrative comprehension (Bailey, Lorch, Milich \& Charmigo, 2009; Lorch et al., 2006). First, there is overlap in the brain areas that relate to comprehension and the attention networks. The engagement of frontal lobe areas is shared by executive and alerting attention processes and the story comprehension processes of theory of mind and the processing of sequential information. The anterior cingulate is also related to both working memory and the executive attention network. In addition, working memory has also been related to the orienting attention network. Temporal lobe areas that involve the representation of story structure are also involved in the alerting network. Second, there is also research connecting the understanding of causal connections in narratives and certain attention networks. Research of children with ADHD suggests that sustained attention, which is an important component of the alerting network, may be related to connecting of causal events (Bailey et al., 2009). There is also evidence suggesting that differences in causal understanding in 
narratives may be due to the ability to allocate attentional resources, a key function of the executive attention network (Lorch et al., 2006).

Attention network skills, narrative comprehension, and poverty. To date, there is a lack of research on the examination of the relationship of attention network skills to narrative comprehension in children growing up in impoverished environments. The investigation of attention network skills as they relate to narrative comprehension in this population of children will not only make an addition to literature concerning children's ability to comprehend narratives, but will also contribute to existing research on the attention network model. The study of this relationship would also help to distinguish whether the attention abilities of children in poverty play a role in the poor comprehension ability found in this population.

Temperament and attention network skills. The self-regulatory component of temperament known as effortful control can be defined as the "ability to inhibit a dominant response inorder to activate a subdominant response, to plan and to detect errors" (Rothbart, Sheese, \& Posner, 2007, p. 3). Effortful control is not observed until the toddler and preschool years when children are able to guide their attention more voluntarily and regulate their reactive emotions and actions. Studies of effortful control have shown that it is positively related to the development of consciousness, empathy, theory of mind, social competence, and compliance (Kochanska, Murray, \& Coy, 1997). Children low in effortful control have shown higher aggression, more frequent problem behaviors, and psychopathology (Rothbart \& Bates, 2006; Rothbart et al., 2006). Children high in effortful control have shown lower emotionality and ideation (Rothbart \& Sheese, 2006). 
Links between effortful control and the executive attention network also exist. It is believed that changes in executive attention allow for the regulation of behavior and emotions, giving way to the development of effortful control. One of the functions of the executive attention network is to monitor and resolve conflict between other brain networks via promoting or suppressing network activation (Botvinick, Braver, Barch, Carter, \& Cohen, 2001). It has been proposed that this conflict resolution function may be important for self-regulation (Rothbart et al., 2007).

Evidence for the relation between effortful control and the executive attention network come from studies of neuroimaging and cognitive control tasks, implicating the anterior cingulate gyrus as a common neural substrate in executive attention and selfregulation. Cognitive control tasks used to access the executive attention network, such as the Stroop task, the spatial conflict task, and the flanker effect, frequently require inhibition of responses to competing stimuli and activate the anterior cingulate gyrus and lateral prefrontal cortex (Fan, Flombaum, McCandliss, Thomas, \& Posner, 2003). In addition, studies have shown activation of the anterior cingulate during emotional regulation tasks in adults (Beauregard, Lévesque, \& Bourgouin, 2001; Ochsner, Bunge, Gross, \& Gabrieli, 2002) and during a task involving emotional stimuli (Etkin, Egner, Peraza, Kandel, \& Hirsch, 2006).

Studies have also connected parent reports of children's effortful control to performance on executive attention tasks. Gerardi-Caulton (2000) used a spatial conflict task, in which children had to respond correctly to a visual stimulus, despite conflicting locations of the stimulus and target. Results showed that the RT for children ages 3 and older was negatively correlated with effortful control and positively related to negative 
affect. Children who resolved conflict faster were reported as having higher effortful control by their parents. Children slower to react to the spatial conflict task were reported as having low effortful control and higher negative affect (Gerardi-Caulton, 2000). Rothbart and colleagues (Rothbart, Ellis, Rueda, \& Posner, 2003) found similar results in children ages 36-37 months. Children experiencing difficulty in the spatial conflict task were rated as lower in effortful control using the CBQ. Parent reports of effortful control have also been connected with attention in 3- to 5-year-olds (Chang \& Burns, 2005) and 7-year-olds (González, Fuentes, Carranza, \& Estévez, 2001). These studies point to a complex relationship between temperament and attention. Because of their connection, it would be valuable to discover what attention network skills may contribute to narrative comprehension beyond that of temperament.

Attention network skills, temperament, narrative comprehension, and poverty.

The research outlined in the preceding sections contributes to the idea that attention processes and temperament are important aspects of narrative comprehension. The study of narrative comprehension would be furthered by the inclusion of individual-level variables such as child temperament and attention network skills. Research that attempts to determine the types of attention processes and temperament characteristics, such as extraversion and effortful control, that work to facilitate successful narrative comprehension is imperative for the improvement of outcomes for children growing up in poverty.

Cognitive engagement. Narrative comprehension in children diagnosed with Attention Deficit/Hyperactivity Disorder (ADHD) has been examined in a series of studies (Landau, Lorch, \& Milich, 1992; Lorch et al., 2000; Milich \& Lorch, 1994; 
Sanchez, Lorch, Milich, \& Welsh, 1999) using a television viewing methodology. This methodology has produced consistent results concerning differences in attention and comprehension and their relationship, ultimately leading to the identification of cognitive engagement as an important part of successful comprehension. This section will first describe the series of studies that led to the development of cognitive engagement as an important concept in comprehension of televised narratives. The section will then review the progression of studies of cognitive engagement as a contributor to narrative comprehension in the body of work by Lorch, Anderson, and colleagues. Finally, the relationship between cognitive engagement and narrative comprehension in the context of poverty will be explored.

Cognitive engagement and narrative comprehension. Landau et al. (1992) compared the visual attention and comprehension of 6- to 12-year-old boys with ADHD and a group of nonreferred boys. The participants watched a 14-minute segment of educational programming in two conditions, with toys present and with no toys. The participants' visual attention to the television was recorded and free and cued recall was measured after each viewing. The results showed that visual attention was not different for the two groups when toys were absent, but the comparison group had higher percent attention to the television than the ADHD group when toys were present. They also found no differences between the two groups in comprehension in either condition.

Lorch et al. (2000) extended the methodology of the Landau et al. (1992) study to include a television program with a more typical length of 23 minutes. The study of $927-$ through 12- year-old boys also included an examination of causal comprehension between story events instead of discrete units of information only. Lorch and colleagues 
found similar results for the comparison of visual attention between groups (e.g. differences in toys present condition but no differences in toys absent condition) but the analysis of comprehension revealed new findings. Boys in the control group performed better on cued recall questions than boys diagnosed with $\mathrm{ADHD}$ during the toys present condition. There was no difference in recall when no toys were present. Exploratory analyses of question type found that in the absence of toys there were no differences between groups on factual or causal questions. However, when toys were introduced, the comparison group answered significantly more causal questions correctly than the ADHD group.

The utility of the television viewing method has also been illustrated with preschool-aged populations (Sanchez et al., 1999). Sanchez and colleagues examined the story comprehension of 91 children, ages 4 through 6 . All children had a decrease in attention when the toys were present versus when they were absent, but the difference was greater for children in the ADHD group. Analysis of factual comprehension showed a decline in the performance of children with ADHD when toys were present but not in the absence of toys. Regardless of the presence or absence of toys, children with ADHD performed more poorly than comparison children on questions testing recall of causal relations.

As Anderson and Levin (1976) noted in their study of television viewing behavior, children exhibit many looks to and away from the television while viewing a program. Very young children from ages 12- to 24- months looked at the television approximately 90 times per hour, whereas 30 - to 48 -month old children looked at the television about 150 times per hour. Characteristics of the television program have been 
studied to understand this visual attention behavior, including formal features, comprehensibility, and pacing (Wright \& Huston, 1983; Anderson \& Lorch, 1983). Anderson and colleagues (1979) have also studied a phenomenon known as attentional inertia which is thought to represent an attentional process operating within looks to the television (Anderson, Alwitt, Lorch, \& Levin, 1979; Anderson, Choi, \& Lorch, 1987). Attentional inertia is defined as "an increasing probability of a look continuing, the longer the look already has been in progress" (Lorch et al., 2004, p. 57). More specifically, "a look at the television is most likely to be terminated early in the look (within the first $3 \mathrm{~s}$ ) with an increasing probability of the look being maintained until around $15 \mathrm{~s}$, when the probability begins to level off" (Lorch et al., 2004, p. 57).

Evidence for attentional inertia is provided by studies using conditional survival probability analysis of television looks, which analyzes the conditional probabilities of look durations. Attentional inertia studies have found a lognormal distribution of looks to the television (Anderson et al., 1979; Burns \& Anderson, 1993; Hawkins, Kim, \& Pingree, 1991). Looks of shorter duration (5-10s) constitute the largest proportion of looks, with the probability of the occurrence of longer duration looks decreasing. Attentional inertia sustains fixation toward the television throughout structural changes in the program, changes in the viewing content, and environmental distracters.

Studies of attentional inertia suggest a link between look length and cognitive engagement across various ages. Burns and Anderson (1993) studied length of looks and recognition memory in adults, finding that memory was highest for television content that occurred during the later parts of long looks (looks $\geq 15$ seconds). Memory decreased as a look away from the television continued. In another study of adults, Hawkins, Tapper, 
Bruce, and Pingree (1995) found that the longer a look was in progress, the longer it continued beyond a content boundary. In addition, the effect was stronger "the more the information that was presented prior to the content boundary needed to be linked to information after the content boundary". The authors concluded that the continuation of long looks across boundaries was due to deeper processing of material. Anderson et al. (1987) studied attentional inertia in a group of 3- to 5-year-olds. The results indicated that when children were exhibiting long looks to Sesame Street, they were both less likely and slower to show attention to a distracter, indicating more involvement with the program during the long looks. In a similar study, Lorch and Castle (1997) demonstrated that 5year-old children had higher RTs in response to a secondary auditory probe the longer a look at Sesame Street was in progress.

Lorch and colleagues investigated this link further in their television viewing study comparing attention and comprehension of 7- to 11-year-old children with and without ADHD (Lorch et al., 2004). Given previous findings of differences in the comprehension of causal information when a distracter is present and increased cognitive engagement later in look length, the study analyzed whether look length accounted for group differences in the understanding of causal connections. The participants watched two episodes of Growing Pains using the aforementioned television-viewing procedure. The scripts of the two episodes were parsed into individual idea units, with each unit coded as on or off the causal chain. Causal connections for each unit were also identified and rated for importance to the story. The timing of the presentation of story units in the episodes were also coded so that answers to cued recall questions could be related to visual attention of the participant. Analysis of visual attention during the distracter 
condition revealed that children with ADHD spent less time in longer looks $(\geq 15 \mathrm{~s})$ than did comparison children and more time in shorter looks $(<15 \mathrm{~s})$ than did comparison children. Analysis of comprehension showed that the comparison children performed significantly better on questions testing causal relations in the distracter condition than did the children with ADHD. Lorch and colleagues used three analytic strategies to examine the relation between attention and comprehension. First, they found that time spent in long looks mediated the group difference in causal relation comprehension, whereas time in short looks did not. Second, using the coding of the presentation of information in the episode and recordings of visual attention of the participants, the groups were compared on their distribution of looks when the information necessary to answer the causal relation questions was presented. Results showed that comparison children were engaged in long looks during information relevant to causal relations questions for significantly more questions than were children with ADHD. In contrast, children with ADHD were looking away during information relevant to causal relations questions for significantly more questions than were comparison children. The final set of analyses compared the groups' performance on causal relations questions for the different types of looks (short, long, looks away). Results showed that the groups did not differ in their performance on causal questions when they were engaged in long looks during the presentation of the relevant information. Additionally, the comparison group performed significantly better than the children with ADHD on causal comprehension when engaged in short looks. Taken together, the findings of this study provide clear support for the relationship between long looks and deeper cognitive processing. 
Cognitive engagement and poverty. Although studies have not explored the relationship between cognitive engagement, comprehension, and poverty, studies have shown a link between growing up in low-SES and sustained attention (Dilworth-Bart, Khurshid, \& Vandell, 2007; Norman \& Breznitz, 1992). Norman and Breznitz (1992) found that the low-SES group of children performed significantly worse on four measures of sustained attention than the high-SES group. In addition, research has shown that children growing up in low-income households are at a higher risk for developing problems in attention, such as ADHD (Pineda et al., 1999). In the prior studies on cognitive engagement, important differences were found between children who have attention problems and those who don't in the way they attend and comprehend a televised narrative. Given that disadvantaged children have been shown to be at a higher risk for developing attention deficits, it is important to study cognitive engagement ability in that population.

\section{Cognitive engagement, temperament, narrative comprehension, and poverty.}

The relationship between cognitive engagement and narrative comprehension has been studied successfully in children with ADHD. Cognitive engagement was shown to be important for children with attention deficits in comprehending causal information in a setting with distractions. However, these studies did not include temperament, an individual-level variable that has been shown to be related to attention, comprehension, and other cognitive skills. In addition, these studies were conducted with children from middle-income backgrounds. Examining the role of cognitive engagement in narrative comprehension above and beyond the role that temperament may play would be especially beneficial for the study of comprehension ability in children from 
disadvantaged backgrounds. Within the context of poverty, the study of these variables together are important to consider in order to add further knowledge to our understanding of how cognitive engagement within a distracting setting relates to narrative comprehension.

\section{Current Study}

The ability to successfully comprehend a narrative can be considered a building block of literacy and as such, it is important to explore its contributory factors, particularly in children from low-income families as this environment has been shown to have a tremendous negative influence on child outcomes. In the current study, child temperament, attention network skills, and cognitive engagement are studied as contributory factors to narrative comprehension. The study of these factors in relation to the narrative comprehension of children from low-income families will give better insight into how comprehension is affected by individual differences in children, specifically by the role temperament and attention skills play in children's narrative comprehension abilities.

The current study employed a television viewing method previously used by researchers studying differences between children with ADHD and nonreferred children in their visual attention and comprehension (Milich \& Lorch, 1994). Children participated in two viewing conditions, one with toys as distracters and one with no toys, and subsequently answered cued recall questions testing factual and causal information related to the televised narrative. The systematic variation of attention through the use of distracter and no-distracter conditions facilitated the study of comprehension and cognitive engagement in two types of environments: distracter, an environment 
containing diversions of children's attention which may reflect their home and school environments more honestly; and no-distracter, an environment which is more conducive to learning. Studies of the home environment of children growing up in poverty show that it is more chaotic and less organized than those of their nonpoor peers (Dumas et al., 2005). Also, the use of both factual and causal comprehension recall questions allowed for the study of different types of comprehension. Research overwhelmingly shows the importance of the ability to understand and use causal connections for successful narrative comprehension. Readers rely on the causal relations among the ideas of the narrative to guide understanding. Additionally, studies show that ideas with many causal relations are better recalled than those with few causal relations (Trabasso \& Magliano, 1996). Consequently, the current study utilized the television viewing methodology with two conditions, distracter and no-distracter, to examine comprehension of two types of information, factual and causal. Additionally, the current study is separated into two experiments, each of which will be described below.

Experiment One. The first experiment explores temperament and attention network skills as contributory factors to narrative comprehension in children from poverty using the television viewing methodology. Specifically, the temperament dimensions of extraversion and effortful control and the alerting, orienting, and executive attention networks are examined in a series hierarchical regression models as predictors of both factual and causal comprehension in both the no-distracter and distracter conditions.

Experiment Two. The second experiment extends the investigation of factors underlying narrative comprehension by investigating cognitive engagement utilizing the 
television viewing methodology with a sample of children from low-income families. In this study, effortful control is examined along with cognitive engagement as predictors of factual and causal narrative information only in the distracter condition, as a setting with no distracters is not expected to elicit variability in looking patterns. In addition, it is expected that cognitive engagement is more important for the comprehension of causal information presented in the televised narrative than factual information, as previous studies support the relationship between cognitive engagement and causal comprehension. 


\section{METHOD}

\section{Participants}

A total of 112 children between 3- and 7-years-old served by a local medical facility attending to low-income families initially participated in this study. Staff from the facility was informed of the study and notified the researchers when a family with an ageappropriate child was interested in participating. Researchers then informed the family of

the details of the study and set up appointments with the family. None of the children had been previously diagnosed with an attention disorder or learning disability. All families met the Federal Poverty Guidelines based on their annual income levels. Caregivers were given a stipend of $\$ 10$ for their time participating in this study and children received a small toy and a t-shirt at the end of their session.

The final sample size consisted of 79 children between the ages of 5- and 7-yearsold (Mean $=73.11$ months, $\mathrm{SD}=8.39)$. Three- and 4-year-olds $(\mathrm{N}=16)$ were initially recruited and participated in the study but were soon determined to be too young due to their lack of understanding during the comprehension portion of the study. A number of other participants were deleted from the study due to instances such as equipment failure. One participant was deleted from the study due to an assessed cognitive ability score that was more than 3 standard deviations below the mean.

The sample included 33 boys and 46 girls. The majority of the participants were African American (82.3\%; Caucasian = 13.9\%). Caregivers indicated their income by 
category, shown in Figure 1, and their highest education level completed. Over half of the caregivers (55.7\%) reported income below $\$ 11,939$. Approximately $10 \%$ of caregivers reported not having a high school diploma or completing a GED. A third of the caregivers' highest level completed was high school (33.3\%) and none of the caregivers graduated from a four-year college.

\section{Procedure}

The study rationale, procedures and rights were individually explained to the parent prior to obtaining consent. Parent interviews and child assessments took place simultaneously in separate rooms. The session began with the television viewing task, described below. The children then completed the computerized attention tasks and the K-BIT. Meanwhile, parents were with a research assistant completing the questionnaires. All measures, assessments and procedures were approved by the Institutional Review Board (IRB \#315.02).

Television viewing task. The current study employed the television viewing task used in previous studies (Milich \& Lorch, 1994). The child was seated at a small table directly in front of a television and VCR. A mirror was positioned behind the child to give a reflection of the television. A video camera was set up to record the child and the reflection of the television in the mirror. Participants viewed two episodes out of six episodes of Rugrats ${ }^{\circledR}$, each lasting approximately 11 minutes for a total viewing time of approximately 22 minutes. The episodes were randomly chosen for each participant. One episode was viewed in a no-distracter condition (without toys) and the other was viewed in a distracter condition (with toys). The order of the conditions was counterbalanced, resulting in $48.1 \%$ of participants receiving the distracter condition first and $51.9 \%$ 
receiving the distracter condition second. Information regarding the use of the videos in conditions is shown in Figure 2. In the no-distracter condition, the child was seated at the table and given the following instructions: "There will be a television program coming on in a minute for you to watch. When it is over, I will be asking you questions about what you saw on television." In the distracter condition, a variety of toys were placed on the table and the instructions included the addition of the following sentence: "There are some toys here too and you can play with them if you want while the television program is on." The experimenter turned on the television and said, "Remember, I'm going to ask you questions about what you watched when the program is over."

\section{Measures}

Cognitive ability. The Kaufman Brief Intelligence Test (KBIT) is a standardized test of cognitive ability and consists of two subtests: Vocabulary and Matrices. The Vocabulary section requires the participant to name pictures. The Matrices section recruits analogical reasoning abilities and requires the participant to complete an analogy depicted in pictures. A composite score is computed based on the performance on the two subtests and is used as a measure of cognitive ability for all participants.

Demographics. Parents filled out a brief questionnaire consisting of information

about the household, such as income, education levels, occupations, age, and ethnicity. A description of the background of the participants is provided in a later section.

Child Temperament. Child temperament was assessed using the Children's Behavior Questionnaire (CBQ; Rothbart, Ahadi, Hershey, \& Fisher, 2001), which was developed for use with children 3 to 7 years of age. The shortened version (Putman \& Rothbart, 2006) consists of 98 questions which assessed the following 16 scales: (1) 
Activity Level; (2) Anger/Frustration; (3) Approach/Positive Anticipation; (4) Attention Focusing; (5) Attention Shifting; (6) Discomfort; (7) Soothability; (8) Fear; (9) High Intensity Pleasure; (10) Impulsivity; (11) Inhibitory Control; (12) Low Intensity Pleasure; (13) Perceptual Sensitivity; (14) Sadness; (15) Shyness; (16) Smiling and Laughter (see Appendix A for description of scales). The alphas for the scales ranged from .64 to .92 with an average of .73 (Rothbart et al., 2001).

The items were read to the parent, who then indicated the degree to which the item was an accurate description of their children's reaction within the past six months. A seven-point scale, which ranged from extremely untrue to extremely true, was used to rate the items. Three factors were extracted from the sixteen scales of the CBQ based on Rothbart and Ahadi (1994). Effortful Control is the aggregate of attention focusing, inhibitory control, low intensity pleasure, and perceptual sensitivity. Extraversion is the aggregate of the scale scores for activity level, high intensity pleasure, impulsivity, smiling and laughter and shyness (reversed). Negative Affect is the average of scale scores for anger, discomfort, fear, sadness, and soothability (reversed). Each child has a score for effortful control, extraversion, and negative affect, although for the purposes of the current study, only scores for effortful control and extraversion are used.

Attention Network Skills. Three computerized tasks were developed by Berger, Jones, Rothbart, and Posner (2000) to measure skills associated with each attention network as defined by Posner and Petersen (1990). All three attention tasks, orienting, alerting, and executive, were run using a touch screen monitor. Reaction times and accuracy were automatically recorded through the computer program. However, the 
reaction times only for accurate responses were calculated and used in the analyses for the current study.

Alerting task. Children were instructed in this task to "help the farmer catch his animals" by touching the animal when it appeared on the screen. Animals (targets) appeared in the center of the screen one at a time, and for half the trials, at various intervals after an auditory warning signal. There were three practice trials and 32 test trials.

Orienting task. Two glass fishbowls appeared to the left and right of a fixation point. A fish appeared inside of one of the fishbowls randomly. The child was told to "feed the fish" by touching the fish when it appears in one of the fishbowls. For each trial, following a fixation point, a cue appeared consisting of a color change in one of the fishbowls from light blue to dark blue to light blue. Duration of the cue was $500 \mathrm{msec}$ and appeared at both fishbowls with equal probability. The orienting task consisted of 3 practice trials and 32 test trials.

Executive task. This spatial conflict task taps into the executive network and requires the child to resolve a cognitive conflict between the location of the stimulus and the location of the response. Children were asked to "help the picture find its home." For each trial, after the appearance of a fixation point, two houses containing pictures inside appeared at the left and right bottom corners of the screen. A picture then appeared on either the left or right upper corner of the screen. Compatible trials consisted of an ipsilateral configuration between the picture at the top and the houses at the bottom, while an incompatible trial consisted of a contralateral configuration. The child touched 
the corresponding house with the same picture inside. There were five practice trials and 32 test trials.

Cognitive Engagement. Children's looks to the television were recorded during the television viewing task and subsequently coded using a computerized behavioral observation program, Noldus Information Technology, which enabled coding gazes to the hundredth of a second. The looks were coded according to the following definition: a fixation of the child's eye to a location that ended once the child fixated to another location. Looks lasting 15 seconds or longer in duration were categorized as long looks. Time spent in long looks served as a measure of cognitive engagement, as it has been in other studies (Brown, Weatherholt, \& Burns, 2010; Lorch, et al., 2004). Interrater reliability was established on $30 \%$ of the participants, yielding a $93 \%$ agreement and .89 Cohen's kappa.

Narrative Comprehension. Following the television viewing task, the researcher asked cued recall questions pertaining to the respective episode watched by the child. The questions assessed both causal and factual comprehension of information contained in the episode. Figure 3 shows the number of causal and factual questions per episode. The question-answer session was recorded and then later transcribed and scored. Each child had an overall comprehension score for each condition, a causal comprehension score for each condition, and a factual comprehension score for each condition, resulting in six comprehension scores per participant. Approximately $23 \%$ of comprehension sessions (36 sessions, 1278 cases) were submitted for interrater reliability, yielding $92.48 \%$ agreement and a .83 Fleiss's kappa. 


\section{RESULTS}

\section{Experiment One}

Preliminary analysis. Preliminary analyses were conducted to address missing data, identify covariates, and to provide a description of the sample's comprehension performance, temperament, and attention network skills. Two participants showed partial missing attention network data, one missing orienting MRT and another missing executive MRT. Because the mean of each participant's non-missing attention network MRT was within one standard deviation of the mean of their age group, a decision was made to replace each respective missing MRT with the mean of their respective age group.

Covariate analyses were conducted to determine if age, gender, and cognitive ability should be controlled for in subsequent analyses. Pearson product-moment correlations were conducted with each comprehension variable (Distracter [D] Factual, D

Causal, No-Distracter [ND] Factual, and ND Causal) and cognitive ability. Point-biserial correlations were conducted with age and gender. Both age and cognitive ability, but not gender, were found to be significantly correlated with each comprehension variable in a two-tailed analysis. Table 1 shows the correlation coefficients for each pair.

Additional preliminary data analyses were conducted to explore and characterize the sample's patterns and differences in comprehension performance, temperament, and attention network performance. Each variable is subsequently addressed. 
Comprehension performance. During the course of transcribing and scoring comprehension, it was noticed that a majority of participants answered some of the same questions incorrectly. Upon further examination, it was apparent that there were some questions in which zero or very few participants answered correctly and thus, these items were deemed as too difficult for the current sample of participants. Therefore, questions in which $90 \%$ or more of the participants answered incorrectly were excluded from further analyses. Inclusion of items that are too difficult for the vast majority of participants creates a floor effect, artificially reducing the variability. Figure 4 shows the number and type of questions that were deleted from each episode. Figure 5 compares the mean comprehension scores for both the original comprehension performance and the revised $(90 \%)$ comprehension performance. As a result of the exclusion of certain questions, mean comprehension performance increased slightly. All subsequent analyses use the revised comprehension scores.

Descriptive statistics, including mean, standard deviation, and range, for comprehension performance are shown in Table 2. Factual and causal comprehension performance by condition and age group is presented in Table 3 . The mean comprehension performance on both types of information, factual and causal, and in both conditions, ND and D, increased as age increased. The mean comprehension performance for each age group is also higher in the ND condition than for the respective score in the D condition. However, a repeated measures analysis of covariance (RM-ANCOVA) showed that after controlling for age and cognitive ability, there was no significant difference between overall comprehension in each condition, $\mathrm{F}(1,76)=.06, p=.81$. An analysis was also conducted to determine whether there were differences in 
comprehension performance according to Rugrats ${ }^{\circledR}$ episode. An analysis of covariance (ANCOVA), controlling for age, cognitive ability, and overall attention to the television, showed that there were no significant differences in overall comprehension by episode type in either condition, $\mathrm{F}(5,70)=1.78, p=.13$ for no-distracter and $\mathrm{F}(5,70)=2.13, p=$ .07 for the distracter condition. The means for comprehension performance for each episode by condition is shown in Figure 6.

Temperament. The distributions of extraversion and effortful control are shown in Figures 7 and 8 . The current sample of children shows a normal distribution of both temperament dimensions. The mean of effortful control was 5.25 , which is similar to that reported in studies of children from families with higher incomes (Deater-Deckard et al., 2009; Valiente, Lemery-Chalfant, \& Swanson, 2010). The mean of extraversion was 2.91, which is lower than that reported in studies of children from higher-income families (Deater-Deckard et al., 2009). A point-biserial correlational analyses showed that effortful control and extraversion were both significantly correlated with gender $\left(\mathrm{r}_{\mathrm{pb}}=.24\right.$, $\mathrm{p}=.04$ and $\left.\mathrm{r}_{\mathrm{pb}}=-.31, \mathrm{p}<.001\right)$ and not correlated with age. Girls had higher effortful control ratings and boys had higher extraversion ratings. Additional correlations showed that neither was correlated with the attention network skills.

The conflicting results found in past research regarding the relationship between temperament and recall, comprehension and prereading skills support an investigation of each temperament dimension separately. Therefore, effortful control and extraversion will be examined independently in relation to narrative comprehension in subsequent hypotheses testing. 
Attention network skills. Examination of the skewness statistic and histograms revealed that each network MRT distribution was positively skewed. Log transformations of the three attention network variables-orienting MRT, executive MRT, and alerting MRT - produced skewness statistics that were less than twice the standard error of the mean, a rule of thumb for judging skewness. All kurtosis statistics were within 3 to -3 , as advised by Tabachnick and Fidell (1989). The log transformed MRT scores for each attention network were used for subsequent ANOVA and correlational, but not descriptive, analyses.

Attention network performance, including mean MRT and accuracy, is presented by age group in Table 4 . As age increased, children showed faster reaction times across the three measures of orienting, alerting and executive attention skills. The most difficult task for the current sample seemed to be the executive task, as suggested by the slower reaction times. For the orienting network, a one-way analysis of variance (ANOVA) showed that MRT did significantly differ by age group $[\mathrm{F}(2,75)=7.13, p=.001]$. For the alerting network, MRT also significantly differed by age group $[\mathrm{F}(2,75)=9.64, p<$ $.001]$ as did MRT for the executive network $[\mathrm{F}(2,75)=9.63, p<.001]$. These data demonstrate a shift in attention skills between 5 and 7 years of age.

Pearson Product-Moment correlational analyses showed that all of the transformed attention network MRTs were significantly correlated with age. Only executive MRT was correlated with cognitive ability and none were correlated with gender (See Table 5). The transformed attention network MRTs were found to be signficantly correlated with one another: orienting network MRT and alerting network 
$\operatorname{MRT}[\mathrm{r}(79)=.57, p<.001]$; orienting network MRT and executive MRT $[\mathrm{r}(79)=.48, p$ $<.001]$; and alerting network MRT and executive MRT $[\mathrm{r}(79)=.49, p<.001]$.

Partial correlational analyses, controlling for age and cognitive ability, were conducted for each network between transformed MRT and accuracy in order to check for a speed-accuracy trade-off. Although only the executive attention network correlation was significant, $\mathrm{r}(79)=-.32, p<.001$, all correlations were negative, providing evidence that as reaction times were faster, accuracy increased.

Experiment one hypothesis testing. Experiment one examines the contributions of temperament and attention skills to children's comprehension performance. The first two hypotheses concern comprehension in the D condition and the final two hypotheses involve comprehension in the ND condition.

Hypothesis 1. Children's comprehension of causal information during a distracter condition will be significantly predicted by ratings of temperament and the attention skills relating to the orienting, alerting, and executive attention networks. In order to determine whether temperament and attention skills significantly predicted children's comprehension of causal information during the D condition, two hierarchical regressions were performed. The first hierarchical regression predicting children's causal comprehension performance in the D condition included the following steps: 1) covariates of age and cognitive ability, 2) effortful control and 3) orienting MRT, alerting MRT, and executive MRT. The second hierarchical regression predicting children's causal comprehension performance in the D condition included the following steps: 1) covariates of age and cognitive ability, 2) extraversion and 3) orienting MRT, alerting MRT, and executive MRT. 
Statistical assumptions. All of the assumptions of multiple regression were examined before conducting the main analysis. The assumption of normality of residuals was checked by observation of normal probability plots in which the expected normal values of residuals and the actual rank-ordered residuals are plotted. The examination of the normal probability plots for each independent variable with the dependent variable indicates that this assumption has been met. The assumption of a linear relationship between the dependent variables and predictor variables was checked through visual examination of bivariate scatterplots of the standardized residuals and standardized predicted values, which showed that this assumption was met. The data were found to have met the assumption of homoscedasticity by examination of bivariate scatterplots of the raw scores of the dependent and predictor variables. The assumption of multicollinearity was checked through the examination of the Variance Inflation Factor (VIF) of the regression analyses for each independent variable with the dependent variable. None of the VIF equaled 10 or more, providing evidence that multicollinearity was not an issue. Another assumption of multiple regression is independence of errors, which has been met through the design of the study in which participants were steadily collected over a period of time and not in clusters or phases, and there was no systematic change in research procedure or the nature of the participants.

Hypothesis testing results. The first hierarchical regression model predicting causal comprehension performance in the D condition included only effortful control in the second block. The addition of effortful control in Step 2 significantly increased the variance accounted for $\left(\Delta \mathrm{R}^{2}=.04\right)$ over the model including only age and cognitive ability, $\mathrm{F}$ change $(1,74)=4.96, p=.03$. A child with higher effortful control will show 
better causal comprehension performance when a distracter is present than will a child with lower effortful control. The addition of attention network skills in Step 3 did not add significantly to the variance accounted for, $\mathrm{F}$ change $(3,71)=.81, p=.46$. Table 6 presents a summary of the hierarchical regression analysis.

The second hierarchical regression model predicting the comprehension of causal information in the D condition included covariates in the first step, extraversion in the second step, and orienting, alerting and executive attention skills in the third step. The addition of extraversion in Step 2 did not account for significant additional variance, $\mathrm{F}$ change $(1,74)=1.64, p=.20$. The addition of the attention network skills also did not account for significant additional variance when added to the model, which does not support the proposed hypothesis $[\mathrm{F}$ change $(3,71)=1.09, p=.36]$. Table 7 shows the summary of the hierarchical regression analysis. Children's level of extraversion and orienting, alerting and executive attention skills after controlling for age and cognitive ability were not related to their causal comprehension performance when a distracter was present.

Hypothesis 2. Children's comprehension of factual information during a distracter condition will be significantly predicted by ratings of temperament, and the attention skills relating to the orienting, alerting, and executive attention networks. In order to determine whether temperament and attention skills significantly predicted children's comprehension of factual information during the D condition, two hierarchical regressions were performed. The first hierarchical regression predicting children's factual comprehension performance in the D condition included the following steps: 1) covariates of age and cognitive ability, 2) effortful control and 3) orienting MRT, alerting 
MRT, and executive MRT. The second hierarchical regression predicting children's factual comprehension performance in the D condition included the following steps: 1) covariates of age and cognitive ability, 2) extraversion and 3) orienting MRT, alerting MRT, and executive MRT.

Statistical assumptions. The assumptions of multiple regression were examined using the same methods as for hypothesis one. The data were found to have met all assumptions.

Hypothesis testing results. The first regression tested the prediction of factual comprehension performance in the D condition by effortful control in the second step and the attention network skills in the third step, after controlling for age and cognitive ability in the first step. The addition of effortful control to the model in step 2 significantly increased the variance accounted for over the first model of age and cognitive ability $\left(\Delta \mathrm{R}^{2}=.05\right), \mathrm{F}$ Change $(1,74)=5.22, p=.03$. The addition of attention network skills in step 3 did not significantly increase the variance accounted for than that predicted by age, cognitive ability, and effortful control, $\mathrm{F}$ change $(3,71)=1.69, p=.18$. Table 8 presents a summary of the hierarchical regression analysis. Children with higher effortful control performed better on factual comprehension when a distracter was present, beyond that of their age and cognitive ability.

The second regression model tested the prediction of factual comprehension performance in the D condition with age, cognitive ability, extraversion and the attention network skills. The addition of extraversion in the second step did not significantly increase the variance accounted for over the first model including just age and cognitive ability, $\mathrm{F}$ change $(1,74)=2.69, p=.10$. The addition of attention network skills in the 
third step also did not significantly increase the variance accounted over the model including age, cognitive ability and extraversion, $\mathrm{F}$ change $(3,71)=2.02, p=.12$. Table 9 shows the summary of the hierarchical regression analysis. Children's level of extraversion and their orienting, alerting and executive attention skills, after controlling for their age and cognitive ability, did not relate to factual comprehension performance when a distracter was present.

Hypothesis 3. Children's comprehension of causal information during a nodistracter condition will be significantly predicted by ratings of temperament and the attention skills relating to the orienting, alerting, and executive attention networks. In order to determine whether temperament and attention skills significantly predicted children's comprehension of causal information during the no-distracter condition, two hierarchical regressions were performed. The first hierarchical regression predicting children's causal comprehension performance in the ND condition included the following steps: 1) covariates of age and cognitive ability, 2) effortful control and 3) orienting MRT, alerting MRT, and executive MRT. The second hierarchical regression predicting children's causal comprehension performance in the ND condition included the following steps: 1) covariates of age and cognitive ability, 2) extraversion and 3) orienting MRT, alerting MRT, and executive MRT.

Statistical assumptions. The assumptions of multiple regression were examined using the same methods as for previous hypotheses. The data were found to have met all assumptions.

Hypothesis testing results. The hierarchical regression analysis testing the prediction of causal comprehension performance in the ND condition by including age 
and cognitive ability in the first block, effortful control in the second block, and attention network skills in the third block resulted in no significant findings for either Step 2 [F change $(1,74)=2.56, p=.11]$, or Step $3[\mathrm{~F}$ change $(3,71)=.12, p=.95]$. Table 10 presents the summary of the hierarchical regression analysis. Children's effortful control and orienting, alerting and executive attention skills, after controlling for their age and cognitive ability, were not related to causal comprehension when no distracters were present.

Additionally, the second regression predicting causal comprehension in the ND condition, but with the inclusion of extraversion as a predictor, did not result in significant findings, either for the addition of Step 2 [F change $(1,74)=.01, p=.92]$, or Step 3 [F change $(3,71)=.22, p=.89]$. Table 11 presents the summary of the hierarchical regression analysis. After controlling for their age and cognitive ability, children's extraversion and orienting, alerting and executive attention skills were not related to causal comprehension when there were no distracters present.

Hypothesis 4. Children's comprehension of factual information during a nodistracter condition will be significantly predicted by ratings of temperament and the attention skills relating to the orienting, alerting, and executive attention networks. In order to determine whether temperament and attention skills significantly predicted children's comprehension of factual information during the no-distracter condition, two hierarchical regressions were performed. The first hierarchical regression predicting children's factual comprehension performance in the no-distracter condition included the following steps: 1) covariates of age and cognitive ability, 2) effortful control and 3) orienting MRT, alerting MRT, and executive MRT. The second hierarchical regression 
predicting children's factual comprehension performance in the no-distracter condition included the following steps: 1) covariates of age and cognitive ability, 2) extraversion and 3) orienting MRT, alerting MRT, and executive MRT.

Statistical assumptions. The assumptions of multiple regression were examined using the same methods as for previous hypotheses. The data were found to have met all assumptions.

Hypothesis testing results. The hierarchical regression analysis testing the prediction of factual comprehension performance in a no-distracter condition by including age and cognitive ability in the first block, effortful control in the second block, and attention network skills in the third block resulted in no significant findings [Step 2: $\mathrm{F}$ change $(1,74)=1.56, p=.22 ;$ Step $3: \mathrm{F}$ change $(3,71)=.54, p=.66]$. Table 12 shows the summary of the hierarchical regression analysis. When no distracters were present, children's effortful control and orienting, alerting and executive attention skills were not related to factual comprehension, after accounting for their age and cognitive ability.

Additionally, the second regression predicting factual comprehension in the nodistracter condition by extraversion in the second step and attention network skills in the third step, was not significant, [Step 2: $\mathrm{F}$ change $(1,74)=.01, p=.91$; Step 3: $\mathrm{F}$ change $(3,71)=.46, p=.71]$. Table 13 presents a summary of the hierarchical regression analysis. After controlling for their age and cognitive ability, children's level of extraversion and orienting, alerting and executive attention skills were not related to factual comprehension when there were no distracters present.

\section{Experiment Two}


Preliminary Analysis. As in the first experiment, age and cognitive ability were significantly correlated with both of the dependent variables, factual and causal comprehension in the D condition, and thus were controlled for in subsequent analyses. Additional preliminary analyses were conducted for experiment two in order to better understand the cognitive engagement of this sample of participants.

Cognitive Engagement. Total time spent in long looks in the distracter condition was used as the measure of cognitive engagement for hypotheses testing. Table 14 shows the means and standard deviations of number of long looks, total time spent looking to the television and total time spent in long looks to the television by age group and condition. To test for a significant difference in cognitive engagement by condition, a repeated measures (RM) ANCOVA was performed with condition as the within-subjects factor, controlling for age. The RM-ANCOVA revealed that there was a main effect of condition, $\mathrm{F}(1,77)=150.39, p<.001$. Children spent a significantly longer time engaged in long looks in the ND condition than in the D condition, regardless of age.

To correct for the positively skewed distribution of the cognitive engagement (D condition) variable, 6 outliers were changed to the next non-extreme data point and then the log transformation was taken. This successfully reduced the skewness from 1.18 to .03. All kurtosis statistics were within 3 to -3 , as advised by Tabachnick and Fidell (1989). The transformed cognitive engagement variable was used in all subsequent hypotheses testing.

Experiment two hypothesis testing. Because the addition of extraversion did not account for a significant $\mathrm{R}^{2}$ change in the regression analyses for the distracter condition in experiment one, it was not included in the hypotheses testing for experiment two. 
Effortful control was retained as the only step 2 variable in each regression model for hypotheses one and two. The first hypothesis includes causal comprehension in the D condition as the dependent variable and the second hypothesis includes factual comprehension in the $\mathrm{D}$ condition as the dependent variable. The third hypothesis examines the difference in the importance of cognitive engagement to the two types of comprehension.

Hypothesis one. Children's comprehension of causal information during a distracter condition will be significantly predicted by effortful control and cognitive engagement. This hypothesis was tested through hierarchical regression analysis with age and cognitive ability entered as covariates in the first step, effortful control in the second step, and cognitive engagement in the third step.

Statistical assumptions. The assumptions of multiple regression were examined using the same methods as for previous hypotheses. The data were found to have met all assumptions.

Hypothesis testing results. The results of the hierarchical regression analysis indicated that the addition of cognitive engagement in step 3 did not increase the variance accounted for over the model including the covariates and effortful control, $\mathrm{F}$ change (1, $74)=1.82, p=.18$. Table 15 presents a summary of the hierarchical regression analysis. Children's cognitive engagement was not related to causal comprehension of a televised narrative when distracters were present after accounting for age, cognitive ability and effortful control.

Hypothesis two. Children's comprehension of factual information during a distracter condition will be significantly predicted by effortful control and cognitive 
engagement. This hypothesis was tested through hierarchical regression analysis with age and cognitive ability entered as covariates in the first step, effortful control in the second step, and cognitive engagement in the third step.

Statistical assumptions. The assumptions of multiple regression were examined using the same methods as for previous hypotheses. The data were found to have met all assumptions.

Hypothesis testing results. The addition of cognitive engagement in step 3 of the hierarchical regression did significantly increase the variance accounted for over that of the previous 2 steps, $\left(\Delta \mathrm{R}^{2}=.07\right) \mathrm{F}$ change $(1,74)=8.29, p=.02$. The final model including age, cognitive ability, effortful control and cognitive engagement accounted for a total of $39.3 \%$ of the variance (Adjusted $\mathrm{R}^{2}$ ). The summary of the hierarchical regression is presented in Table 16. Cognitive engagement was related to children's factual comprehension of a televised narrative when distracters were present after accounting for age, cognitive ability and effortful control.

Hypothesis three. Cognitive engagement will be more important for causal comprehension than for factual comprehension.

Hypothesis testing results. The hypothesis was not supported. The above results from the regression analyses determined that cognitive engagement in the presence of distracters was significantly related to factual comprehension and was not related to causal comprehension of a televised narrative after controlling for age, cognitive ability and effortful control. 


\section{DISCUSSION}

The focus of the current study was to better understand narrative comprehension in children from low-income families by examining individual differences in temperament, attention skills, and cognitive engagement. Studies of literacy have established the importance of the contribution of higher-order skills, such as comprehension, to successful reading ability, as well as showing that children from disadvantaged backgrounds are at a higher risk for poor reading skills. However, few studies have investigated the role of individual differences in child-level characteristics in relation to the narrative comprehension skills of children from low-income families. The current study sought to address this gap in the research by examining the relationships among temperament, attention, and narrative comprehension in a sample of 5- to 7-yearold children from disadvantaged homes. A television viewing methodology allowed for the study of narrative comprehension ability in prereaders and included two conditions, no-distracter and distracter, enabling the systematic investigation of comprehending narratives in a naturalistic setting in which children have competing demands on their cognitive resources. The hypotheses of the first experiment proposed that child temperament and attention skills would be significantly related to narrative comprehension in both conditions. The second experiment proposed that cognitive engagement would be related to comprehension in the distracter condition, above that of temperament, and in addition, would be more important for the comprehension of causalthan factual information as past studies have shown. The findings partially 
supported the hypotheses, showing that effortful control is important for both causal and factual comprehension when there is a distracter present and cognitive engagement is related to the comprehension of factual information, after accounting for a child's level of effortful control.

\section{Temperament, Attention, and Comprehension}

The hypotheses regarding temperament and attention network skills tested in experiment one revealed interesting findings about the comprehension of factual and causal information in the current sample of children from disadvantaged backgrounds. First, temperament and attention skills did not significantly account for more variance in comprehension than that beyond age and cognitive ability when there were no distracters. Second, extraversion was not related to factual or causal comprehension in either condition. Third, effortful control accounted for a significantly more amount of variance in causal and factual comprehension performance in a distracter setting beyond that of age and cognitive ability, but attention network skills did not.

No-Distraction Condition. The proposed hypotheses that effortful control, extraversion and attention network skills would predict comprehension performance in the no-distracter condition were not supported. In the current sample, children's temperament and attention skills were not related to their factual or causal narrative comprehension when there were no competing demands.

The lack of significant findings in the no-distracter condition could be explained by the nature of the condition and task; when a highly enjoyable task is presented with no other competing demands, children may be able to direct and utilize all of their mental resources for comprehension, regardless of their temperament or attentional abilities. 
Two children who differ in their level of extraversion or effortful control may perform similarly in how much they comprehend from a televised narrative when it is their singular task. Likewise, holding their temperament constant, children who differ in attention skills may perform similarly in their comprehension of a televised narrative when there is nothing distracting them from the activity. This explanation is consistent with recent work showing that high-quality classroom organization ameliorates children's difficult temperament in relation to achievement (Curby et al., 2011). Children rated as having a difficult temperament had similar achievement to those with less difficult temperaments when the classroom was highly organized. Similarly, children's differences in temperament and attention may not play a role in comprehension performance when in a non-distracting environment.

Extraversion and comprehension. Extraversion was not related to comprehension performance of either type of information in either condition. Past research has shown an inconsistent relationship between extraversion and recall of information. For example, in 13-month-olds, long-term recall was positively correlated with extraversion measures, but in 20-month-old infants, extraversion was negatively correlated with recall (Bauer et al., 2002). In a study of 5- to 8 -year-olds, shyness ${ }^{1}$ was negatively related to cued recall in 7- to 8-year-olds, but unrelated to recall in 5- to 6-year-olds (Chae \& Ceci, 2005). The findings from the current study do not support a relationship between extraversion and recall or comprehension in 5- to 7-year-olds. The inconsistency in the older children's findings may be a result of differences in recall and temperament measures. For example, the study of 5- to 8-year-olds assessed recall of a staged argument between two adults one week after the event. However, the current study measured recall of an engaging

\footnotetext{
${ }^{1}$ Extraversion is assessed in the current study partly through reversed shyness scores.
} 
televised narrative directly after viewing and also distinguished between causal and factual comprehension. Difference in the recall measures both in timing and type of information could account for the discrepancy in results concerning extraversion. Also, researchers must be careful when drawing conclusions from research using different temperament assessments and constructs. The current study uses Rothbart's paradigm whereas the study by Chae and Ceci (2005) uses Buss and Plomin's model. The findings for the current study illustrate that 5- to 7-year-old children's level of extraversion is not related to comprehension of factual or causal information presented in a televised narrative.

Additionally, other studies have examined the relationship between extraversion and prereading skills, again with inconsistent results. Fuhs, Wyant, and Day (2011) found that impulsivity was a significant predictor of prereading skills after controlling for age, gender, and cognitive ability in 3- to 5-year-olds who attended Head Start. Children rated as lower in impulsivity had higher prereading skills. Another study (Deater-Deckard et al., 2009) found that effortful control, but not extraversion, was related to word identification and pseudo-word reading in five- to eight-year-old children. Although the literature shows mixed findings regarding the relationship of extraversion to recall and prereading skills, the current study adds to the evidence that extraversion is not related to narrative comprehension.

Effortful control and comprehension. Effortful control was found to be a significant predictor of children's factual and causal comprehension during the distracter condition and accounted for a significant increase in variance in comprehension beyond that of age and cognitive ability. The current study shows that children with higher 
effortful control are able to comprehend information more effectively when a competing demand is present. Effortful control was assessed by subscales relating to maternal ratings of children's inhibitory control, low intensity pleasure, perceptual sensitivity, and attentional focusing. It is likely that higher levels of effortful control in children allow them to ignore distracters and therefore focus on the primary task, given the inclusion of ratings of inhibitory control and attentional focusing. Whereas the no-distracter condition did not require inhibitory skills, the distracter condition may have, in a sense, activated effortful control in children.

The findings showed that effortful control is helpful for the comprehension of different types of information, both factual and causal. For causal comprehension, it is possible that effortful control allows children to persist in the cognitive processes associated with connecting events to form understanding of causal relations within the narrative. Children with low effortful control may not be able to maintain regulation of their cognitive resources in order to make those connections. However, the fact that effortful control was not related to causal comprehension in the no-distracter condition makes this explanation less plausible. It is also possible that the child's level of effortful control became important when a competing task was presented. However, it is important to note that effortful control was important for both factual and causal comprehension, not just one of type of comprehension. Taken together, these findings establish the importance of effortful control in how well children comprehend information in a distracting environment.

Attention skills and comprehension. The current study hypothesized that orienting, alerting, and executive attention skills would predict both types of 
comprehension beyond that of age, cognitive ability, and temperament. Surprisingly, the results indicated that in the current sample, none of the attention network skills were related to comprehension of either type in either condition. The lack of relationship between the skills associated with the attention networks and comprehension performance was postulated to exist because of the role attention plays in the selection of and orienting to information in the narrative. Additionally, attention skills were postulated to be important in the distracter condition for inhibiting response to the toys and orienting attention to the television. There are no definitive answers as to why there is a lack of relationship between comprehension and attention skills, although there are a few possibilities. As aforementioned, in the no-distracter condition, children's level of attention skills may not have been important in such an engaging task as a children's television program. Past research has shown that even children with ADHD perform similarly to non-referred children on comprehension measures when there are no competing distracters (Lorch et al, 2000). Prior studies have found that effortful control and attention skills are related, (Barkley, 1997; Chang \& Burns, 2005; Harris, Robinson, Chang, \& Burns, 2007) lending to the possibility that the attentional component of effortful control could have undermined the effect of the attention skills. However, in the current study, effortful control and performance on the attention networks were not related, making this explanation less plausible.

A major possibility is that the attention network skills do not relate to comprehension as a whole, but to specific aspects of comprehension. For example, a study by Brown (2008) examined how attention network skills related to causal comprehension by analyzing the storytelling abilities of preschool children. Various 
aspects of causal comprehension were coded from the narratives produced, including the number of causal connections made, distance between information causal connections, number of physical and between-scene connections, and goal production. The findings from the study showed that alerting skills were related to the distances between the use of causality, meaning that children with high alerting skills made more connections between content that was farther apart. Additionally, children's orienting ability was related to the number of connections produced, the number of physical and between connections produced, and overall goal production in their narratives. The study showed that children who were better able to shift their attention also produced more connections and included an overall goal in their stories. In the current study, attention skills did not relate to overall causal comprehension, but it is possible that they could relate to features of causal and factual comprehension. Future studies with children from low-income are needed to further investigate the relationship between comprehension and attention skills.

\section{Cognitive Engagement, Temperament, and Comprehension}

Experiment two explored the relationship among effortful control, cognitive engagement, and comprehension of both factual and causal information in a condition with distracters. Although cognitive engagement was related to factual comprehension after controlling for a child's age, cognitive ability and effortful control, it was not related to the comprehension of causal information. This finding was quite surprising given past research supporting the relationship between causal comprehension and engagement in long looks. However, this is the first study to incorporate effortful control into the study of the relationship between comprehension and cognitive engagement, as well as in a population of children from low-income families. 
Prior studies found that cognitive engagement accounted for differences in causal understanding of a televised narrative between typically developing children and children with ADHD. It was thought that the longer looks to the television enabled children to form more complete representations of the relations among events in the story and that children with ADHD had a lower ability to engage in long looks when a distracter was present, therefore hindering their causal comprehension performance. Also, past studies found that the groups did not differ in causal comprehension when they were engaged in long looks during the presentation of the relevant information. In the current study, although the reason for the lack of relationship between cognitive engagement and causal comprehension is unclear, it is possible that long looks to the television are not a strong enough component to help children from low-income families with the complex process of comprehending causal relations. Engagement in long looks was enough to aid in factual comprehension, but not causal comprehension.

Another possibility is that the current sample did not engage in enough long looks to support connecting events presented in the television program, but was sufficient for the understanding of discrete facts. This indicates that distracting environments have a powerful negative influence on children's ability to form causal relations between events, which has important implications. For example, it is possible that when children experience distraction in the classroom, they may miss connecting important pieces of information presented, such as teacher instructions and lectures. Nevertheless, the current study shows that children's comprehension and cognitive engagement suffered as a result of the introduction of a competing task. 
To further address the lack of relationship between cognitive engagement and causal comprehension and low levels of cognitive engagement shown by the study participants, other visual attention behaviors were explored in relation to comprehension performance in this sample. The mean of total time spent in long looks to the television was 52.37 seconds, which equates to only about $8 \%$ of the television program. It was decided that examining the combination of both short looks (looks shorter than 15 seconds) and long looks (equaling total time spent looking to the television) rather than just long looks to the television would be beneficial to explore. The results of the hierarchical regression analysis indicated that the addition of this visual attention measure, total time spent looking at the television, in step three accounted for a significant increase in variability in causal comprehension beyond that accounted for by age, cognitive ability, and effortful control. [F change $(1,74)=10.60, p=.002]$. For the current sample, it seems that long looks needed to be supplemented with short looks to the television during the distracter condition in order to significantly contribute to the comprehension of causal events presented in the program. The combination of short looks and long looks to the television provided ample variability from which to discern differences in comprehension of causal information. This finding uncovers a new visual attention pattern that appears to be important for the causal comprehension of children from low-income families. Whereas past studies showed that engaging in long looks mediated differences in causal comprehension performance between children with ADHD and non-referred children, this exploratory analysis of visual attention in children from low-income families provides evidence that this population needs more than just long looks for the connecting of causal events presented in a televised narrative. 


\section{Theoretical and Research Implications}

One of the goals of the study was to contribute to current knowledge about the narrative comprehension abilities of children from low-income families. This study was the first to attempt to understand the narrative comprehension of factual and causal information in children from disadvantaged homes and how temperament, attention, and cognitive engagement relate. The findings illustrate that narrative comprehension of children from low-income families is an area in need of further study. Narrative comprehension is an important part of the everyday experience of children, both at home and at school. The low levels of performance of narrative comprehension in the children of this sample are disconcerting, but not surprising. Children growing up in disadvantaged homes generally score lower on tests of reading, math, and cognitive ability (Bradley \& Corwyn, 2002; Dickinson \& Snow, 1987). As narrative comprehension is an underlying skill needed for many school-related tasks, the findings of this study concerning children's narrative comprehension performance fall in line with studies of other skills. However, that is also a reason to delve further into the study of comprehension processes in this population of children. It is possible that narrative comprehension ability is a factor that extends to children's performance on academic measures of other school subjects.

The study also has important research methodological implications. It is important to gain insight into the comprehension skills of children who are not yet literate, as comprehension is a skill that begins before a child learns to read. Milich and Lorch were the first to use the television viewing methodology to study narrative comprehension in children. The current study was able to extend this methodology for use with children 
from economically disadvantaged backgrounds to effectively study their narrative comprehension in combination with temperament and attention. The television viewing methodology was an effective way to systematically vary the conditions in order to investigate how children comprehend information in distracting settings. It also allowed for the examination of various visual attention allocation patterns in relation to comprehension, such as that found after exploring the combination of long looks and short looks. The distraction setting used in the methodology included a television program and toys available for play, which is a natural environment for children. The television viewing methodology was effective in engaging children and provided useful information regarding children's comprehension skills.

\section{Applied Implications}

One of the important outcomes of this study was the finding of the importance of effortful control on children's narrative comprehension in distracting conditions. This finding has important implications for applied settings, such as classroom management and organization in schools and preschools. Distractions often occur in the classroom, including disruptive classmates, visitors entering and leaving the room, and exterior noises from the playground. Children in a disruptive classroom may not be able to maximize their learning potential due to their levels of effortful control. The current study found that children with higher effortful control showed better comprehension performance. Children with low effortful control in a disruptive classroom may not be getting the most out of their school experience. Additional work has shown that difficult temperaments may impede a children's ability to learn (Martin \& Holbrook, 1985). For example, children with a high activity level and low levels of soothability may face 
greater challenges in learning. However, a study by Curby and colleagues (Curby et al., 2011) showed that a high-quality classroom environment, such as one that is well organized, can ameliorate the effects of a difficult temperament on academic outcomes. Taken together, these studies show that taking individual differences in children's temperament into account when considering the classroom environment can greatly improve a child's ability to succeed in school.

\section{Limitations of the Current Study}

A limitation to the current study is the moderate effect size associated with the analyses. The number of predictors and sample size did now allow for the detection of a small effect size. It is possible that in the current analyses, relationships between variables, such as comprehension performance and attention network skills were not found due to the small sample size for regression analyses. A second limitation which may have affected cognitive engagement is the lack of diversity reflected among the characters in the Rugrats $\mathbb{R}$ episodes. Although Rugrats was selected to be broadly attractive across age and gender, the sample of the current study was largely AfricanAmerican and there were no African-American characters included in the Rugrats episodes used. Studies have shown that children prefer same-race television programs to opposite-race television programs (Liss, 1981).

\section{Future Directions in Research}

Future research should examine the influence of additional child characteristics on comprehension skills. For example, children differ in how they approach challenging tasks. This motivation style has been shown to influence outcomes on cognitive measures and also interacts with aspects of their temperament. Chang and Burns (2005) found that 
children with a performance-oriented motivation style gained more from effortful control than children with a mastery-oriented motivation style in terms of accuracy on attention measures. Interesting findings could result from the study of how differing motivation patterns of children affect narrative comprehension of factual and causal information. Another direction of future research should include the examination of comprehension in applied settings. Observations of children in the classroom, especially in highly distracting ones, and assessments of students' comprehension of lectures, teacher directions for tasks, and stories could be studied to better inform practical interventions for improving learning in school. The current climate of school reform also lends support to the study of classroom environment in struggling schools, as they may have more disruptive classrooms and could in turn affect student learning. Establishing best practices for classroom organization and management that would support young students' comprehension would be a basic but necessary line of research.

Studies have also explored interventions with children using attention training to overcome a variety of obstacles to learning, including the reduction of inattention, impulsivity and hyperactivity symptoms (Bakhshayesh, Hänsch, Wyschkon, Rezai, \& Esser, 2011), decreasing social anxiety (Cowart \& Ollendick, 2011), and increases in motivation and working memory performance (Prins, Dovis, Ponsioen, ten Brink, \& van der Oord, 2011). Future research should focus on the development of interventions to increase effortful control, cognitive engagement, and improve comprehension performance in children.

\section{Conclusion}


The current study made new contributions to existing research by examining narrative comprehension of children from impoverished homes. It was the first study to use a television-viewing methodology with children from low-income families to study the relationships among temperament, attention, cognitive engagement, and comprehension of factual and causal information in order to better understand individual differences in children's narrative comprehension skills. The study helped to identify the factors affecting the comprehension of narratives while engaged in a single task as well as when competing demands are present. The findings of the study emphasized the importance of effortful control and organized learning environments for comprehension ability in children from low-income families, which has important implications for literacy interventions and classroom organization. The study also showed that the visual attention patterns needed for the comprehension of causal information may be different for children from low-income families than other groups. More investigations of the comprehension skills of children from low-income families are needed as this basic skill is necessary for successful school achievement, and this population is at a higher risk for problems in reading and prereading ability. 


\section{REFERENCES}

Ackerman, B. P, Brown E. D., \& Izard, C. E. (2004). The relations between contextual risk, earned income, and the school adjustment of children from economically disadvantaged families. Developmental Psychology, 40, 204-216. doi: $10.1037 / 0012-1649.40 .2 .204$

Anderson, D. R., Choi, H. P., \& Lorch, E. P. (1987). Attentional inertia reduces distractibility during young children's TV viewing. Child Development, 58, 796806.

Anderson, D. R., Alwitt, L. F., Lorch, E. P., \& Levin, S. R. (1979). Watching children watch television. In G. Hale and M. Lewis (Eds.), Attention and Cognitive Development. New York: Plenum.

Anderson, D. R., \& Levin, S. R. (1976). Young children's attention to "Sesame Street". Child Development, 47, 806-811.

Anderson, D. R., \& Lorch, E. P. (1983). Looking at television: Action or reaction? In J. Bryant \& D. R. Anderson (Eds.), Children's understanding of TV: Research on attention and comprehension. New York: Academic Press.

August G. J., \& Garfinkel, B. D. (1990). Comorbidity of ADHD and reading disability among clinic-referred children. Journal of Abnormal Child Psychology, 18, 2945. 
Bakhshayesh, A. R., Hänsch, S., Wyschkon, A., Rezai, M. J., \& Esser, G. (2011). Neurofeedback in ADHD: A single-blind randomized controlled trial. European Child and Adolescent Psychiatry, 20,481-491.

Bailey, U. L., Lorch, E. P., Milich, R., \& Charmigo, R. (2009) Developmental changes in attention and comprehension among children with ADHD. Child Development, $80,1842-1855$

Barkley, R. A. (1997). ADHD and the nature of self-control. New York: Guilford Press.

Barrocas, A. L., \& Hankin, B. L. (2011). Developmental pathways to depressive symptoms in adolescence: A multi-wave prospective study of negative emotionality, stressors, and anxiety. Journal of Abnormal Child Psychology, 39, $489-500$.

Basavanna, M., \& Rani, M. U. (1984). Differential impact of social and economic factors on intellectual and scholastic abilities. Journal of Psychological Researches, $28(3), 121-128$.

Bates, J. E, \& Wachs, T. D. (1994). Temperament: Individual differences at the interface of biology and behavior. Washington, DC: American Psychological Association.

Bauer, P. J., Burch, M. M., \& Kleinknecht, E. E. (2002). Developments in early recall memory: Normative trends and individual differences. In R. V. Kail (Ed.), Advances in child development and behavior (pp.103-152). San Diego, CA: Academic Press.

Beauregard, M., Lévesque, J., \& Bourgouin, P. (2001). Neural correlates of conscious self-regulation of emotion. The Journal of Neuroscience, 21, 6993-7000. 
Berger, A., Jones, L., Rothbart, M. K., \& Posner, M. I. (2000). Computerized games to study the development of attention in childhood. Behavior Research Methods, Instruments, \& Computers, 32, 297-303.

Bjørnebekk, G., \& Diseth, A. (2010). Approach and avoidance temperaments and achievement goals among children. Personality and Individual Differences, 49, 938-943.

Bolger, K. E., Patterson, C. J., Thompson, W. W., \& Kupersmidt, J. B. (1995). Psychosocial adjustment among children experiencing persistent and intermittent family economic hardship. Child Development, 66, 1107-1129.

Botvinick, M. M., Braver, T. S., Barch, D. M., Carter, C. S., \& Cohen, J. D. (2001). Psychological Review, 108, 624-652.

Bowey, J. A. (1995). Socioeconomic status differences in preschool phonological sensitivity and first grade reading achievement. Journal of Educational Psychology, 87, 476-487.

Bradley, L., \& Bryant, P. E. (1983) Categorizing sounds and learning to read: A causal connection. Nature, 301, 419-421.

Bradley, R. H., \& Corwyn, R. F. (2002). Socioeconomic status and child development. Annual Review of Psychology, 53, 371-399.

Bradley, R. H., Corwyn, R. F., McAdoo, H. P., \& Coll, C. G. (2001). The home environments of children in the United States Part I: Variations by age, ethnicity, and poverty status. Child Development, 72, 1844-1867.

Breznitz, Z. (1987). Reducing the gap in reading performance between Israeli lower- and middle-class first-grade pupils. The Journal of Psychology, 121, 491-501. 
Broadbent, D. E. (1958.) Perception and communication. Elmsford, NY: Pergamon Press.

Brown, D. D. (2008). Young children's use of causal connections during storytelling: The role of context and individual differences in attention. Dissertation Abstracts International: Section B: The Sciences and Engineering, 68(12), 8432.

Brown, D. D., Day, C. A., \& Burns, B. M. (2010). Characterizing attention network skills of children from middle-and low-income families. Poster presented at the 21 st Biennial Conference on Human Development. New York, NY.

Burns, J. J., \& Anderson, D. R. (1993). Attentional inertia and recognition memory in adult television viewing. Communication Research, 20, 777-799.

Buss, A. H., \& Plomin, R. (1984). Temperament: Early developing personality traits. Hillsdale, NJ: Lawrence Erlbaum Associates.

Calvert, S. L., \& Huston, A. C. (1987). Television and children's gender schemata. New Directions for Child and Adolescent Development, 1987(38), 75-88.

Carmel, D., \& Bentin, S. (2002). Domain specificity versus expertise: Factors influencing distinct processing of faces. Cognition, 83, 1-29.

Chang, F., \& Burns, B. M. (2005). Attention in preschoolers: Associations with effortful control and motivation. Child Development, 76, 247-263.

Cherry, E. C. (1953). Some experiments on the recognition of speech, with one and with two ears. Journal of the Acoustical Society of America, 25, 975-979.

Cohen, J., Cohen, P., West, S. G., \& Aiken, L. S. (2003). Applied multiple regression/correlation analysis for the behavioral sciences. Mahwah, NJ: Laurence Erlbaum Associates, Inc. 
Coplan, R. J., Barber, A. M., \& Lagace-Seguin, D. G. (1999). The role of child temperament as a predictor of early literacy and numeracy skills in preschoolers. Early Childhood Research Quarterly, 14, 537-553.

Corbetta, M., Miezin, F. M., Dobmeyer, S., Shulman, G. L., \& Peterson, S. E. (1991). Selective and divided attention during visual discrimination of shape, color, and speed: Functional anatomy by positron emission tomography. Journal of Neuroscience, 11, 2383-2402.

Costello, E. J., Compton, S. N., Keeler, G., \& Angold, A. (2003). Relationships between poverty and psychopathology. Journal of the American Medical Association, 290, 2023-2029.

Cowart, M. J. W., \& Ollendick, T. H. (2011). Attention training in socially anxious children: A multiple baseline design analysis. Journal of Anxiety Disorders, 25, 972-977.

Crooks, D. L. (1995). American children at risk: poverty and its consequences for children's health, growth, and school achievement. American Journal of Physical Anthropology, 38(S21), 57-86.

Curby, T. W., Rudasill, K. M., Edwards, T., \& Perez-Edgar, K. (2011). The role of classroom quality in ameliorating the academic and social risks associated with difficult temperament. School Psychology Quarterly, 26, 175-188.

doi: $10.1037 / \mathrm{a} 0023042$

Dearing, E., McCartney, K., \& Taylor, B. A. (2001). Change in family income-to-needs matters more for children with less. Child Development, 72, 1779-1793. 
Deater-Deckard, K., Mullineaux, P. Y., Petrill S. A., \& Thompson, L. A. (2009).

Effortful control, surgency, and reading skills in middle childhood. Reading and Writing, 22, 107-116. doi: 10.1007/s11145-007-9111-9

Desimone, R., \& Duncan, J. (1995). Neural mechanisms of selective attention. Annual Review of Neuroscience, 18, 193-222.

Dickinson D. K., \& Snow, C. E., (1987). Interrelationships among prereading and oral language skills in kindergarten from two social classes. Early Childhood Research Quarterly, 2, 1-25.

Dilworth-Bart, J. E., Khurshid, A., \& Vandell, D. L. (2007) Do maternal stress and home environment mediate the relation between early income-to-need and 54-months attentional abilities. Infant and Child Development, 16, 525-552.

DiPietro, J. A., Costigan, K. A., Shupe, A. K., Pressman, E. K., \& Johnson, T. R. B. (1998). Fetal neurobehavioral development: Associations with socioeconomic class and fetal sex. Developmental Psychobiology, 33, 79-91.

Dumas, J. E., Nissley, J., Nordstrom, A., Smith, E. P., Prinz, R. J., \& Levine, D. W. (2005). Home chaos: Sociodemographic, parenting, interactional, and child correlates. Journal of Clinical Child and Adolescent Psychology, 34, 93-104.

Etkin, A., Egner, T., Peraza, D., Kandel, E., \& Hirsch, J. (2006). Resolving the emotional conflict: A role for the rostral anterior cingulate cortex in modulating activity in the amygdala. Neuron, 51, 871-882.

Fan, J., Flombaum, J. I., McCandliss, B. D., Thomas, K. M., \& Posner, M. I. (2003). Cognitive and brain consequences of conflict. NeuroImage, 18, 42-57. doi:10.1006/nimg.2002.1319 
Faul, F., Erdfelder, E., Lang, A., \& Buchner, A. (2007). G*Power 3: A flexible statistical power analysis program for the social, behavioral, and biomedical sciences. Behavior Research Methods, 39, 175-191.

Fletcher, C. R., van den Broek, P., \& Arthur, E. J. (1996). A model of narrative comprehension and recall. In B. Britton \& C. Graesser (Eds.), Models of understanding text. Mahwah, $\mathrm{NJ}$ : Lawrence Erlbaum Associates, Inc.

Fuhs, M. W., Wyant, A. B., \& Day, J. D. (2011). Unique contributions of impulsivity and inhibition to prereading skills in preschoolers at Head Start. Journal of Research in Childhood Education, 25, 145-159. doi: 10.1080/2568543.2011.555497

Garrison, W. T., \& Earls, F. J. (1987). Temperament and child psychopathology. Thousand Oaks, CA: Sage Publications, Inc.

Gesell, A. (1928). Infancy and human growth. Oxford, England: Macmillan.

Gerardi-Caulton, G. (2000). Sensitivity to spatial conflict and the development of selfregulation in children 24-36 months of age. Developmental Science, 3, 397-404.

Goldsmith, H. H., and Campos, J. J. (1986). Fundamental issues in the study of early temperament: The Denver twim temperament study. In M. E. Lamb, A. L. Brown, \& B. Rogoff (Eds.), Advances in developmental psychology (Vol. 4, pp. 231-283). Hillsdale, NJ: Lawrence Erlbaum Associates, Inc.

Goldsmith, H. H., Buss, A. H., Plomin, R., Rothbart, M. K., Thomas, A., Chess, S., . . McCall, R. B. (1987). Roundtable: What is temperament? Four approaches. Child Development, 58, 505-529. 
González, C., Fuentes, L. J., Carranza, J. A., \& Estévez, A. F. (2001). Temperament and attention in the self-regulation of 7-year-old children. Personality \& Individual Differences, 30, 931-946.

Greenhoot, A. F., Ornstein, P. A., Gordon, B. N., and Baker-Ward, L. (1999). Acting out the details of a pediatric check-up: The impact of interview condition and behavioral style on children's memory reports. Child Development, 70, 363-380.

Griffin, I. C., \& Nobre, A. C. (2003). Orientational attention to locations in internal representations. Journal of Cognitive Neuroscience, 15, 1176-1194.

Gunnar, M. R., \& Nelson, C. A. (1994). Event-related potentials in year-old infants: Relations with emotionality and cortisol. Child Development, 65, 80-94.

Harris, R. C., Robinson, J. B., Chang, F., \& Burns, B. M. (2007). Characterizing preschool children's attention regulation in parent-child interactions: The roles of effortful control and motivation. Journal of Applied Developmental Psychology, $28,25-39$.

Hawkins, R. P., Kim, Y., \& Pingree, S. (1991). Ups and downs of attention to television. Communication Research, 18, 53-76.

Hawkins, R. P., Tapper, J., Bruce, L., \& Pingree, S. (1995). Strategic and nonstrategic explanations for attentional inertia. Communication Research, 22, 188-206.

Hawley, T., \& Disney, E. (1992). Crack's children: The consequences of maternal cocaine abuse. Social Policy Report, 6, 1-22.

Hecht, S. A., Burgess, S. R., Torgesen, J. K., Wagner, R. K., \& Rashotte, C. A., (2000). Explaining social class differences in growth of reading skills from beginning kindergarten through fourth-grade: The role of phonological awareness, rate of 
access, and print knowledge. Reading and Writing: An Interdisciplinary Journal, $12,99-127$.

Hrabok, M., Kerns, K. A., \& Müller, U. (2007). The vigilance, orienting, and executive attention networks in 4-year-old children. Child Neuropsychology, 13, 408-421. doi: $10.1080 / 13825580600977224$

Isralowitz, R. E., \& Singer, M. (1986). Unemployment and its impact of adolescent work values. Adolescence, 21, 145-158.

Jansen, P. W., Raat, H., Mackenbach, J. P., Jaddoe, V. W. V., Hofman, A., Verhulst, F. C., \& Tiemeier, F. C. (2009). Socioeconomic inequalities in infant temperament: The generation R study. Social Psychiatry and Psychiatric Epidemiology, 44, 8795.

Johnson, M. H., Posner, M. I., \& Rothbart, M. K. (1991). Components of visual orienting in early infancy: Contingency learning, anticipatory looking, and disengaging [Special Issue]. Journal of Cognitive Neuroscience, 3, 335-344.

Kendeou, P., Bohn-Gettler, C., White, M. J., \& van den Broek, P. (2008). Children's inference generation across different media. Journal of Research in Reading, $32(3), 259-272$.

Kendeou, P., Lynch, J. S., van den Broek, P., Espin, C. A., White, M. J., \& Kremer, K. E., (2005). Developing successful readers: Building early comprehension skills through television viewing and listening. Early Childhood Education Journal, 33, 91-98. doi: 10.1007/s10643-005-0030-6

Kendeou, P., van den Broek, P., White, M. J., \& Lynch, J. (2007). Comprehension in preschool and early elementary children: Skill development and strategy 
interventions. In McNamara, D. S. (ed.), Reading Comprehension Strategies:

Theories, Interventions, and Technologies, (pp. 27-45). Mahwah, NJ: Erlbaum.

Kochanska, G., Murray, K. T., \& Coy, K. C. (1997). Inhibitory control as a contributor to conscience in childhood: From toddler to early school age. Child Development, $68,263-277$.

Kramer, M. S. (1987). Determinants of low birth weight: Methodological assessment and meta-analysis. Bulletin of the World Health Organization, 65, 663-737.

Landau, S., Lorch, E. P., \& Milich, R. (1992). Visual attention to and comprehension of television in Attention-Deficit Hyperactivity disordered and normal boys. Child Development, 63, 928-937.

Liss, M. B. (1981). Children's television selections: A study of indicators of same-race preferences. Journal of Cross-Cultural Psychology, 12, 103-110.

Lorch, E. P., Milich, R., Sanchez, R. P., van den Broek, P., Baer, S., Hooks, K., Hartung, C., \& Welsh, R. (2000). Comprehension of televised stories in boys with ADHD and nonreferred boys. Journal of Abnormal Psychology, 109, 321-330.

Lorch, E. P., \& Castle, V. J. (1997). Preschool children's attention to television: Visual attention and probe response times. Journal of Experimental Child Psychology, $66,111-127$.

Lorch, E. P., Eastham, D., Milich, R., Lemberger, C. C., Sanchez, R. P., Welsh, R., \& van den Broek, P. (2004). Difficulties in comprehending causal relations among children with ADHD: The role of cognitive engagement. Journal of Abnormal Psychology, 113, 56-63. doi: 10.1037/0021-843x.113.1.56 
Lorch, E. P., Milich, R., Astrin, C. C., \& Berthiaume, K. S. (2006). Cognitive engagement and story comprehension in typically developing children and children with ADHD from preschool through elementary school. Developmental Psychology, 42, 1206-1219. doi:10.103/0012-1649.42.6.1206

Low, J., \& Durkin, K. (2000). Event knowledge and children's recall of television based narratives. British Journal of Developmental Psychology, 18, 247-267.

Lynch, J. S., van den Broek, P., Kremer, K. E., Kendeou, P., White, M. J., \& Lorch, E. P. (2008). The development of narrative comprehension and its relation to other early reading skills. Reading Psychology, 29, 327-265.

Mackworth, J. F., \& Mackworth, N. H. (1956). The overlapping of signals for decisions. The American Journal of Psychology, 69, 26-47.

Mar, R. A. (2004). The neuropsychology of narrative: Story comprehension, story production and their interrelation. Neuropsychologia, 42, 1414-1434. doi:10.1016/j.neuropsychologia.2003.12.016

Martel, M. M., \& Nigg, J. T. (2006). Child ADHD and personality/temperament traits of reactive and effortful control, resiliency, and emotionality. Journal of Child Psychology and Psychiatry, 47, 1175-1183.

Martin, R. P., \& Holbrook, J. (1985). Relationship of temperament characteristics to the academic achievement of first-grade children. Journal of Psychoeducational Assessment, 3, 131-140.

Mattingly, I. G., (1984). Reading, linguistic awareness, and language acquisition. In J. Downing and R. Valtin (Eds.), Language awareness and learning to read (pp. 925). New York, NY: Springer. 
McDonough, P. (2009). TV viewing among kids at an eight-year high. The Nielsen Company. Retrieved from http://blog.nielsen.com/nielsenwire/media_entertainment/tv-viewing-among-kidsat-an-eight-year-high/

McLoed, J. D., and Shanahan, M. J. (1993). Poverty, parenting, and children's mental health. American Sociological Review, 58, 351-366.

Mezzacappa, E. (2004). Alerting, orienting, and executive attention: Developmental properties and sociodemographic correlates in an epidemiological sample of young, urban children. Child Development, 75, 1373-1386.

Mian, N. D., Wainwright, L., Briggs-Cowan, M. J., \& Carter, A. S. (2011). An ecological risk model for early childhood anxiety: The importance of early child symptoms and temperament. Journal of Abnormal Child Psychology, 39, 501-512.

Milich, R., \& Lorch, E. P. (1994). Television viewing methodology to understand cognitive processing of ADHD children. Advances in Clinical Child Psychology, $16,177-201$.

Miller, M. H. (2000). The relationship of temperament at school entry, cognitive ability, gender, ses, and at-risk status to later school achievement. Dissertation Abstracts interactional Section A: Humanities and Social Sciences, 60, 2373.

Morales, M., Mundy, P., Delgado, C. E. F, Yale, M., Neal, R., \& Schwartz, H, K. (2000). Responding to joint attention across the 6- through 24-month age period and early language acquisition. Journal of Applied Developmental Psychology, 21, 283-298.

Morrison, F. J. (1982) The development of alertness. Journal of Experimental Child Psychology, 34, 187-199. 
Mountcastle, V. (1978). An organizing principle for cerebral function: The unit model and distributed system. In G. M. Edelman and V. B. Mountcastle (Eds.), The mindful brain. Cambridge, MA: MIT Press.

Mullane, J. C., Corkum, P. V., Klein, R. M., McLaughlin, E. N., \& Lawrence, M. A. (2011). Alerting, orienting and executive attention in children with ADHD. Journal of Attention Disorders, 15, 310-320. doi:10.1177/108705471036638

Noel, M., Peterson, C., \& Jesso, B. (2008). The relationship of parenting stress and child temperament to language development among economically disadvantaged preschoolers. Journal of Child Language, 35, 823-843. doi:

$10.1017 / \mathrm{s} 0305000908008805$

Norman, G., \& Breznitz, Z. (1992). Differences in the ability to concentrate in first-grade Israeli pupils of low and high socioeconomic status. The Journal of Genetic Psychology, 153, 5-17.

Oakhill, J., Cain, K., \& Bryant, P. E. (2003). The dissociation of word reading and text comprehension: Evidence from component skills. Language and Cognitive Processes, 18, 443-468.

Ochsner, K. N., Bunge, S. A., Gross, J. J., \& Gabrieli, J. D. (2002). Rethinking feelings: An fMRI study of the cognitive regulation of emotion. Jounal of Cognitive Neuroscience, 14, 1215-1229.

Overpeck, M. D., Brenner, R. A., Trumble, A. C., Trifiletti, L. B., \& Berendes, H. W. (1998). Risk factors for infant homicide in the Unit States. The New England Journal of Medicine, 339, 1211-1216. 
Paris, A. H., \& Paris, S. G., (2003). Assessing narrative comprehension in young children. Reading Research Quarterly, 38, 36-76.

Patterson, C. J., Vaden, N. A., Griesler, P. C., \& Kupersmidt, J. B. (1991). Income level, gender, ethnicity, and household composition as predictors of children's peer companionship outside of school. Journal of Applied Developmental Psychology, $12,447-465$.

Petterson, S. M., \& Albers, A. B. (2001). Effects of poverty and maternal depression on early child development. Child Development, 72, 1794-1813.

Pineda, D., Ardila, A., Rosselli, M., Arias, B. E., Henao, G. C., Gomez, L. F., . . Miranda, M. L. (1999). Prevalence of ADHD symptoms in 4- to 17-year-old children in the general population. Journal of Abnormal Child Psychology, 27, $455-462$.

Posner, M. I., \& Petersen, S. E. (1990). The attention system of the human brain. Annual Review of Neuroscience, 13, 25-42.

Prins, P. J., Dovis, S., Ponsioen, A., ten Brink, E., \& van der Oord, S. (2011). Does computerized working memory training with game elements enhance motivation and training efficacy in children with ADHD? Cyberpsychology, Behavior, and Social Networking, 14, 115-122.

Putnam, S. P., \& Rothbart, M. K. (2006). Development of short and very short forms of the children's behavior questionnaire. Journal of Personality Assessment, 87, 102112.

Rapp, D. N., \& van den Broek, P. (2005). Dynamic text comprehension: An integrative view of reading. Current Directions in Psychological Science, 14, 276-279. 
Rapp, D. N., van den Broek, P., McMaster, K. L., Kendeou, P., \& Espin, C. A. (2007). Higher-order comprehension processes in struggling readers: A perspective for research and intervention. Scientific Studies of Reading, 11, 289-312.

Raz, I. S., \& Bryant, P. (1990). Social background, phonological awareness and children's reading. British Journal of Developmental Psychology, 8, 209-225.

Raz, A., \& Buhle, J. (2006). Typologies of attentional networks. Nature Reviews Neuroscience, 7, 367-379.

Rothbart, M. K., \& Ahadi, S. A. (1994). Temperament and the development of personality. Journal of Abnormal Psychology, 103, 55-66.

Rothbart, M. K., Ahadi, S. A., Hershey, K. L., \& Fisher, P. (2001). Investigations of temperament and three to seven years: the children's behavior questionnaire. Child Development, 72, 1394-1408.

Rothbart, M. K., \& Bates, J. E. (2006). Temperament. In N. Eisenberg, W. Damon, and R. M. Lerner (Eds.), Handbook of child psychology (Vol. 3, pp. 99-166). Hoboken, NJ: John Wiley \& Sons, Inc.

Rothbart, M. K., \& Derryberry, D. (1981). Development of individual differences in temperament. In M. E. Lamb \& A. L. Brown (Eds.), Advances in developmental psychology (Vol. 1, pp. 37-86). Hillsdale, NJ: Erlbaum.

Rothbart, M. K., Derryberry, D., \& Hershey, K. (2000). Stability of temperament in childhood: Laboratory infant assessment to parent report at seven years. In V. J. Molfese and D. L. Molfese (Eds.), Temperament and personality development across the life span. Mahwah, NJ: Lawrence Erlbaum Associates. 
Rothbart, M. K., Ellis, L. K., Rueda, M. R., \& Posner, M. I. (2003). Developing mechanisms of temperamental effortful control. Journal of Personality, 71, 1113 1143

Rothbart, M. K., \& Posner, M. I. (2006). Temperament, attention, and developmental psychopathology. In D. Cicchetti \& D. J. Cohen (Eds.), Developmental psychopathology: Developmental neuroscience (Vol. 2, pp. 465-501). Hoboken, NJ: John Wiley \& Sons, Inc.

Rothbart, M. K., \& Sheese, B. E. (2006). Temperament and emotion-regulation. In J. Gross (Ed.), Handbook of emotion-regulation (pp.331-350). New York: Guilford Press.

Rothbart, M. K., Sheese, B. E., \& Posner, M. I. (2007). Executive attention and effortful control: Linking temperament, brain networks, and genes. Child Development Perspectives, 1, 2-7. doi:10.1111/j.1750-8606.2007.00002.x

Rudasill, K. M., Reio, T. G., Stipanovic, N., \& Taylor, J. E. (2010). A longitudinal study of student-teacher relationship quality, difficult temperament, and risky behavior from childhood to early adolescence. Journal of School Psychology, 48, 389-412.

Rueda, M. R., Fan, J., McCandliss, B. D., Halparin, J. D., Gruber, D. B., Lercari, L. P., \& Posner, M. I. (2004). Development of attentional networks in children. Neuropsychologia, 42, 1029-1040. doi: 10.1016/j.neuropsychologia.2003.12.012

Ruff, H. A., \& Rothbart, M. K. (1996). Attention in early development: Themes and variations. New York: Oxford University Press. 
Sanchez, R. P., Lorch, E. P., Milich, R., \& Welsh, R. (1999). Comprehension of televised stories by preschool children with ADHD. Journal of Clinical Child Psychology, $28,376-385$.

Shirley, M. M. (1933). The first two years. III. Personality manifestations. Oxford, England: University of Minnesota Press.

Smith, J., Brooks-Gunn, J., \& Klebanov, P. (1997). Consequences of living in poverty for young children's cognitive and verbal ability and early school achievement. In G.

J. Duncan and J. Brooks-Gunn (Eds.), Consequences of growing up poor (pp. 132-189). New York, NY: Russell Sage.

Snow, C. E. (1991). The theoretical basis for relationships between language and literacy development. Journal of Research in Childhood Education, 6, 5-10.

Starfield, B. (1989). Child health care and social factors: Poverty, class, race. Bulletin of the New York Academy of Medicine, 65, 299-306.

Starfield, B. (1992). Effects of poverty on health status. Bulletin of the New York Academy of Medicine, 68, 17-24.

Preliminary analysis of a randomized trial of computer attention training in children with attention deficit/hyperactivity disorder.

Strelau, J. (1983) A regulative theory of temperament. Australian Journal of Psychology, $35,305-317$.

Tabachnick, B. G., \& Fidell, L. S. (1989). Using Multivariate Statistics. New York, NY: Harper Collins Publishers.

Thomas, A., \& Chess, S. (1977). Temperament and development. Oxford, England: Brunner/Mazel. 
To, T., Guttmann, A., Dick, P. T., Rosenfield, J. D., Parkin, P. C., Tassoudji, M., . . . Harris, J. K. (2004). Risk markers for poor developmental attainment in young children: Results from a longitudinal national survey. Archives of Pediatrics and Adolescent Medicine, 158, 643-649.

Trabasso, T., \& Magliano, J. P. (1996). Conscious understanding during comprehension. Discourse Processes, 21, 255-287.

Trabasso T., \& Stein, N., (1997). Narrating, representing, and remembering event sequences. In P. W. van den Broek, P. J. Bauer, \& T. Bourg (Eds.), Developmental spans in event comprehension and representation (pp. 237-270). Mahwah, NJ: Erlbaum.

Trabasso, T., Secco, T., \& van den Broek, P., (1984). Causal cohesion and story coherence. In H. Mandl, N. L. Stein, \& T. Trabasso (Eds.), Learning and comprehension of text (pp. 83-111). Mahwah, NJ: Erlbaum.

Valiente, C., Lemery-Chalfant, K., \& Swanson, J. (2010). Prediction of kindergartners' academic achievement from their effortful control and emotionality: Evidence for direct and moderated relations. Journal of Educational Psychology, 102, 550-560. van den Broek, P. (1989). The effects of causal structure on the comprehension of narratives: Implications for education. Reading Psychology: An International Quarterly, 10, 19-44.

van den Broek, P. (1997). Discovering the cement of the universe: The development of event comprehension from childhood to adulthood. In P. W. van den Broek, P. J. Bauer, \& T. Bourg (Eds.), Developmental spans in event comprehension and 
representation: Bridging fictional and actual events. (pp. 321-342). Mahwah, NJ: Erlbaum.

van den Broek, P., Kendeou, P., Kremer, K., Lynch, J. S., Butler, J., White, M. J., \& Lorch, E. P. (2005). Assessment of comprehension abilities in young children. In S. Paris \& S. Stahl (Eds.), New directions in assessment of reading comprehension (pp. 107-130). Mahwah, NJ: Erlbaum.

van den Broek, P., Lorch, E. P., \& Thurlow, R. (1996). Children's and adults' memory for television stories: The role of causal factors, story-grammar categories, and hierarchical level. Child Development, 67, 3010-3028.

Vrijheid, M., Dolk, H., Stone, D., Abramsky, L., Alberman, E., \& Scott, J. E. S. (2000). Socioeconomic inequalities in risk of congenital anomaly. Archives of Disease in Childhood, 82, 349-352. doi:10.1136/adc.82.5.349

Wachs, T. D., Morrow, J., \& Slabach, E. H. (1990). Intra-individual variability in infant visual recognition memory performance: Temperamental and environmental correlates. Infant Behaviors \& Development, 13, 397-403.

Wasserman, C. R., Shaw, G. M., Selvin, S., Gould, J. B., \& Syme, S. L. (1998). Socioeconomic status, neighborhood social conditions, and neural tube defects. American Journal of Public Health, 88, 1674-1680.

Weatherholt, T. N. (2007). Integrative review of educational television for young children: Implications for children from low-income families. National Head Start Dialog Journal, 10, 171-188.

Werner, E. (1989). High-risk children in young adulthood: A longitudinal study from birth to 32 years. American Journal of Orthopsychiatry, 59, 72-81. 
Whitehurst, G. J., \& Lonigan, C. J., (1998). Child development and emergent literacy. Child Development, 69, 848-872.

Wilson, A. L. (1993). Poverty and children's health. The Child, Youth, and Family Services Quarterly, 16, 14-16.

Wright, J. C., \& Huston, A. C. (1983). A matter of form: Potentials of television for young viewers. American Psychologist, 38, 835-843. 
Figure 1. Frequencies of families per income category.

\section{Family Income}

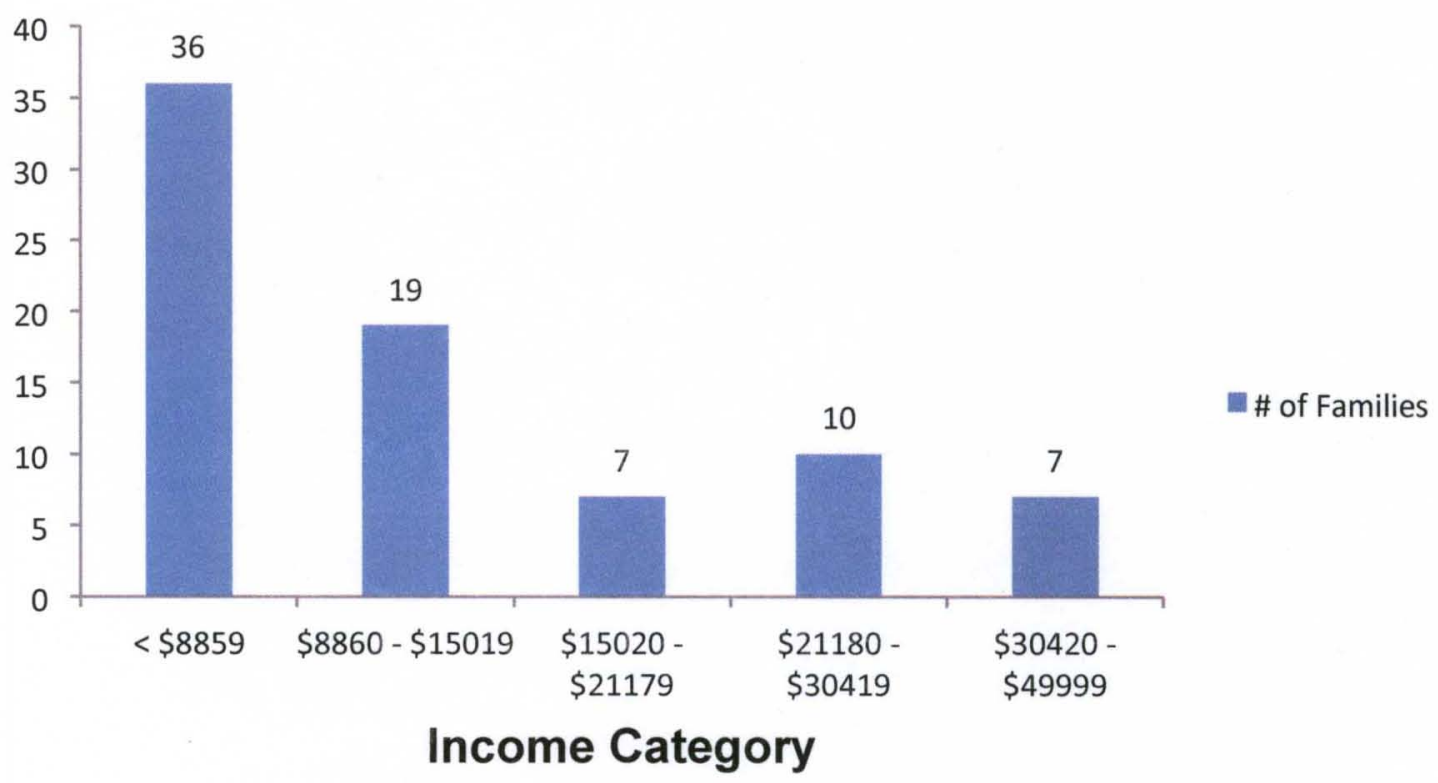


Figure 2. Percentage use of episode by condition.

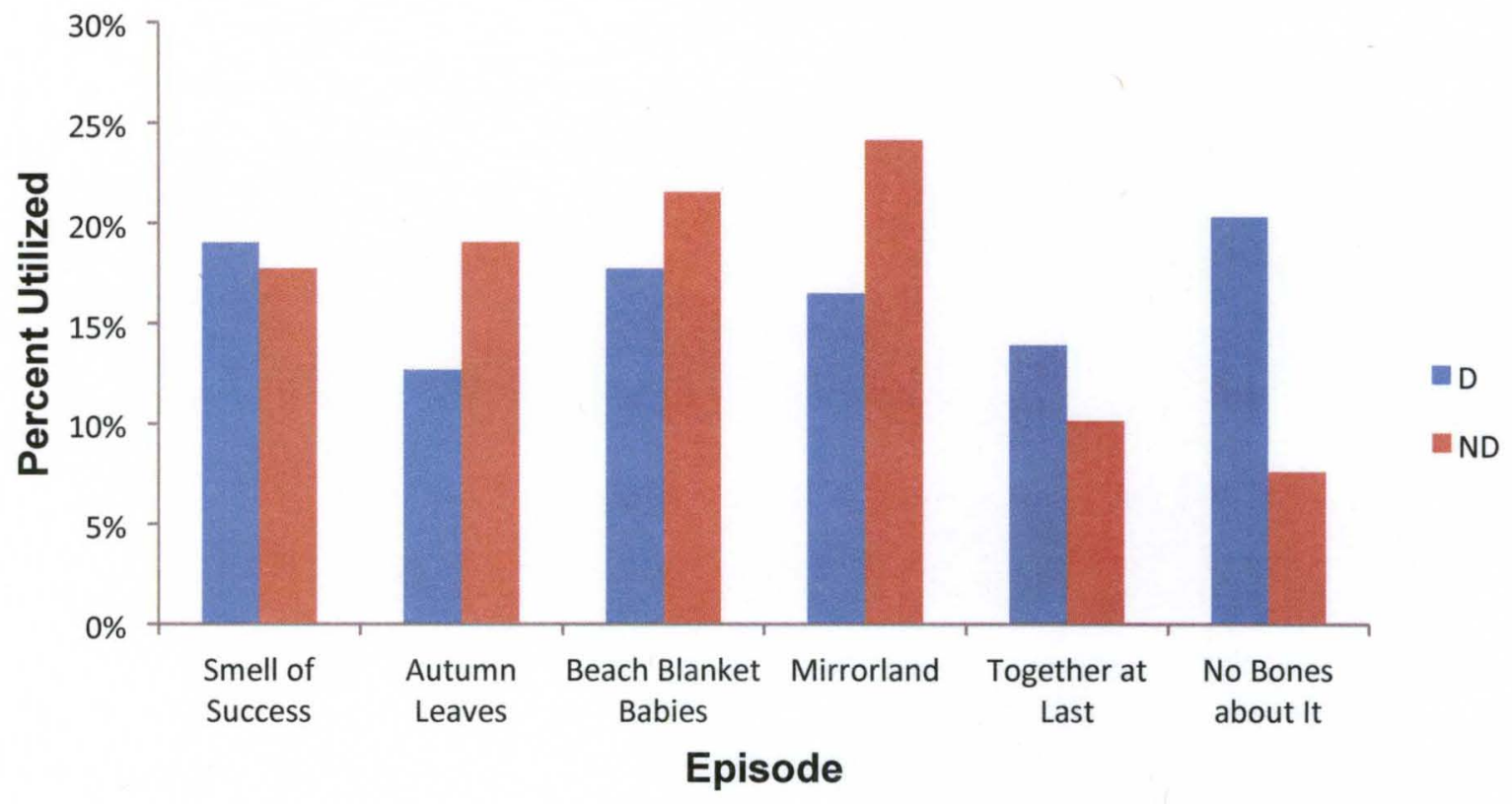


Figure 3. Number of factual and causal questions per episode.

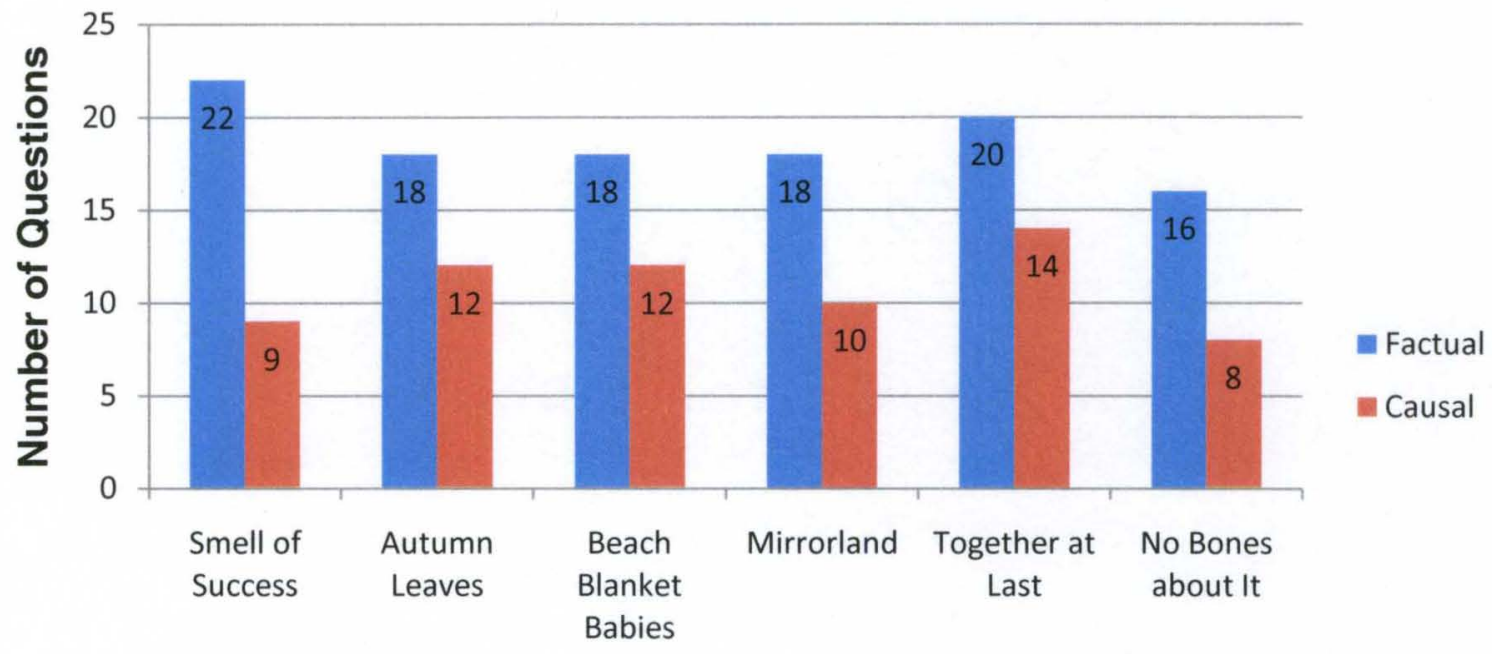

\section{Episode}


Figure 4. Number and type of questions deleted from original comprehension scores.

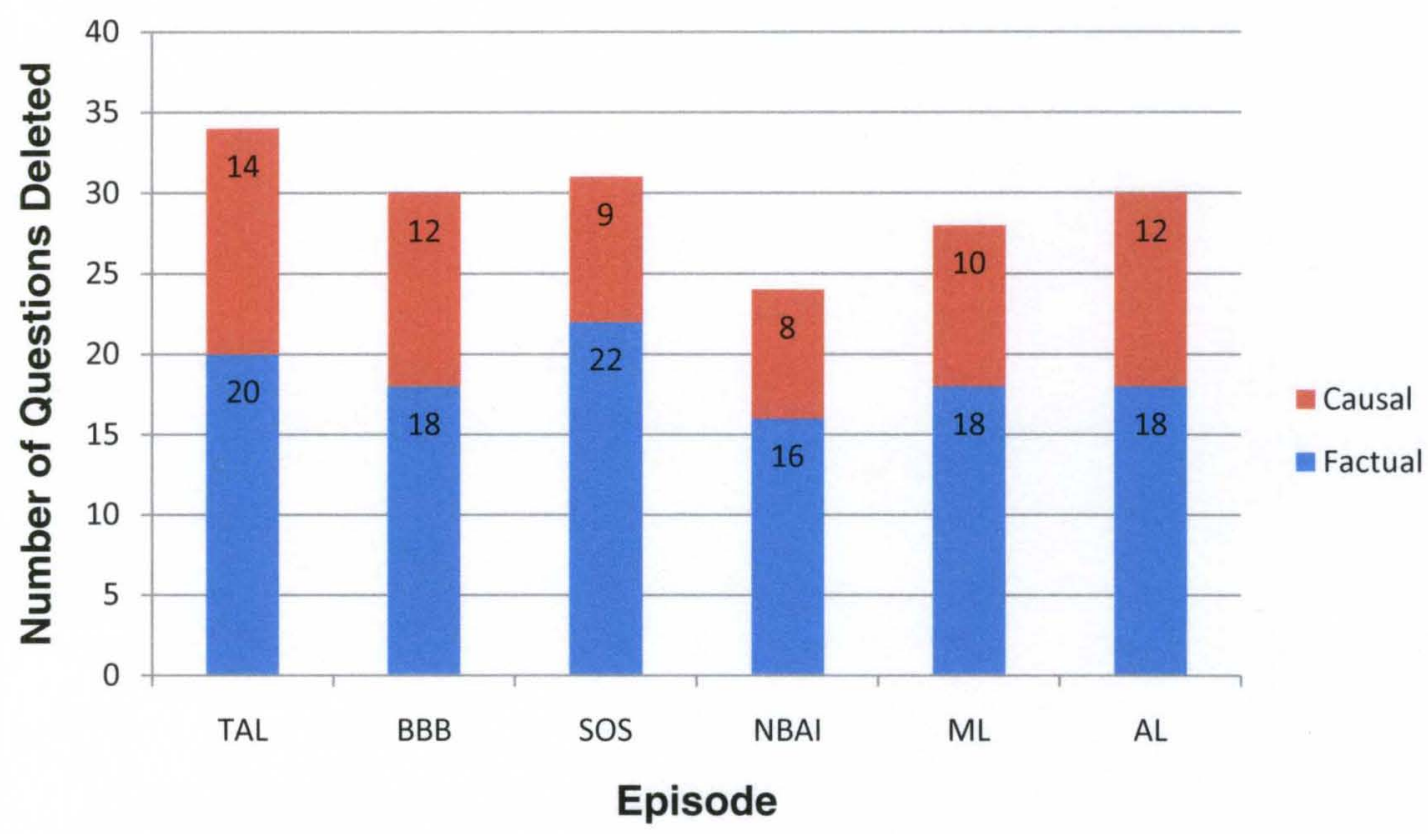


Figure 5. Means of comprehension performance of original comprehension scores and transformed comprehension scores.

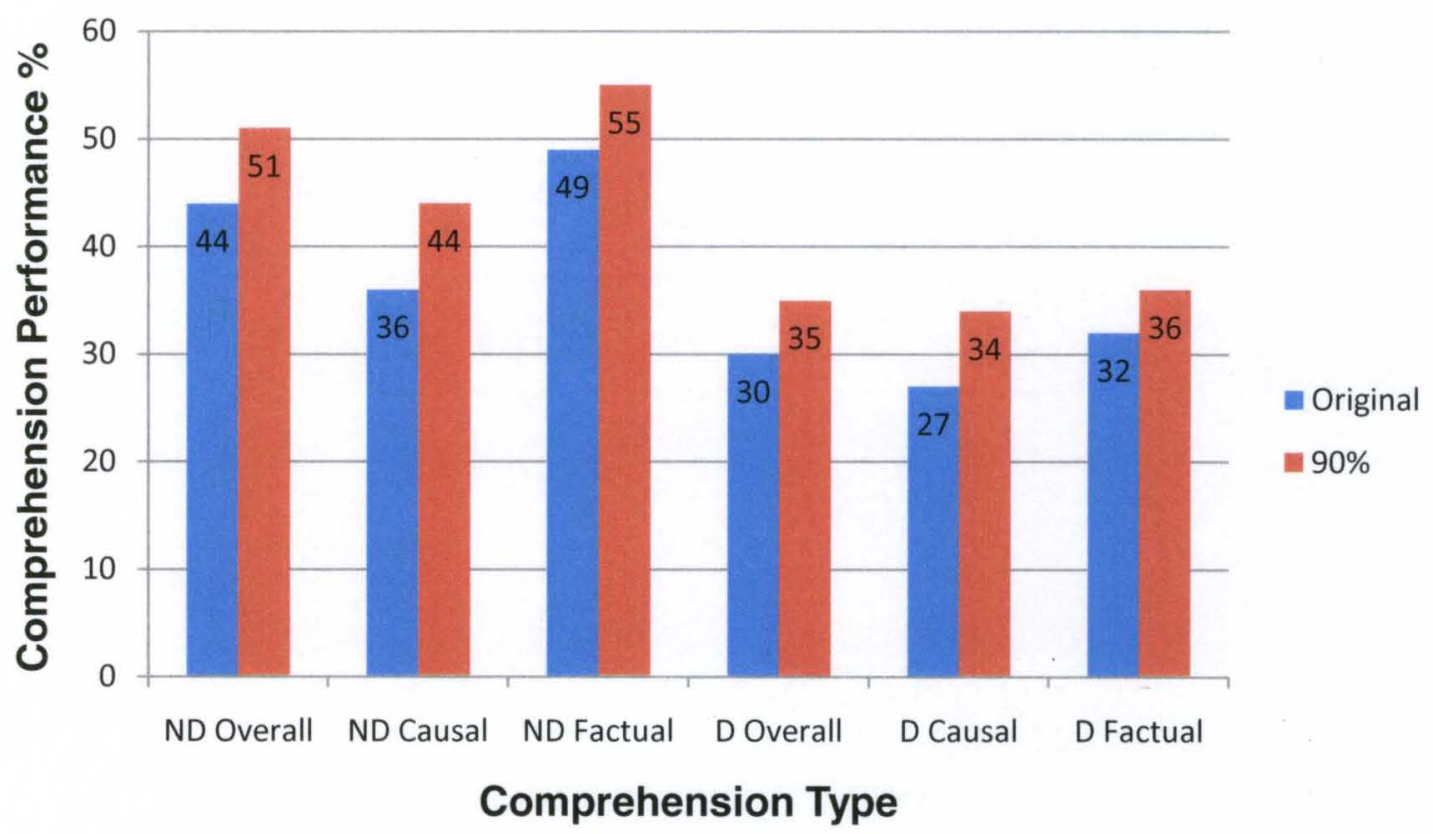


Figure 6. Mean proportion of overall comprehension performance for each Rugrats® episode by condition.

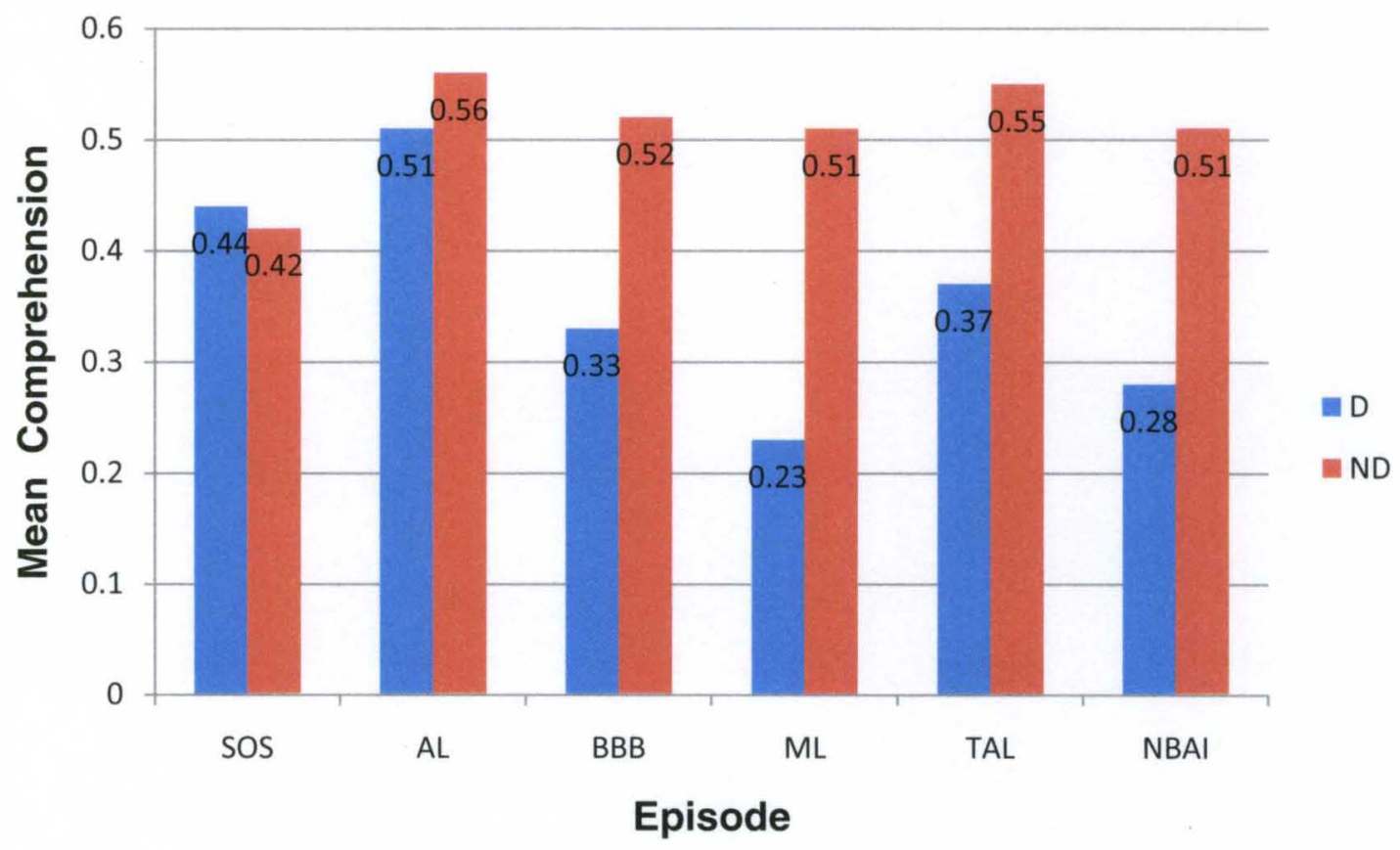


Figure 7. Distribution of extraversion ratings.

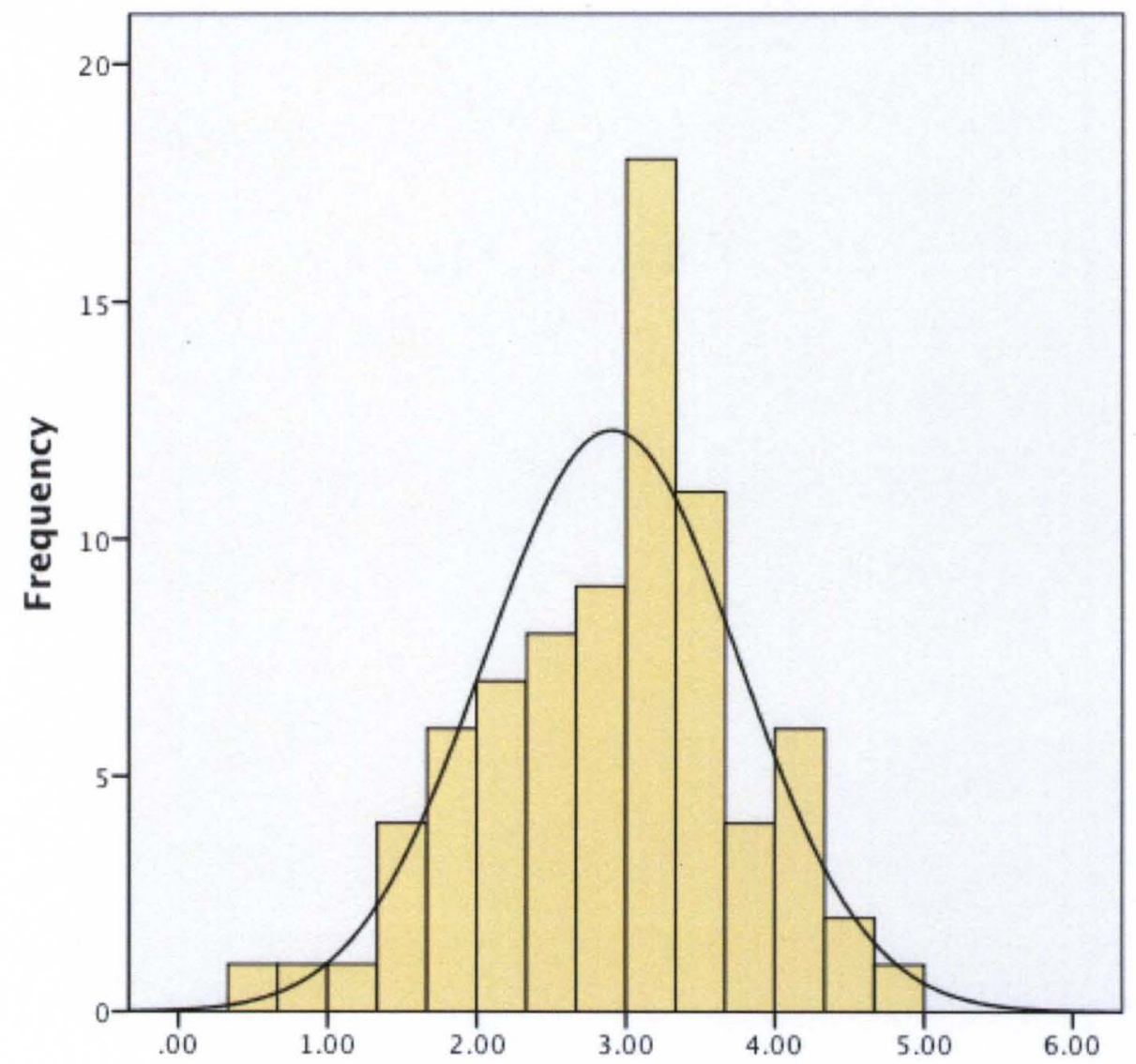


Figure 8. Distribution of effortful control ratings.

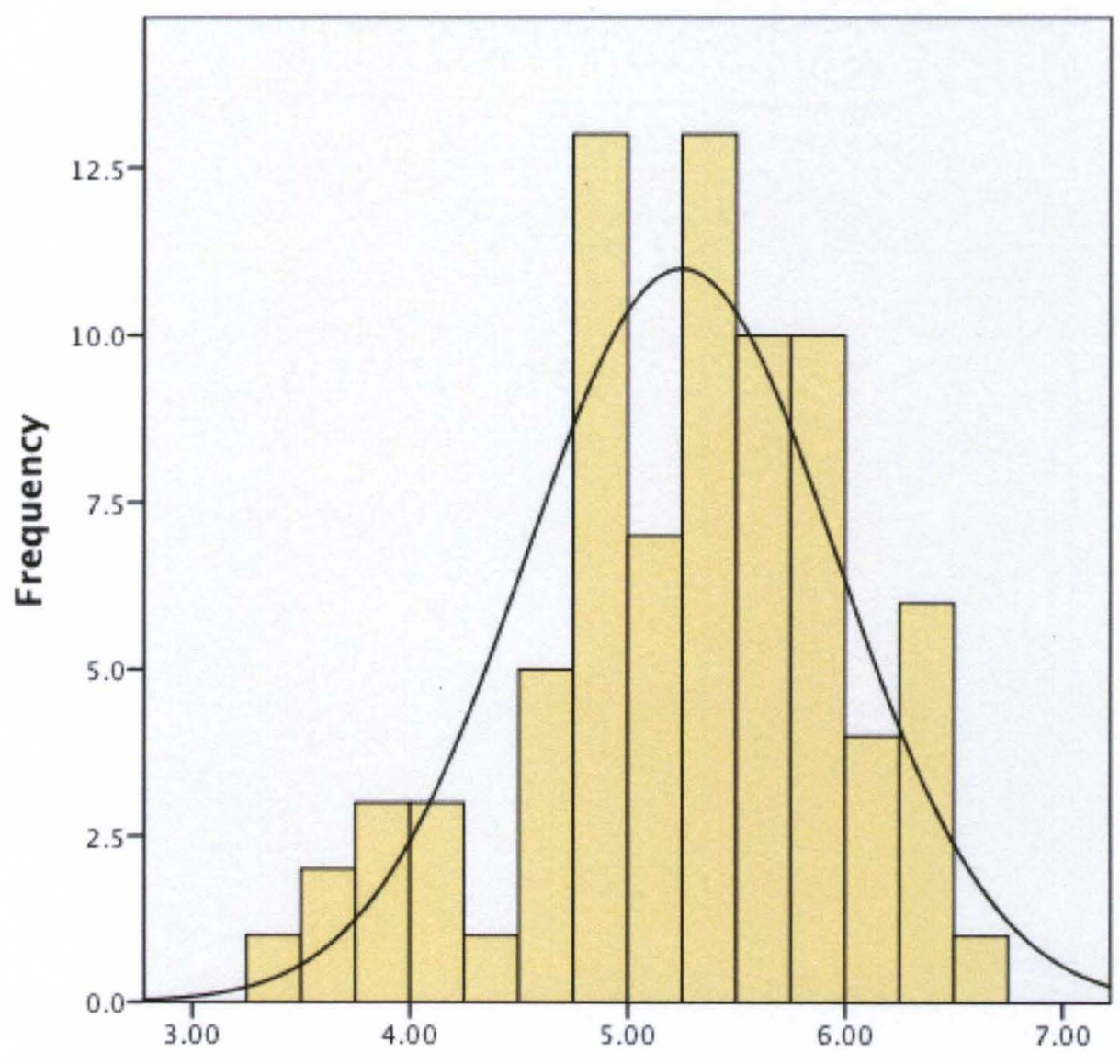


Figure 9. Boxplots of factual and causal comprehension in the distracter condition.

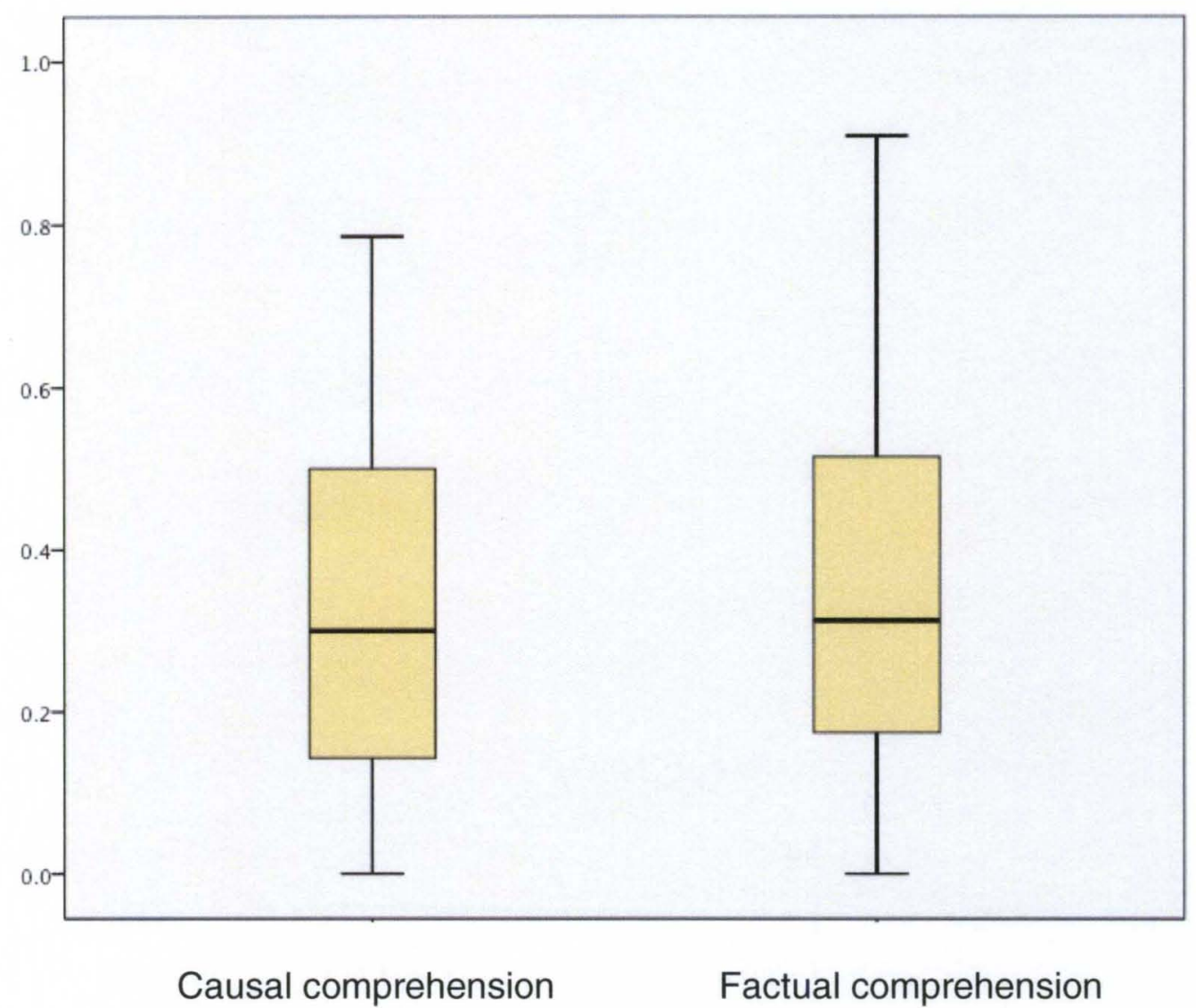


Table 1

Covariate Analyses with Gender, Age, and Cognitive Ability.

\begin{tabular}{lccc}
\hline & & Correlation & \\
Dependent Variable & Age & Gender & Cognitive Ability \\
\hline TA Factual & $.44^{* *}$ & .04 & $.33^{* *}$ \\
TA Causal & $.42^{* *}$ & -.06 & $.25^{*}$ \\
TP Factual & $.45^{* *}$ & -.00 & $.25^{*}$ \\
TP Causal & $.46^{* *}$ & -.08 & $.27^{*}$ \\
\hline
\end{tabular}

Note. ${ }^{*} \mathrm{p}<.05,{ }^{* *} \mathrm{p}<.001$ 
Table 2

Means, Standard Deviations, Range, and Medians of Comprehension Performance by Condition.

\begin{tabular}{|c|c|c|c|}
\hline $\begin{array}{l}\text { Comprehension } \\
\text { by Condition }\end{array}$ & Mean & $S D$ & Range \\
\hline
\end{tabular}

ND

\begin{tabular}{lllll} 
Overall & .51 & .22 & .70 & .53 \\
Causal & .44 & .25 & .80 & .43 \\
Factual & .55 & .23 & .85 & .56 \\
Overall & .35 & .22 & .59 & .29 \\
Causal & .34 & .23 & .71 & .30 \\
Factual & .36 & .24 & .65 & .31 \\
\hline
\end{tabular}


Table 3

Means and Standard Deviations of Comprehension Performance by Age Group and Condition.

\begin{tabular}{lllll}
\hline & \multicolumn{2}{c}{ No-Distraction } & \multicolumn{2}{c}{ Distraction } \\
Age Group & Factual & Causal & Factual & Causal \\
\hline 5-year-olds & $.46(.23)$ & $.36(.21)$ & $.28(.18)$ & $.23(.18)$ \\
6 -year-olds & $.59(.18)$ & $.46(.26)$ & $.38(.24)$ & $.39(.21)$ \\
7 -year-olds & $.75(.15)$ & $.68(.14)$ & $.61(.23)$ & $.53(.27)$ \\
\hline
\end{tabular}


Table 4

Means and Standard Deviations of MRT and Accuracy on Attention Network Measure.

Mean MRT in msec (SD) Percentage Correct (SD)

Orienting

$\begin{array}{lll}\text { 5-year-olds } & 1069.67(146.63) & 99.03(2.94) \\ \text { 6-year-olds } & 970.63(147.50) & 99.61(1.02) \\ \text { 7-year-olds } & 911.73(145.16) & 99.72(.94)\end{array}$

Alerting

$\begin{array}{lll}\text { 5-year-olds } & 936.0(162.23) & 99.07(3.0) \\ \text { 6-year-olds } & 828.77(100.19) & 99.80(.78) \\ \text { 7-year-olds } & 762.41(84.34) & 100.0(.00)\end{array}$

Executive

$\begin{array}{lll}\text { 5-year-olds } & 1693.58(373.96) & 97.23(6.7) \\ \text { 6-year-olds } & 1498.83(282.46) & 98.64(2.7) \\ \text { 7-year-olds } & 1273.36(194.49) & 98.87(2.1)\end{array}$

Notes: These statistics do not include the participants for whom the mean data were substituted for missing data. MRTs reported were calculated only for accurate trials. 


\section{Table 5}

Correlational Analyses with Attention Network MRTs and Age, Gender, and Cognitive Ability.

\section{Correlation}

\begin{tabular}{lccc} 
Dependent Variable & Age & Gender & Cognitive Ability \\
\hline Orienting MRT & $-.40^{* *}$ & .08 & -.18 \\
Alerting MRT & $-.41^{* *}$ & .07 & .05 \\
Executive MRT & $-.40^{* *}$ & .08 & $-.25^{*}$ \\
\hline
\end{tabular}

Notes. These statistics use the transformed MRT scores for attention skills.

${ }^{*} \mathrm{p}<.05, * * \mathrm{p}<.001$ 
Table 6

Summery of Hieranchical Regression Analy sisfor the Prediction of Cousal

Comprehension in the Distracter Condition by Efforful Control and A tte ntion Stills.

\begin{tabular}{|c|c|c|c|c|c|c|c|c|c|}
\hline & & Model 1 & & & Model 2 & & & Model 3 & \\
\hline Variable & $B$ & $S E B$ & $\beta$ & $B$ & $S E B$ & $\beta$ & $B$ & $S E B$ & $\beta$ \\
\hline Age & .16 & .03 & $47^{* *}$ & .16 & .03 & $.48 * *$ & .15 & .04 & $.46 *$ \\
\hline Cognitive Ability & .01 & .00 & $.29 *$ & .01 & .00 & $.27^{*}$ & .01 & .00 & $24^{*}$ \\
\hline Effotful Control & & & & .07 & .03 & $.21 *$ & .06 & .03 & $.19 *$ \\
\hline Orienting 8bills & & & & & & & -30 & .19 & -.19 \\
\hline Alertiog Skills & & & & & & & .17 & .19 & .11 \\
\hline Execative Still & & & & & & & .02 & .14 & .02 \\
\hline Adjunted $R^{2}$ & & 283 & & & 319 & & & 313 & \\
\hline F Change & & $16.18 * *$ & & & $4.95 *$ & & & 81 & \\
\hline
\end{tabular}

${ }^{*} p<.05 ; * * p<.001$ 
Table 7

Summany of Hieran hical Regression A nalysis for the Predic tion of Causal Comprehension in the Distracter Conation by Extranersion and Attention Skills.

\begin{tabular}{|c|c|c|c|c|c|c|c|c|c|c|}
\hline & & & Model 1 & & & Model 2 & & & Model 3 & \\
\hline & Variable & $B$ & $S E B$ & $\beta$ & $B$ & $S E B$ & $\beta$ & $B$ & $S E B$ & $B$ \\
\hline & Age & .16 & .03 & $.47^{* *}$ & .15 & .03 & $.45 *$ & .14 & .04 & $.42 \neq *$ \\
\hline & Cognitive Ability & .01 & .00 & $29 *$ & .01 &.$\infty$ & $31^{*}$ & .01 & .00 & $.25 *$ \\
\hline $\overrightarrow{0}$ & Extaversion & & & & -.04 & .03 & -.13 & -.03 & .03 & -.12 \\
\hline & Orienting Skills & & & & & & & .32 & .19 & -21 \\
\hline & Alerting Sloills & & & & & & & .24 & .19 & .16 \\
\hline & Executive Skills & & & & & & & .05 & .14 & -.05 \\
\hline & Adjuated $R^{2}$ & & .283 & & & .289 & & & 292 & \\
\hline & F Change & & $16.18 *$ & & & 1.64 & & & 1.09 & \\
\hline
\end{tabular}


Table 8

Summary of Hierarchical Regression Analy sis for the Prectiction of Factual Compre hension in the Distracter Condition by Effortful Control and Attention Stills.

\begin{tabular}{|c|c|c|c|c|c|c|c|c|c|}
\hline & & Model 1 & & & Model 2 & & & Model 3 & \\
\hline Variable & $B$ & $S E B$ & $\beta$ & $B$ & $S E B$ & $\beta$ & $B$ & $S E B$ & $\beta$ \\
\hline Age & .15 & .03 & $.46^{* *}$ & .15 & .03 & $.46 * *$ & .16 & .04 & $.47 *$ \\
\hline Copnitive Ability & .01 & 00 & $.26 *$ & .01 & .00 & $.24 *$ & .01 &.$\infty$ & $20^{*}$ \\
\hline Effotfol Control & & & & .07 & $.0 B$ & $.2 *$ & .07 & .03 & $20 *$ \\
\hline Orienting Slaills & & & & & & & -.41 & .19 & $-.26 *$ \\
\hline Alerting Stalls & & & & & & & .30 & .19 & .20 \\
\hline Executive Sbills & & & & & & & .06 & 14 & .05 \\
\hline Adjucted $R^{2}$ & & 251 & & & .291 & & & .310 & \\
\hline F Change & & $1389 *:$ & & & $5.22 *$ & & & 1.68 & \\
\hline
\end{tabular}

${ }^{*} p<.05 ; * p<.001$ 
Table 9

Summary of Hierarchical Regression Analysis for the Prediction of Factual Compre hension in the Distracter Conctition by Extraversion and Atrention Stolls.

\begin{tabular}{|c|c|c|c|c|c|c|c|c|c|}
\hline & & Model 1 & & & Modd 2 & & & Model 3 & \\
\hline Variable & $B$ & $S E B$ & $\beta$ & $B$ & $S E B$ & $\beta$ & $B$ & $S E B$ & $\beta$ \\
\hline Age & .15 & .03 & $.46 *$ & .14 & .03 & $.43 *$ & .14 & .04 & $.42^{* *}$ \\
\hline Cognitive Ability & .01 & .00 & $.26 *$ & .01 & .00 & $28 *$ & .01 &.$\infty$ & $.22 *$ \\
\hline Extraversion & & & & -.05 & .08 & -.16 & .04 & .03 & -.16 \\
\hline Orienting Sbills & & & & & & & -.43 & .20 & $-28 *$ \\
\hline Alertiog S1olls & & & & & & & .37 & .19 & $.25 *$ \\
\hline Enecutive Shill & & & & & & & -.02 & .14 & -.02 \\
\hline Adjouted $R^{2}$ & & 251 & & & 267 & & & 297 & \\
\hline F Change & & $13.89 * *$ & & & 26 & & & 2.02 & \\
\hline
\end{tabular}

${ }^{*} p<.05 ;{ }^{* 8} p<.001$ 
Table 10

Summary of Hierachical Regression Analysis for the Prectiction of Causal Comprehension in the No-Distracter Condition of Efforful Control and A tte ntion Skills.

\begin{tabular}{|c|c|c|c|c|c|c|c|c|c|}
\hline & & Model I & & & Mode 2 & & & Model 3 & \\
\hline Variable & $B$ & $S E B$ & $\beta$ & $B$ & $S E B$ & $\beta$ & $B$ & $S E B$ & $\beta$ \\
\hline Age & .15 & .03 & $.46 *$ & .14 & .08 & $.43 * *$ & .14 & .04 & $.42 *$ \\
\hline Cognitive Ability & .01 & .00 & $.26 *$ & .01 &.$\infty 0$ & $28^{*}$ & .01 & .00 & $.22 *$ \\
\hline Effotful Coatrol & & & & -.05 & .03 & -.16 & -.04 & .03 & -.16 \\
\hline Orientiong Skills & & & & & & &. .43 & .20 & -.28 \\
\hline Alerting S10ills & & & & & & & .37 & .19 & 25 \\
\hline Execotive Sbill & & & & & & & -.08 & .14 & .02 \\
\hline Adjoutad $R^{2}$ & & 251 & & & 267 & & & 297 & \\
\hline F Change & & $13.89 * *$ & & & 26 & & & 2.08 & \\
\hline
\end{tabular}

$* p<.05 ; * * p<.001$ 
Table 11

Summan of Hierarchical Regression Analysis for the Prediction of Causal Comprehension in the Na-Distracter Condition by Extranersion and Attention Shills.

\begin{tabular}{|c|c|c|c|c|c|c|c|c|c|}
\hline & & Model 1 & & & Model 2 & & & Sodel 3 & \\
\hline Variable & $B$ & $S E B$ & $\beta$ & $B$ & $S E B$ & $\beta$ & $B$ & $S E B$ & $B$ \\
\hline Age & .15 & .04 & $.43^{* *}$ & .15 & .04 & $.43 * *$ & .13 & .04 & $38 *$ \\
\hline Cognitive Ability & .01 & .00 & $.27 *$ & .01 & .00 & $.27 *$ & .01 & .00 & $24^{*}$ \\
\hline Extraversion & & & & -.00 & .08 & -.01 & $-\infty 0$ & .03 & -.01 \\
\hline Orienting Skitls & & & & & & & -.08 & 22 & -.05 \\
\hline Alerting Slitl & & & & & & &. $\boldsymbol{\infty}$ & 21 & .01 \\
\hline Executive Sbill & & & & & & & -09 & 16 & -.07 \\
\hline Adjuad $\mathbf{R}^{2}$ & & .230 & & & .219 & & & .194 & \\
\hline F Change & & $12.47 * *$ & & & .01 & & & 22 & \\
\hline
\end{tabular}

$p<.05 ; * 0<.001$ 
Table 12

Summan of Hierachical Regression Analy sis for the Prediction of Fact wal Comprehension in the No-Distracter Condition by Effortful Control and Attention Skills

\begin{tabular}{|c|c|c|c|c|c|c|c|c|c|}
\hline & & Model 1 & & & Model 2 & & & Model 3 & \\
\hline Variable & $B$ & SE $B$ & $\beta$ & $B$ & $S E B$ & $\beta$ & $B$ & $\operatorname{SEB}$ & $\beta$ \\
\hline Age & .14 & .03 & $45 * *$ & .14 & .03 & $.45 * *$ & .12 & .04 & $.40^{* *}$ \\
\hline Cognitive Ability & .01 & .00 & $34^{* *}$ & .01 & .00 & $.32 * *$ & .01 & .00 & $33 *$ \\
\hline Effortful Control & & & & .04 & .08 & .12 & .04 & .03 & .13 \\
\hline Orienting Slaills & & & & & & & -.07 & 19 & -.05 \\
\hline Alerting Shills & & & & & & & -.17 & .19 & -.12 \\
\hline Execolive Shilb & & & & & & & .04 & .16 & .04 \\
\hline Adjuated $\mathrm{R}^{2}$ & & .289 & & & .294 & & & .280 & \\
\hline F Change & & $16.63 * *$ & & & 156 & & & 54 & \\
\hline
\end{tabular}

${ }^{*} p<.05 ; * * p<.001$ 
Table 13

Summary of Hierarchical Regression Anahysis for the Prediction of Fatual Compre hension in the No-Distracter Conction by Extrawersion and Attention Stills.

\begin{tabular}{|c|c|c|c|c|c|c|c|c|c|}
\hline & & Model I & & & Model 2 & & & Model 3 & \\
\hline Variable & $B$ & $S E B$ & $\beta$ & $B$ & $S E B$ & 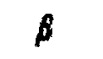 & $B$ & $S E B$ & $\beta$ \\
\hline Age & .14 & .03 & $.45 *$ & .14 & .03 & $.45 *$ & .12 & .04 & $.38^{*}$ \\
\hline Cognitive Ability & .01 & .00 & $.34 *$ & .01 & .00 & $.34 *$ & .01 & .00 & $.33^{*}$ \\
\hline Extraversion & & & & -.00 & .03 & -.11 &. .00 & $.0 B$ & -.01 \\
\hline Orienting S1cills & & & & & & & .09 & .19 & -.06 \\
\hline Alertios S1ails & & & & & & &. .12 & .18 & -.09 \\
\hline Enecotive Shalls & & & & & & & -.00 & .13 & -.00 \\
\hline Adjuined $R^{2}$ & & 289 & & & 279 & & & .268 & \\
\hline F Charge & & $16.63^{* *}$ & & & .01 & & & .46 & \\
\hline
\end{tabular}


Table 14

Means and Standard Deviations of Visual Attention Behaviors by Age Group and by Condition

\begin{tabular}{|c|c|c|c|c|c|c|}
\hline \multirow[b]{2}{*}{$\begin{array}{l}\text { Age } \\
\text { Group }\end{array}$} & \multicolumn{3}{|c|}{ No-Distraction } & \multicolumn{3}{|c|}{ Distraction } \\
\hline & $\begin{array}{l}\text { Mean } \# \text { of } \\
\text { Long Looks }\end{array}$ & $\begin{array}{l}\text { Mean of Total } \\
\text { Time Spent } \\
\text { Looking at TV } \\
\text { in seconds } \\
\end{array}$ & $\begin{array}{c}\text { Mean of Total Time } \\
\text { Spent in Long Looks } \\
\text { to TV } \\
\text { in seconds }\end{array}$ & $\begin{array}{c}\text { Mean \# of } \\
\text { Long Looks }\end{array}$ & $\begin{array}{l}\text { Mean of Total } \\
\text { Time Spent } \\
\text { Looking to TV } \\
\text { in seconds } \\
\end{array}$ & $\begin{array}{c}\text { Mean of Total Time } \\
\text { Spent in Long Looks } \\
\text { to TV } \\
\text { in seconds }\end{array}$ \\
\hline $\begin{array}{l}\text { 5-year- } \\
\text { olds }\end{array}$ & $7.35(2.68)$ & $579.76(64.80)$ & $526.47(97.17)$ & $1.22(1.62)$ & $105.19(88.30)$ & $42.33(75.36)$ \\
\hline $\begin{array}{l}\text { 6-year- } \\
\text { olds }\end{array}$ & $7.65(2.96)$ & $591.54(68.87)$ & $534.28(100.08)$ & $1.55(2.14)$ & $127.73(88.14)$ & $45.84(71.05)$ \\
\hline $\begin{array}{l}\text { 7-year- } \\
\text { olds }\end{array}$ & $8.82(2.4)$ & $601.76(51.89)$ & $552.35(79.37)$ & $4.55(3.01)$ & $267.44(141.54)$ & $172.51(144.58)$ \\
\hline Overall & $7.67(2.76)$ & $587.44(64.58)$ & $533.86(93.31)$ & $1.81(2.33)$ & $136.62(109.86)$ & $52.73(68.62)$ \\
\hline
\end{tabular}


Table 15

Summay of Hierarchical Regression Anatysis for the Prediction of Causal

Comprehension in the Distracter Conati ion by Efforful Control and Cognitive

Engagement.

\begin{tabular}{|c|c|c|c|c|c|c|c|c|c|}
\hline & & Model 1 & & & Model 2 & & & Model & \\
\hline Variable & $B$ & $S E B$ & p & $B$ & $S E B$ & $\beta$ & $B$ & $S E B$ & $\beta$ \\
\hline Age & .15 & .03 & $.47^{* *}$ & .16 & .03 & $.47 * *$ & .14 & 32 & $.44 * *$ \\
\hline Cognitive Ability & .01 & .00 & $.29 *$ & .01 & .00 & $.27 *$ & .01 & $\infty$ & $28 *$ \\
\hline Effortful Control & & & & .06 & .03 & $.20 *$ & .06 & .03 & $.19 *$ \\
\hline Cognitive Engagement & & & & & & & .08 & .02 & .13 \\
\hline Adjuated $\mathbf{R}^{2}$ & & .276 & & & 306 & & & 313 & \\
\hline P Change & & $1586 * *$ & & & $4.27 *$ & & & 1.82 & \\
\hline
\end{tabular}

${ }^{*} p<.05 ; *{ }^{* *} p<.001$ 
Table 16

Summary of Hierarchical Regression Analysis for the Prediction of Fact wal Comprehension in the Distracter Condition by Effortful Control and Cognitive Engagement.

\begin{tabular}{|c|c|c|c|c|c|c|c|c|c|}
\hline & & Model 1 & & & Model 2 & & & Model & \\
\hline Variable & $B$ & $S E B$ & 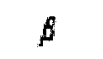 & $B$ & $S E B$ & $\beta$ & $B$ & $S E B$ & $B$ \\
\hline Age & .15 & .03 & $46^{* *}$ & .15 & .03 & $.46^{* *}$ & .13 & 31 & $.39 * *$ \\
\hline Cognitive Ability & .01 & .00 & $297 *$ & .01 & .00 & $.24 *$ & .01 & .00 & $28^{*}$ \\
\hline Effottrul Control & & & & .08 & .03 & $.23 *$ & .07 & .03 & $21 *$ \\
\hline Cognitive Engagement & & & & & & & .07 & .02 & $27^{*}$ \\
\hline Adjusted $\mathrm{R}^{2}$ & & .255 & & & .298 & & & .360 & \\
\hline F Change & & $1434^{* *}$ & & & $5.64 *$ & & & $8.29 *$ & \\
\hline
\end{tabular}

${ }^{*} p<05 ; * p<.001$ 


\begin{abstract}
APPENDIX
Description of Temperament scales and subscales:

SURGENCY/EXTRAVERSION

Activity Level: Level of gross motor activity including rate and extend of locomotion.

Positive Anticipation/Approach: Amount of excitement and positive anticipation for expected pleasurable activities.
\end{abstract}

High Intensity Pleasure: Amount of pleasure or enjoyment related to situations involving high stimlus intensity, rate, complexity, novelty, and incongruity.

Impulsivity: Speed of response initiation.

Shyness: Slow or inhibited approach in situations involving novelty or uncertainty.

\title{
EFFORTFUL CONTROL
}

Inhibitory Control: The capacity to plan and to suppress inappropriate approach responses under instruction or in novel or uncertain situations.

Low Intensity Pleasure: Amount of pleasure or enjoyment related to situations involving low stimulus intensity, rate, complexity, novelty, and incongruity.

Attentional Focusing: Tendency to maintain attentional focus upon task-related channels.

Perceptual Sensitivity: Amount of detection of slight, low intensity stimuli from the external environment.

\section{NEGATIVE AFFECT:}

Sadness: Negative affect and/or diminished energy related to disappointment and object loss.

Discomfort: Negative affect from sensory qualities of stimulation.

Fear: Negative affect related to anticipated pain, distress, or potential threat. 
Anger/Frustration: Negative affect related to the interruption of tasks or the blocking of goals.

Falling Reactivity/Soothability: Rate of recovery from peak distress, excitement, or general arousal 


\title{
CURRICULUM VITAE
}

\section{Tara N. Weatherholt}

University of Louisville
Department of Psychological and
Brain Sciences
Louisville, KY 40292
Tnweat03@louisville.edu

\author{
Duke University \\ Center for Child and Family Policy \\ Durham, NC 27708 \\ Tara.Weatherholt@duke.edu \\ 919.684.3635
}

\section{Education}

2011 Ph.D. Candidate, Experimental Psychology

University of Louisville

Department of Psychological and Brain Sciences

Specialization: Cognitive Development

Projected Graduation: December 2011

Dissertation: Narrative comprehension abilities of children from low-income

families: Role of temperament, attention skills, and cognitive engagement

$2004 \quad$ M.A., Psychology

University of Louisville

Department of Psychological and Brain Sciences

$2000 \quad$ B.A. Psychology

Department of Psychological and Brain Sciences

\section{Research and Professional Experience}

Dec 2010 - Present Research Analyst II

Center for Child and Family Policy, Duke University

Durham, NC

- Assist in evaluations of initiatives in social services and education, including the state-mandated Multiple Response System and the federal-funded Comprehensive Family Assessment in North Carolina.

- Collect quantitative and qualitative data, including focus groups, interviews with state and county level officials and workers, and child protective services case file reviews.

- Write evaluation reports for county, state and federal groups. 
- Manuscript writing for journals in the social services field.

- Manage program evaluation tasks for various projects, such as data collection, participant recruitment, and IRB approval process.

July 2010 - Dec $2010 \quad$ Evaluation Internship

Accountability, Research \& Planning Department

Jefferson County Public Schools; Louisville, KY

- Collect quantitative and qualitative data, including focus groups with students and staff surveys; survey development

- Conduct mixed methods analyses for evaluation of district-wide programs and initiatives.

- Report writing for program evaluations for district, state and federal groups; presentation of findings to program directors and coordinators.

Aug 2009 - May 2010 Intervention Coach \& Data Collector, First Steps to Success

Kent School of Social Work, University of Louisville

- Quantitative and qualitative data collection for pre-and postevaluation, including classroom observations of students and teachers, interviews with parents.

- Weekly meetings with teachers and at-risk families (home visits) to discuss parenting topics, child behavior and outcomes; motivational interviewing.

- Contacting families and conducting home visits for recruitment of at risk families in research program.

- Trained in EcoFIT family check up which guides work with families.

Jan 2009 - May 2009 Psychology Instructor, Cognitive Processes (PSYC 322)

Department of Psychological and Brain Sciences

University of Louisville

- Development of lecture materials, exams, and lab work; maintaining correspondence with students; grading.

Aug 2007 - June 2008 Research Assistant II

Education Development Center

Center for Children and Technology

New York, NY

- Evaluated large-scale technology project and teacher professional development program.

- Data analyses for mixed methods research design, database management, wrote technical program evaluation reports.

- Conducted school visits with teachers, administrators, and students; collected quantitative and qualitative data.

Aug 2006 - Aug 2007 Senior Trainer

Early Intervention Program 
Department of Health and Mental Hygiene

New York, NY

- Assisted in implementation of city-wide Families as Partners initiative, trained city staff and child mental health providers on new policy, continuously met with mental health providers and city staff to provide support.

- Development of training presentations and materials; assisted with the creation of marketing materials for program awareness including a documentary of families served by NYC Early Intervention.

July 2005 - June 2006 Clinical Research Coordinator

Division of Child Psychiatry

Mount Sinai School of Medicine

- Wrote foundation grant proposals, implemented research assessments in MSSM Therapeutic Nursery, organized maternal attachment training.

Jan 2005 - Mar 2007

Assistant Editor

National Head Start Association Dialog Journal

- Managed submitted manuscripts, including assigning peer reviewers, maintaining correspondence with authors, tracking manuscript revisions.

- Proofread and edited issues; recruited peer reviewers and guest contributors; organized and attended editorial board meetings.

May 2002 - June 2005 Graduate Research Assistant, Cognitive Development Lab

Department of Psychological and Brain Sciences

University of Louisville

- $\quad$ Organized and maintained human studies approval with university IRB, developed research protocol for study with economically disadvantaged families, and recruited and assessed study participants.

- Coded and analyzed data using sophisticated computer programs, managed various research projects and supervised undergraduate research assistants.

- $\quad$ Assisted with research publications, conducted literature reviews and remained well informed on current relevant research, presented on current research.

Aug 2002 - May 2005 Graduate Teaching Assistant, various courses

- Corresponded with students, graded exams and papers and maintained grade database, proctored exams

- Prepared and gave lectures, led lab sessions, met weekly with supervisors for problem solving and support.

Sept 2000 - May 2002 Psychometrician II

Louisville Family Twin Study 
Department of Pediatrics, University of Louisville

- Administered cognitive, behavioral, and emotional assessments to twins and families of twins; maintained continuous relationship and rapport with families involved in the study, scored assessments.

\section{Publications (Peer-reviewed)}

Brown, D. B., Weatherholt, T. N., \& Burns, B. (2010). Understanding parent reports of children's attention behaviors: Role of children's attention skills, temperament, and home chaos. Journal of Early Childhood and Infant Psychology, 6, 41-58.

Clement, C. A., Harris, R. C., Burns, B. M., \& Weatherholt, T. N. (2010). An eye-tracking analysis of the effect of prior comparison on analogical mapping. Current Psychology: Online First, September 2010.

Brown, D. B., Weatherholt, T. N., \& Burns, B. (2010). Attention skills and looking to television in children from low income families. Journal of Applied Developmental Psychology, 31, 330-338.

Weatherholt, T. N. (2007). Integrative review of educational television for young children: Implications for children from low-income families. National Head Start Dialog Journal, 10, 171-188.

Weatherholt, T. N., Harris, R. C., Clement, C., \& Burns, B (2006). Analysis of attention and analogical reasoning in children of poverty. Journal of Applied Developmental Psychology, 27, 25-35.

Weatherholt, T. N.., Lamb-Parker, F. \& Burns, B. M. (2006) NHSA Dialog: A Research-To- Practice Journal for the Early Intervention Field. In R.S. New \& M. Cochran (Eds.) Early Childhood Education: An International Encyclopedia. Greenwood Publishing.

\section{Technical Reports}

Weatherholt, T., Hadley, M., \& Snyder-Fickler, E. (2011). Fatherhood Engagement Report. Report to the Alamance County North Carolina Department of Social Services.

Lawrence, C. N., Rosenbalm, K., \& Weatherholt, T. (2011). Multiple Response System Evaluation: Juvenile Petitions. Report to the North Carolina Division of Social Services.

Weatherholt, T. N. \& Vanderhaar, J.E. (2010). Steps to Respect Program Evaluation. Report to the Jefferson County Public Schools: Office of Safe and Drug Free Schools.

Vanderhaar, Judi \& Weatherholt, T. N. (2010). Protecting You/Protecting Me Program Evaluation. Report to the Jefferson County Public Schools: Office of Safe and Drug Free Schools. 
Martin, W., Strother, S., Weatherholt, T., \& Dechaume, M. (2008). eMINTS program evaluation report: An investigation of program fidelity and its impact on teacher mastery and student achievement. Education Development Center: Center for Children and Technology. New York, NY.

\section{Professional Training}

Introduction to Focus Groups, Social Sciences Research Institute, Duke University, November 2011, Durham, NC.

Effective Survey Design for Online, Paper, and Mixed-Mode Questionnaires, Social Sciences Research Institute, Duke University, November 2011, Durham, NC.

Funding Opportunities at the Institute of Education Sciences, webinar given by National Center for Education Research as part of the Funders Forum at Social Sciences Research Institute, Duke University, November 2011, Durham, NC.

Introduction to Survey Research, Social Sciences Research Institute, Duke University, October 2011, Durham, NC.

SAS Programming 1: Essentials Training, SAS Campus, January 2011, Cary, NC.

Hierarchical Linear Modeling, Summer Statistics Institute, University of Texas, May 2010, Austin, Texas

Structural Equation Modeling, Summer Statistics Institute, University of Texas, May 2010, Austin, Texas

EcoFIT Family Check-Up Training, Child and Family Center, University of Oregon, November 2009, Eugene, Oregon.

Introduction to Hierarchical Linear Modeling, American Education Research Association Conference, March 2008, New York, NY

Qualitative Research for Quantitative Researchers, American Education Research Association Conference, March 2008, New York, NY

An Introduction to Latent Class Models, Mixture Rasch Models, and Diagnostic Mixture Models, American Education Research Association Conference, March 2008, New York, NY

\section{Teaching Experience}

Spring $2009 \quad$ Instructor

Cognitive Processes (PSYC 322)

Fall 2008

Graduate Teaching Assistant

Cognitive Processes (PSYC 322) 
Spring 2005

Fall 2004

SPR 2004, 2003

Fall 2002

Fall 2003
Graduate Teaching Assistant

Life - Span Psychology (PSYC 363)

Graduate Teaching Assistant

Honors Life-Span Psychology (PSYC 363)

Lab Instructor

Introduction to Psychology (PSYC 201)

Graduate Teaching Assistant

Social Psychology (PSYC 372)

\section{Paper and Poster Symposium Presentations}

Brown, D. D., Weatherholt, T. N., \& Burns, B. M. (June 2010). Examining attentional inertia to television in children from low-income families. Poster presented at the Head Start National Research Conference, Washington, D.C.

Ba, H., Boyd, A., Meade, T., Weatherholt, T., \& Lewis, A. (September, 2008). Implementing, evaluating, scaling, and sustaining a large-scale technology innovation. Paper presented at the World Conference on Educational Multimedia, Hypermedia and Telecommunications. Vienna, Austria.

Dreier, M, \& Weatherholt, T. (December, 2006). Improving parent-child attachment and resilience of child. Paper presented at the International Conference on Social Work in Health and Mental Health. Hong Kong, China.

Sanderfer, M., Weatherholt, T., Robinson, J., \& Burns, B. (April, 2005). Maternal anxiety and depression and children's attention abilities: A study of Head Start families. Poster presented at the University of Louisville Undergraduate Research Symposium.

Chang, F., Robinson, J., Snyder, E., Weatherholt, T., \& Burns, B. (April, 2005). Cumulative risk factors effortful control, and attention regulation in children from lowincome backgrounds. Poster presented at the biennial meeting of the Society for Research in Child Development, Atlanta, GA.

Weatherholt, T., Snyder, E., Brown, D., Nickels, A., Wilcox, L., Cummins, R., Burns, B. (April, 2004). An examination of the relationship between visual attention to a televised story and attentional abilities in children from poverty. Paper presented at the National Conference on Human Development, Washington, D.C.

Weatherholt, T., Snyder, E., Brown, D., Nickels, A., Wilcox, L., Robinson, J., Franco, S., Lorch, E., Milich, R., Burns, B. (July, 2003). The Relationship between Attention and Comprehension of a Televised Story in Children from Low-Income Backgrounds. Poster presented at Head Start's Annual National Research Conference. 
Robinson, J., Dossett, D., Chang, F., Snyder, E., Davis, D., Weatherholt, T., and Burns, B. (April, 2003). Individual differences in attention regulation in children of poverty. Poster presented at the Society for Research in Child Development Conference, Tampa, FL.

Larkan, K., Weatherholt, T., Snyder E., Nickels, A., Milich, R., Lorch, E., Burns, B., and Franco, S. (April, 2003). An examination of attention abilities and comprehension in children of poverty. Poster presented at the annual meeting of the University Wide Undergraduate Research Symposium, University of Louisville, Louisville, KY.

Burns, B., Snyder, E., Robinson, J., Strother, S., and Weatherholt, T. (March, 2003). Temperament and attention in children from low-SES families: Impact on early math and verbal achievement. Poster presented at the First Annual Kentucky Innovation and Enterprise Conference, Lexington, KY

Meredith, A., Weatherholt, T., Chang, F. \& Burns, B. (May, 2000). Examining the relation of attentional strategies and pre-reading abilities in children from Head Start. Poster presented at the annual meeting of the University Wide Undergraduate Research Symposium, University of Louisville, Louisville, KY.

\section{Professional Activities}

NHSA Dialog Journal Peer Reviewer

Weatherholt, T. (co-presenter), “Attention Skills, and the Brain”, (2003 October).

National Black Child Development Institute Conference, New Orleans, LA

Weatherholt, T. (co-presenter), "Attention Skills, Attention Regulation, and the Brain", (2003 June). The Wee People Institute, Louisville, KY.

Graduate Student Council Representative (Fall 2003).

American Psychological Association for Graduate Students (APAGS) Campus Representative, (Fall 2002-Spring 2004). University of Louisville, Department of Psychological and Brain Sciences Experimental Ph.D. program

\section{Awards and Honors}

- Graduate student research travel grant based on a submitted proposal for the dissemination of research at professional or academic conferences 
of Psychological and Brain Sciences (\$750/year)

- Graduate student research travel grant based on a submitted plan of research for the respective academic year

\section{Course Curriculum}

\section{Graduate Courses}

\section{Graduate Seminars in Psychology}

\section{Graduate Statistics}

PSYC 621 Cognitive Processes

PSYC 585 Abnormal Psychology

PSYC 575 Personality

PSYC 642 Behavioral Neuroscience

PSYC 622 Cognitive Development PSYC 622 Language Acquisition PSYC 622 Developmental Disabilities PSYC 622 Analogy and Metaphor PSYC 622 Social Cognition

PSYC 611 Advanced Statistics II (ANOVA) PSYC 514 Advanced Statistics II (Probability Theory)

PSYC 612 Multivariate Statistics 